ANUARIO MUSICAL, N. ${ }^{\circ} 69$

enero-diciembre 2014, 5-50

ISSN: 0211-3538

\title{
ANTONIO DE CABEZÓN, REDIVIVO
}

\section{ANTONIO DE CABEZON, REVISITED}

Javier Artigas Pina

Conservatorio Superior de Música "Manuel Masotti Littel”, Murcia \&

Escola Superior de Música de Catalunya, Barcelona

$\&$

Antonio Ezquerro Esteban

DCH-Musicología, IMF, CSIC, Barcelona

\section{Resumen}

En el año 2010 se celebró el quinto centenario del nacimiento del gran músico del Quinientos hispano, organista de Felipe II, Antonio de Cabezón. El presente trabajo pretende compilar nueva aunque brevemente la trayectoria y significado de su producción musical, al tiempo que servir de recordatorio, marco inicial, y antecedente, a la reflexión que su obra suscita en la actualidad (como se verá en los artículos que siguen inmediatamente a éste), en un intento de reivindicación de la mejor música para tecla, arpa y vihuela del período histórico de mayor esplendor y proyección en ámbito hispánico.

\section{Palabras clave}

Antonio de Cabezón; Siglo XVI; Tecla, arpa y vihuela; Felipe II; órgano; Musicología histórica.

\begin{abstract}
In 2010 we celebrated the fifth centenary of the birth of the great sixteenth-century Spanish musician, organist Philip II, Antonio de Cabezon. The present work aims to compile the history and meaning of his musical output again albeit briefly, while as a reminder and reflection background to his work raises at present (as discussed in the articles that follow it immediately), in an attempt to claim the best music for keyboard, harp and vihuela dating from the historic period of maximum splendor and projection in the Hispanic world.
\end{abstract}

\section{Key words}

Antonio de Cabezon; $16^{\text {th }}$ century; Keyboard, harp, vihuela; Philip II of Spain; Organ; Historical Musicology
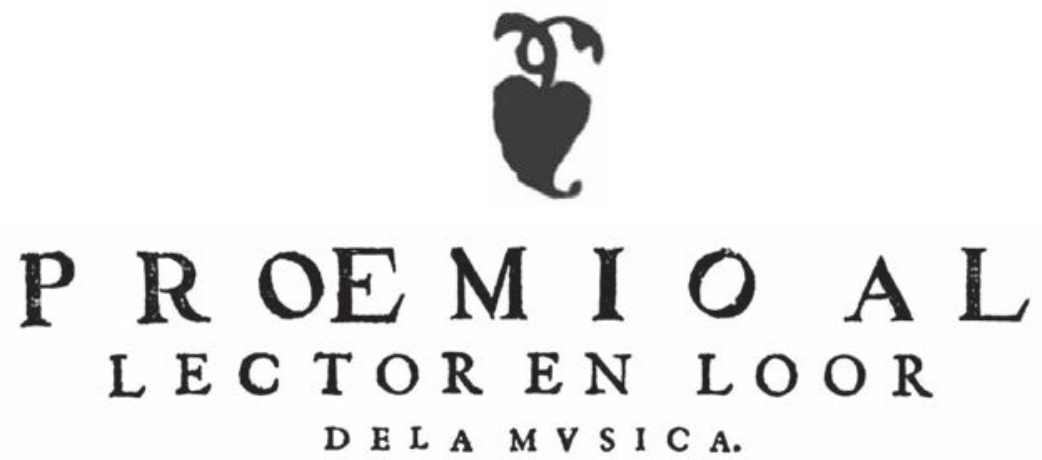


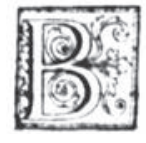

ueno sería aceptar por todos que en el tacto (la pulsación, el tañido, el tiento) debió tener su dominio aquel gran hombre, conocido y admirado por tantos, llamado Don Antonio de Cabezón (acaso conocido por un mucho más cercano "Antonio", a secas), que fuera "dado a luz", aunque pronto privado de la misma, hoy hace quinientos años.

El que fuera con el tiempo organista y compositor para instrumentos de tecla más ilustre de la Europa del Renacimiento y uno de los compositores más insignes de la historia musical española, se alistaba en la estirpe de músicos ciegos tan excelentes como la misma patrona de la música, santa Cecilia de Roma - siempre representada pulsando un órgano-, o de sus antecesores Francesco Landini o Arnolt Schlick, siendo coetáneo de vihuelistas también invidentes como Miguel de Fuenllana, y de otros organistas como el tratadista y catedrático Francisco de Salinas, Luis Brooman o Antonio Valente, y ya tiempo después, de Pablo Bruna, el franciscano Pablo Nassarre, Charles John Stanley, o incluso, el más cercano a nuestros días, Louis Vierne o el también español Joaquín Rodrigo.

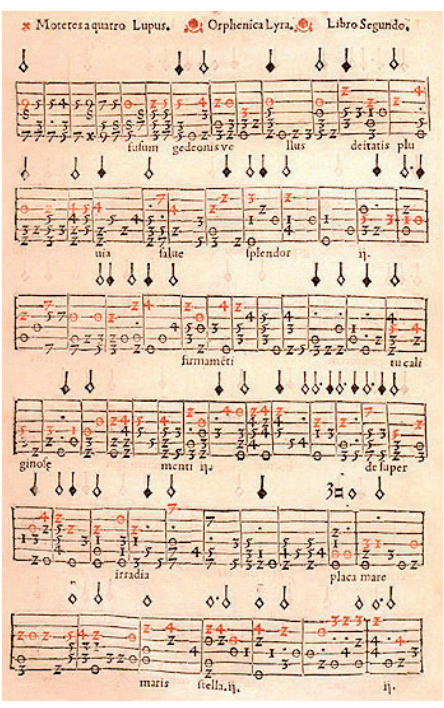

Miguel de FUENLLANA: Libro de música para vihuela, intitulado Orphénica Lyra. Sevilla, Martín de Montesdoca, 1554.

Antonio de Cabezón, que por su discapacidad física y su entorno (la Castilla rural del primer cuarto del siglo XVI) pudiera haber tenido un horizonte personal francamente limitado, tuvo la fortuna, en cambio, de ser incorporado muy pronto, desde el obispado palentino en el que se formó, a las cortes más fastuosas de su tiempo, para solaz y enseñanza de príncipes e infantas.

Sus dotes le auguraban un futuro esplendoroso, de arduos trabajos y jornadas, pero de reconocimiento y proyección profesional. De ello nos da cuenta el cortesano y caballero de Santiago, de origen extremeño, Luis Zapata de Chaves $(* 1526 ; \dagger 1595)$, que había sido paje de la emperatriz Isabel y más tarde estuviera al servicio del príncipe Don Felipe - años después, rey Felipe II-, a quien acompañó, como Cabezón, en su viaje a Italia y Flandes en 1549. Tal vez el singular Zapata (célebre por su obesidad - estaba obsesionado por adelgazar- y sus dotes como espadachín, cetrero - llegó a escribir un tratado sobre dicha disciplinay jinete) conociera a nuestro músico. Había sido encarcelado durante varios años, por una infidelidad conyugal habida en su segundo matrimonio, y al quedar libre, escribió una famosa Miscelánea. Silva de casos curiosos (o Varia historia) en el año 1592, cuyo relato recogía diversas anécdotas, dichos graciosos y escenas de la vida política, social y literaria de su tiempo, entre milagros, duelos, supersticiones, agudezas y un sinfín de curiosidades ${ }^{1}$. En dicha Miscelánea, capítu-

1 Natural de Llerena (Badajoz) y perteneciente a la nobleza (era Señor de Çehel), vivió en la corte, como paje de la emperatriz Isabel cortesano y mayordomo del emperador- y luego al servicio de Felipe II, desde que tenía ocho años hasta los treinta. Desde 1566, y durante más de veinte años, estuvo encarcelado por motivos relacionados con su vida escandalosa y grandes deudas). Hombre de amplia cultura, escribió también el poema épico - una crónica a modo de panegírico-Carlo famoso (Valen- 
10 "De habilidades de ciegos", Zapata aseguraba lo siguiente (E-Mn, Mss.2790 fol.105v-106r-106v):

"[...] Pero volviendo a los ciegos de ahora, ninguno dicen que igualó a Antonio de Cabezón, músico del órgano, ni en estos ni en los tiempos pasados. No sólo le tocaba, mas le concertaba todo hasta la misma parte de él, como si viera. Casó por amores, que fue gran maravilla, un ciego, bien que con los amores todos lo están, y los enamorados no se quejen: así, pues, aun el ciego amor tiene dominio en los ciegos. Vivía, antes que con el rey, con un obispo de Palencia, y en las manos conocía a todos cuantos vivían con él, en tocándoles [...]".
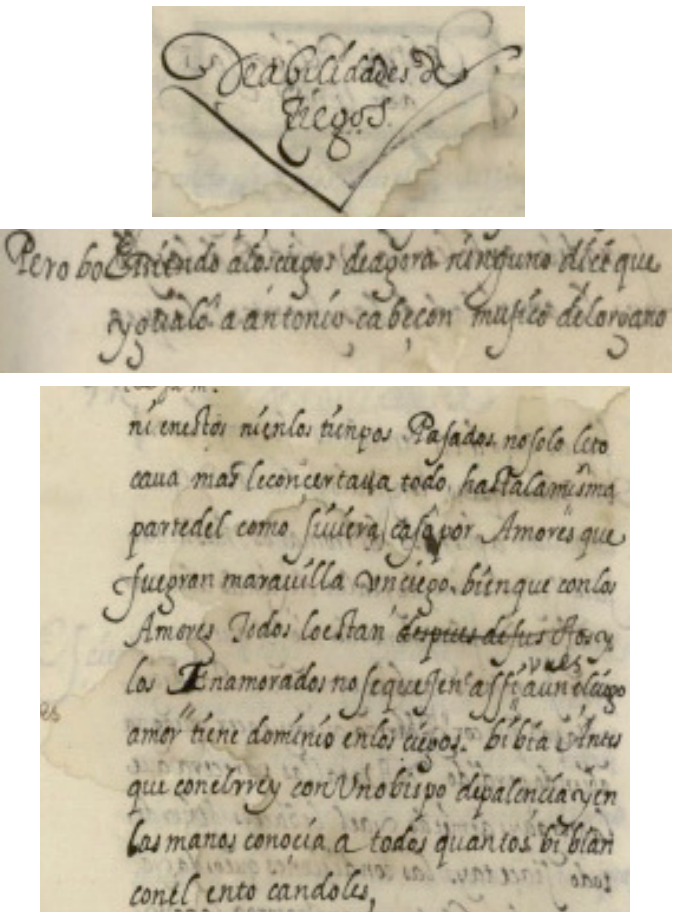

cia, Juan Mey, 1566), dedicado a Felipe II, que le ocupó trece años de su vida, y que trata de la vida y hechos de Carlos V (desde 1516 hasta la muerte del emperador en 1558), conocidos como "Caroleidas". Este libro, por el que se le considera el primer poeta en tratar del descubrimiento y conquista del Nuevo Mundo, se compone de nada menos que veintidós mil versos en octavas reales, dispuestos en cincuenta cantos. Redactó también, durante su prisión, el mencionado y extenso Libro de cetrería en verso, dedicado a Diego de Córdoba en Madrid, que quedó manuscrito (E-Mn, Mss.3336, 4219 y 7844), compuesto por 8.500 endecasílabos de rima encadenada o leonina, distribuidos en 159 capítulos, en los que, en ocasiones, ejerce también como cronista de la época. Tradujo luego el Ars Poetica de Horacio, que dedicó al conde de Chinchón (Quinto Horacio Flaco: Arte Poética. Lisboa, Alexandre de Syqueira, 1592). Por su parte, su célebre y aquí citada Miscelánea, que se compone de 255 textos breves, se conserva manuscrita en la Biblioteca Nacional (E-Mn, Mss.2790; párrafo citado, fols. [77]105v-106v). [Existen varias ediciones de esta última obra: ZAPATA, Luis, 1983, vol.1; y ZAPATA, Luis, 1999]. Sobre este mismo autor, puede verse también: MALDONADO FERNÁNDEZ, Manuel, 2002: 991-1029.
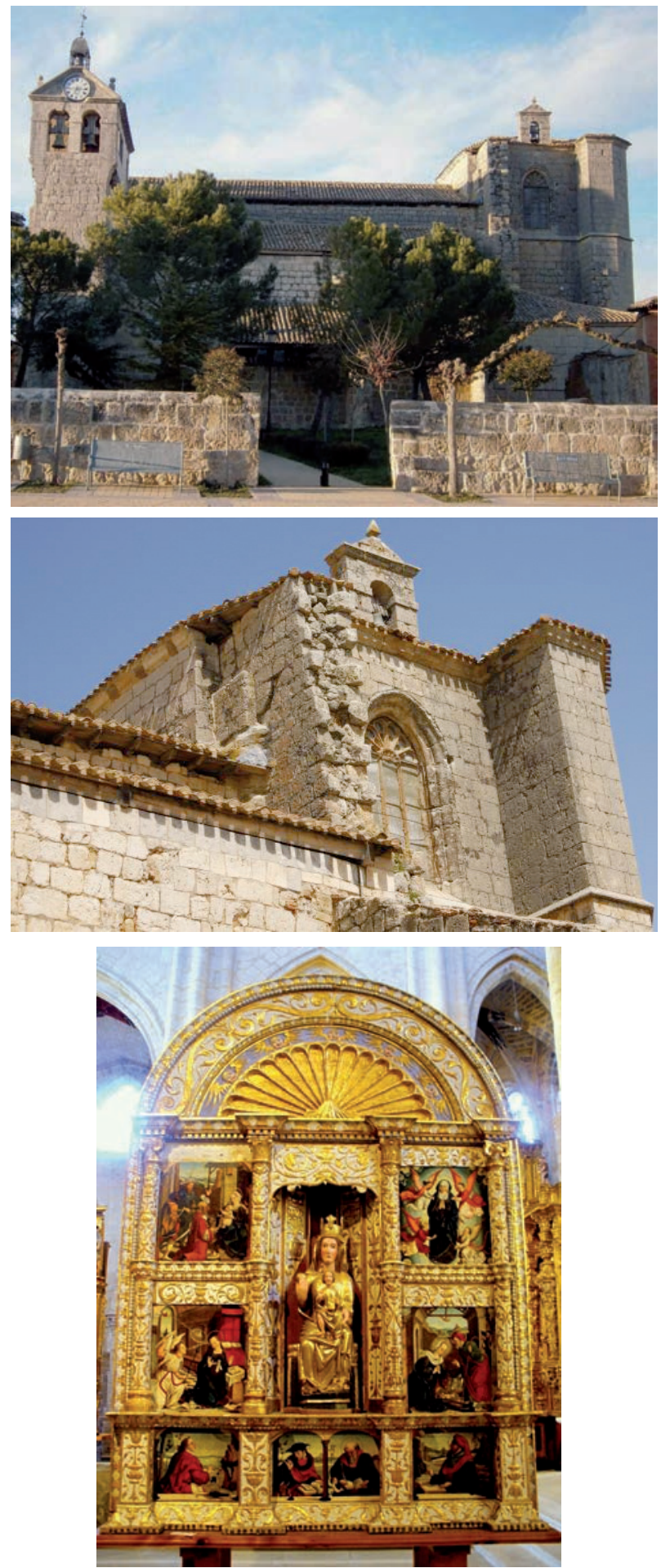

Iglesia de San Esteban, de Castrillo Matajudíos, y retablo de la Virgen. 
Sea como fuere, Antonio vino al mundo como hijo primogénito de Sebastián de Cabezón y María Gutiérrez. Era "oriundo de la montaña", natural de Castrillo de Matajudíos

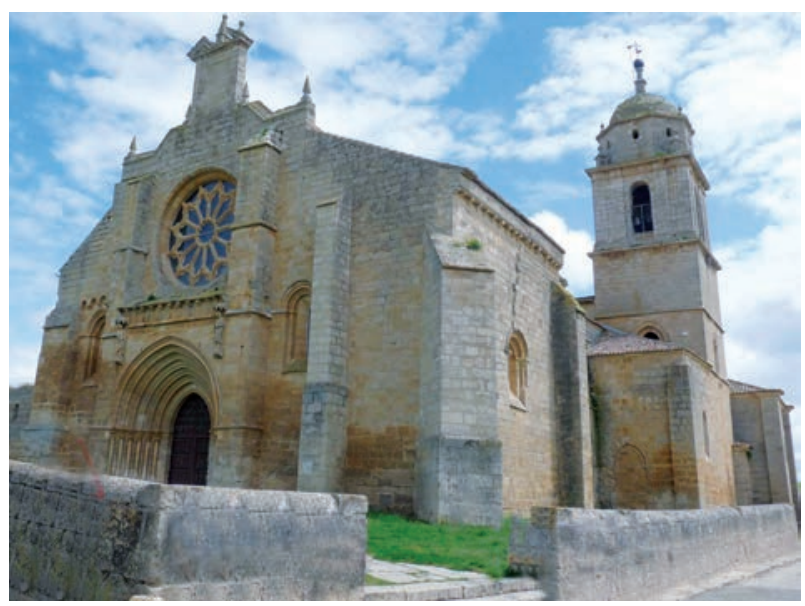

(o "Castrillo Mota de Judíos" como se ha rebautizado recientemente al pequeño municipio, junto a la más relevante localidad burgalesa de Castrojeriz).

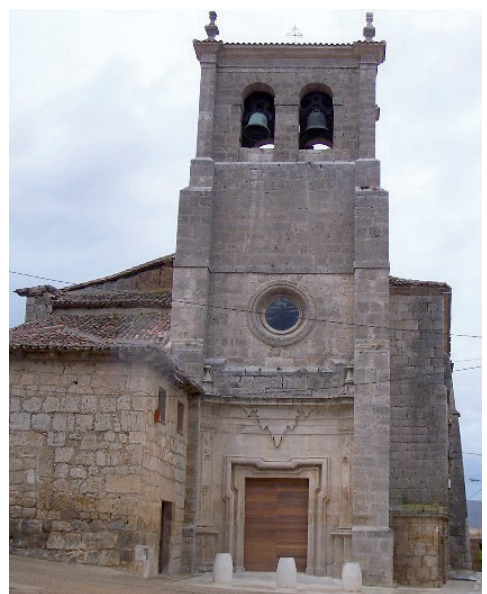

Castrojeriz (Burgos). Iglesia de Nuestra Señora del Manzano, e Iglesia de Santo Domingo.
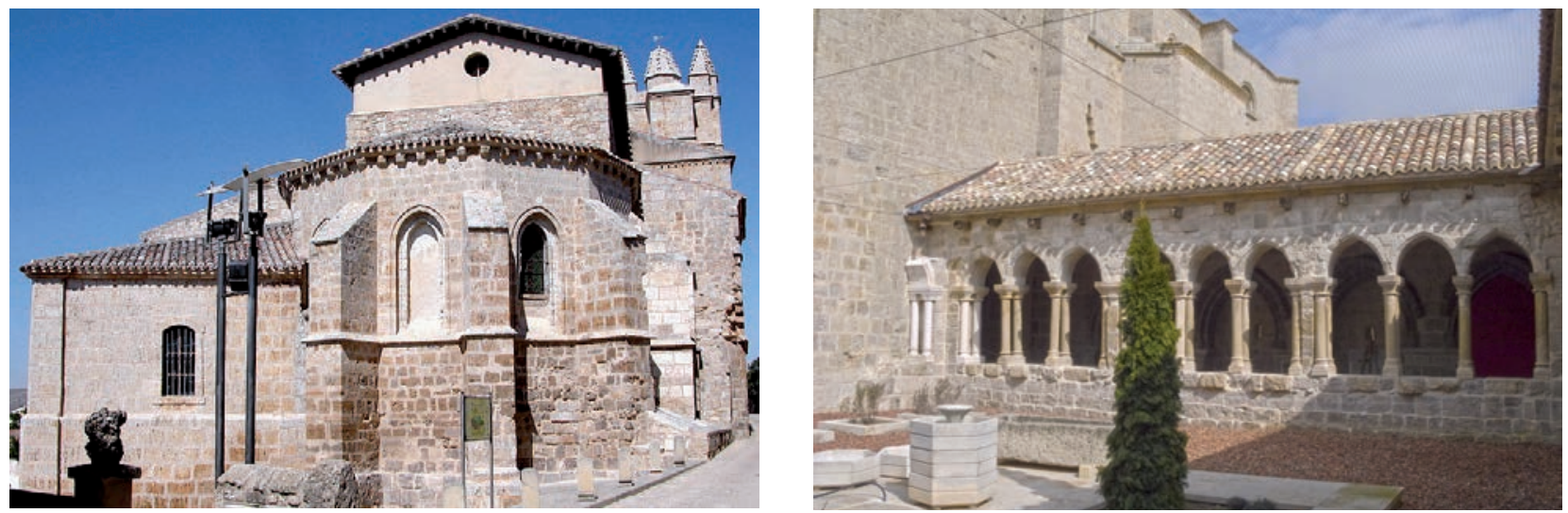

Castrojeriz (Burgos). Iglesia de San Juan: exterior, y claustro.

Siendo todavía niño fue apoyado por un tío suyo (el canónigo de la catedral de Burgos, Esteban Martínez de Cabezón), para pasar pronto a ser protegido por el obispo de Palencia, donde al parecer se formó musicalmente entre
1521 y 1525 , acaso con el entonces organista de la catedral de San Antolín, García de Baeza (quien debió enseñar asimismo a otro ilustre músico ciego, Francisco de Salinas) ${ }^{2}$. Poco más se sabe de su infancia.

2 Por aquellos años ocuparon la sede episcopal palentina los prelados D. Pedro Ruiz de la Mota (1520-1522); y D. Antonio de Rojas Manrique (1524-1525). (El paso de Cabezón de tierras burgalesas a Palencia habría estado motivado por el nombramiento de su tío como Provisor General de la diócesis de Palencia en 1520). 

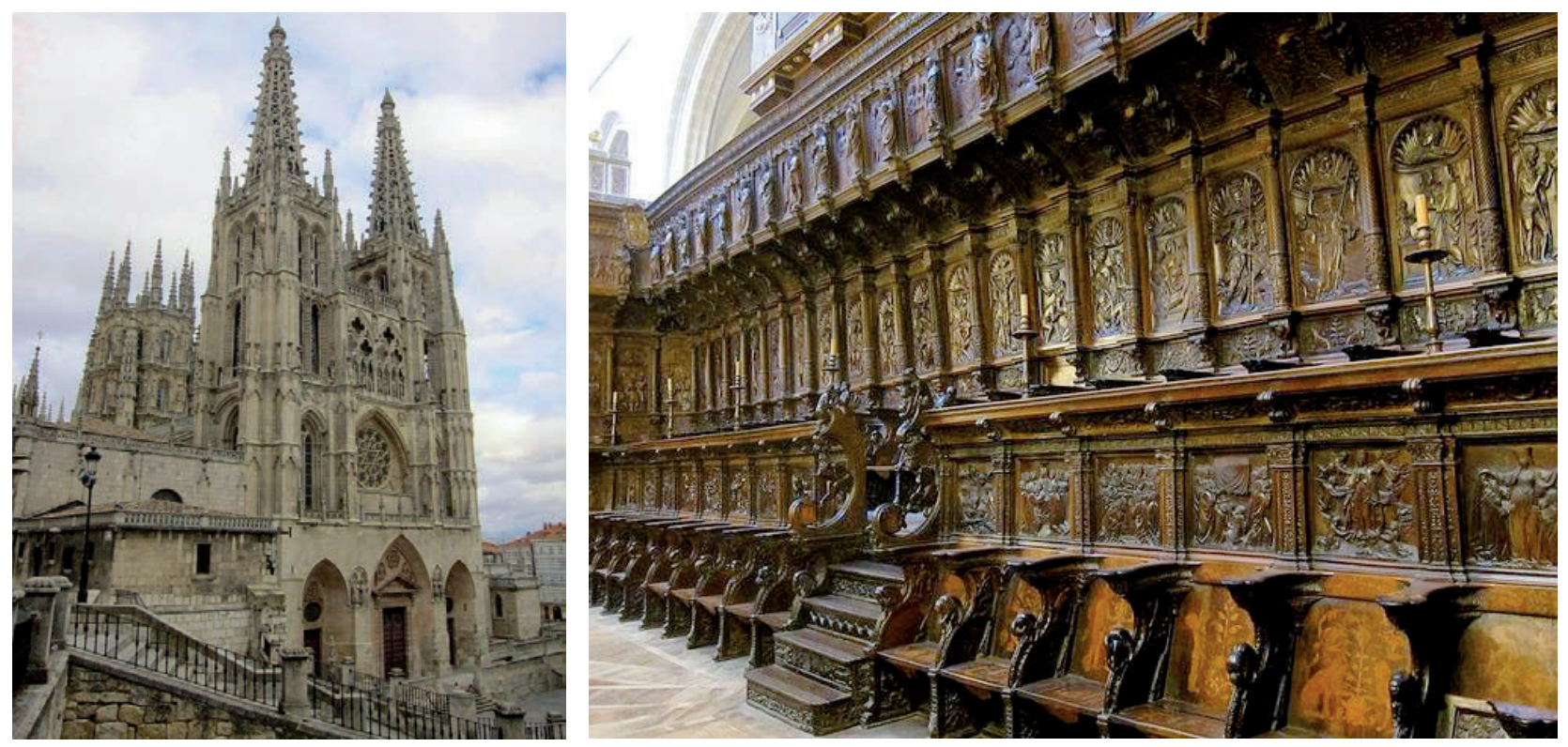

Catedral de Burgos. Vista exterior y sillería de coro plateresca, de Felipe Bigarny.
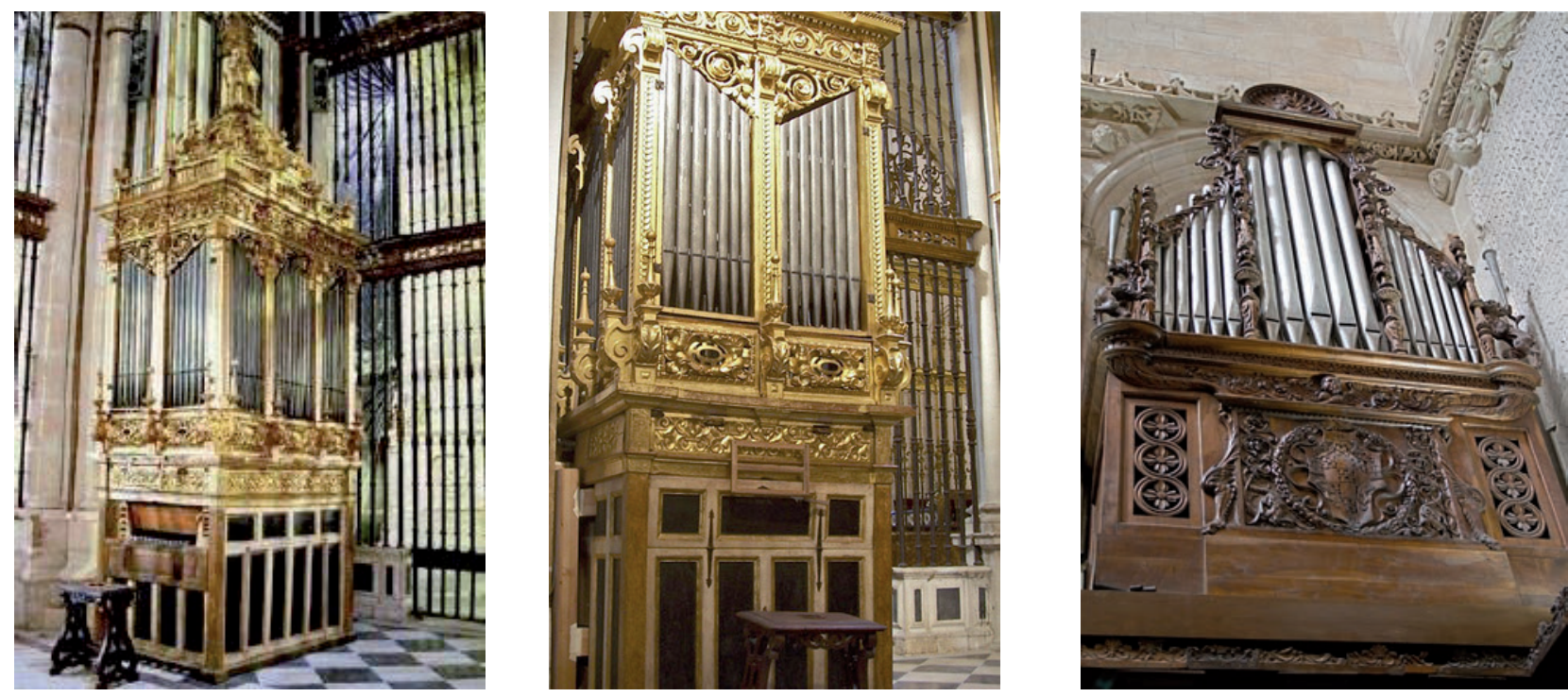

Dos aspectos del realejo (izda. y centro), y órgano de la capilla del Condestable (dcha.), ambos, de la catedral de Burgos (siglo XVI). 

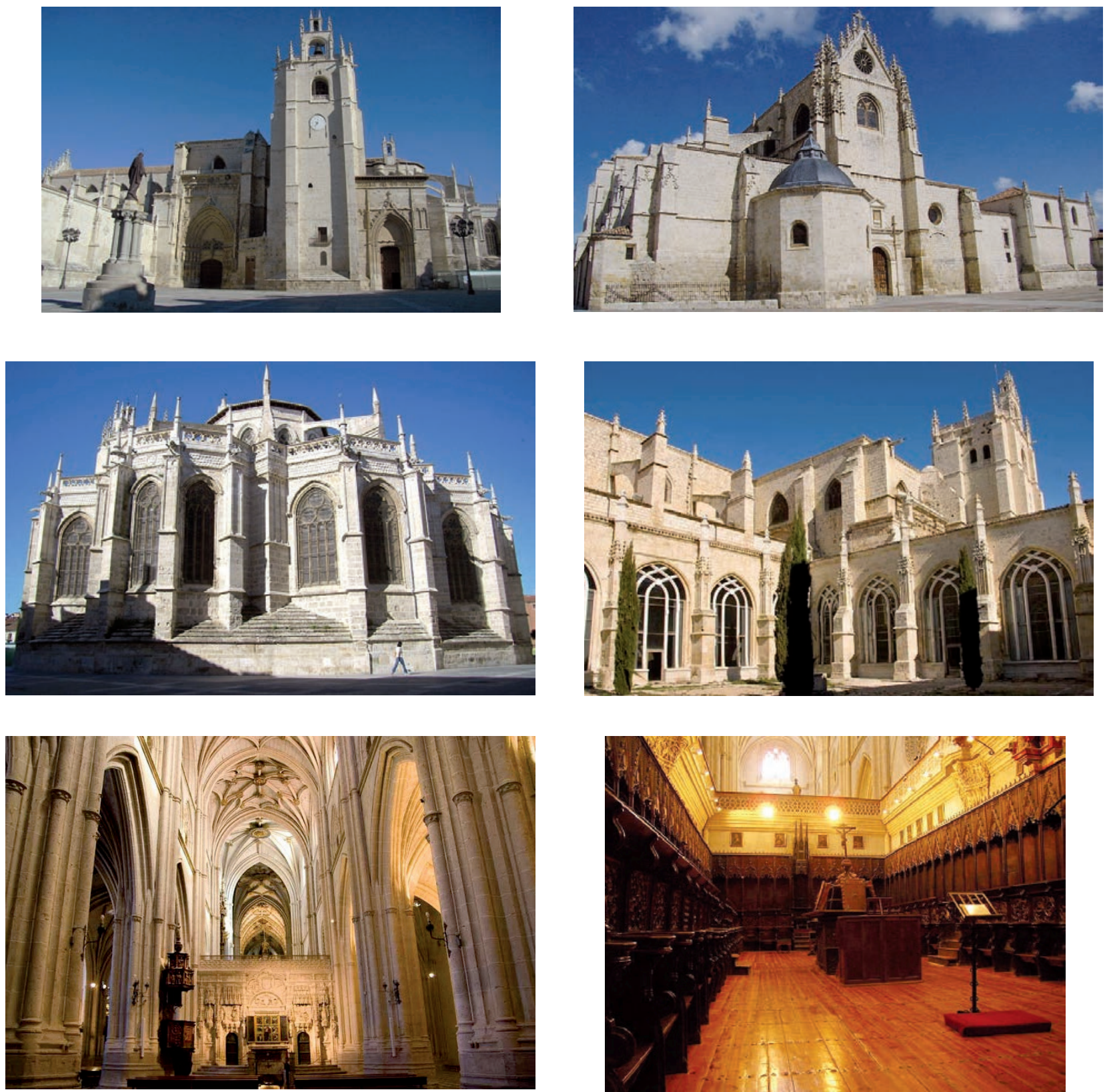

Catedral de San Antolín, de Palencia.

Arriba, fachadas exteriores; centro, ábside y claustro; y abajo, interior y sillería de coro.

Su trayectoria, resumida a grandes trazos, le llevó a ser presentado al emperador Don Carlos en 1522, cuando Antonio tendría apenas doce años. En 1525, el soberano se casó con Doña Isabel de Portugal, trasladándose entonces Cabezón a Toledo, para ingresar, al siguiente año, 1526, con sólo 16 años, al servicio de la capilla musical de la emperatriz (regida por Mateo Fernández y formada básicamente por españoles y portugueses), como organista y clavicordista. 

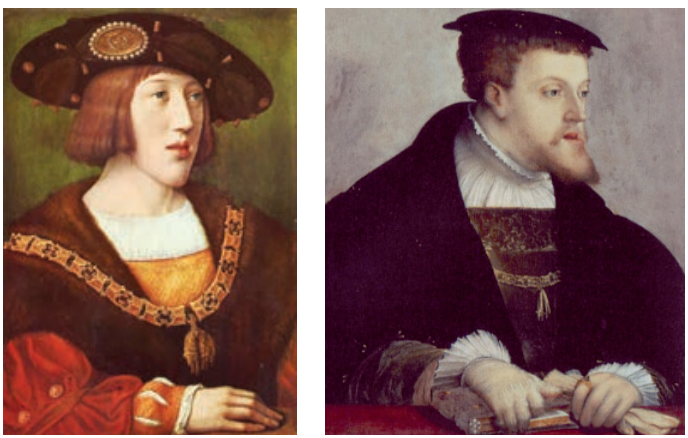

Izda.: Retrato de Carlos V (*1500; †1558) por Bernard van Orley (1516-1519). Museo del Louvre.

Dcha.: Retrato de Carlos V emperador del Sacro Imperio, por Christoph Amberger (1532c; Gemäldgalerie, Berlín).
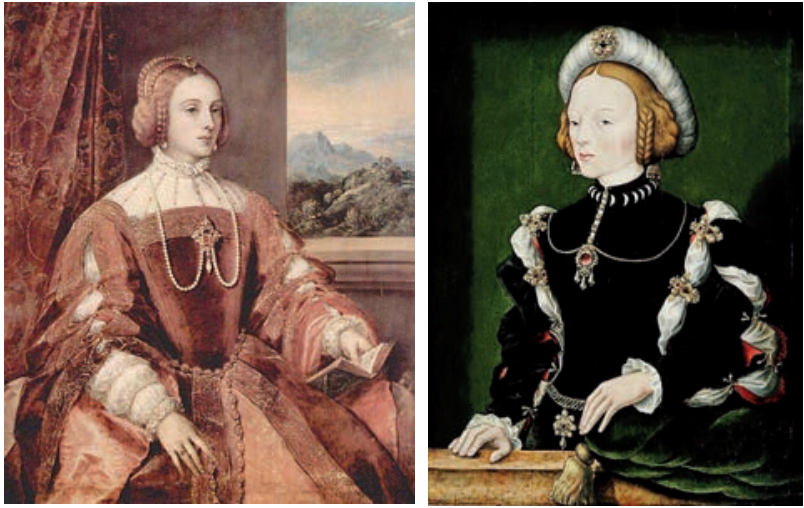

La emperatriz Isabel de Portugal $(* 1500 ; \dagger 1539)$, esposa de Carlos V, a cuyo servició entró Antonio de Cabezón, en dos retratos póstumos, de Tiziano

(1548; Museo del Prado, Madrid) y William Scrots (1550; Museo Nacional de Poznan, Polonia), respectivamente.
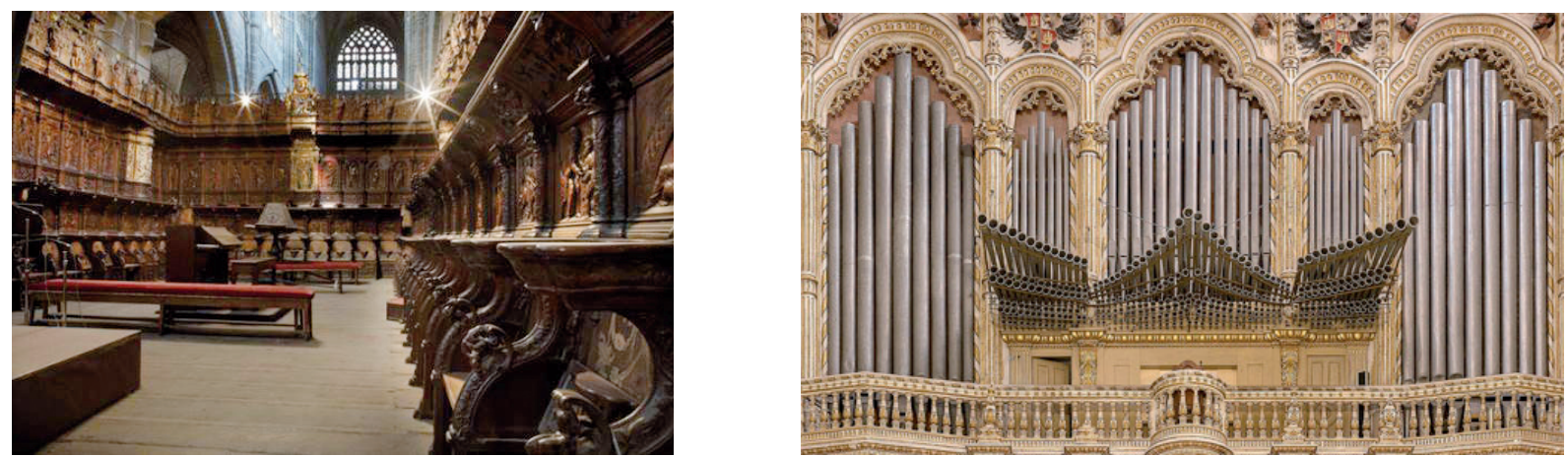

Catedral de Toledo. Sillería de coro (Alonso Berruguete y Felipe Bigarny, 1539-1543), y Órgano del Emperador (Gonzalo Hernández de Córdoba, finalizado por Juan Gaytán, 1543-1549).

Joven y seguramente necesitado de ayuda para el desempeño de su trabajo, iba a compartir sus obligaciones con otros destacados músicos de tecla: en 1527 aparece en la capilla de la emperatriz Tomás García como "sonador de los órganos de palacio", en 1528 ingresaba también el clavicor- dista Francisco de Soto como "músico de cámara" (así como consta también un "maestre Aloy", posiblemente organero), y en 1529 figura asimismo Francisco Gómez como "organista de la emperatriz" y afinador de sus instrumentos de tecla. 


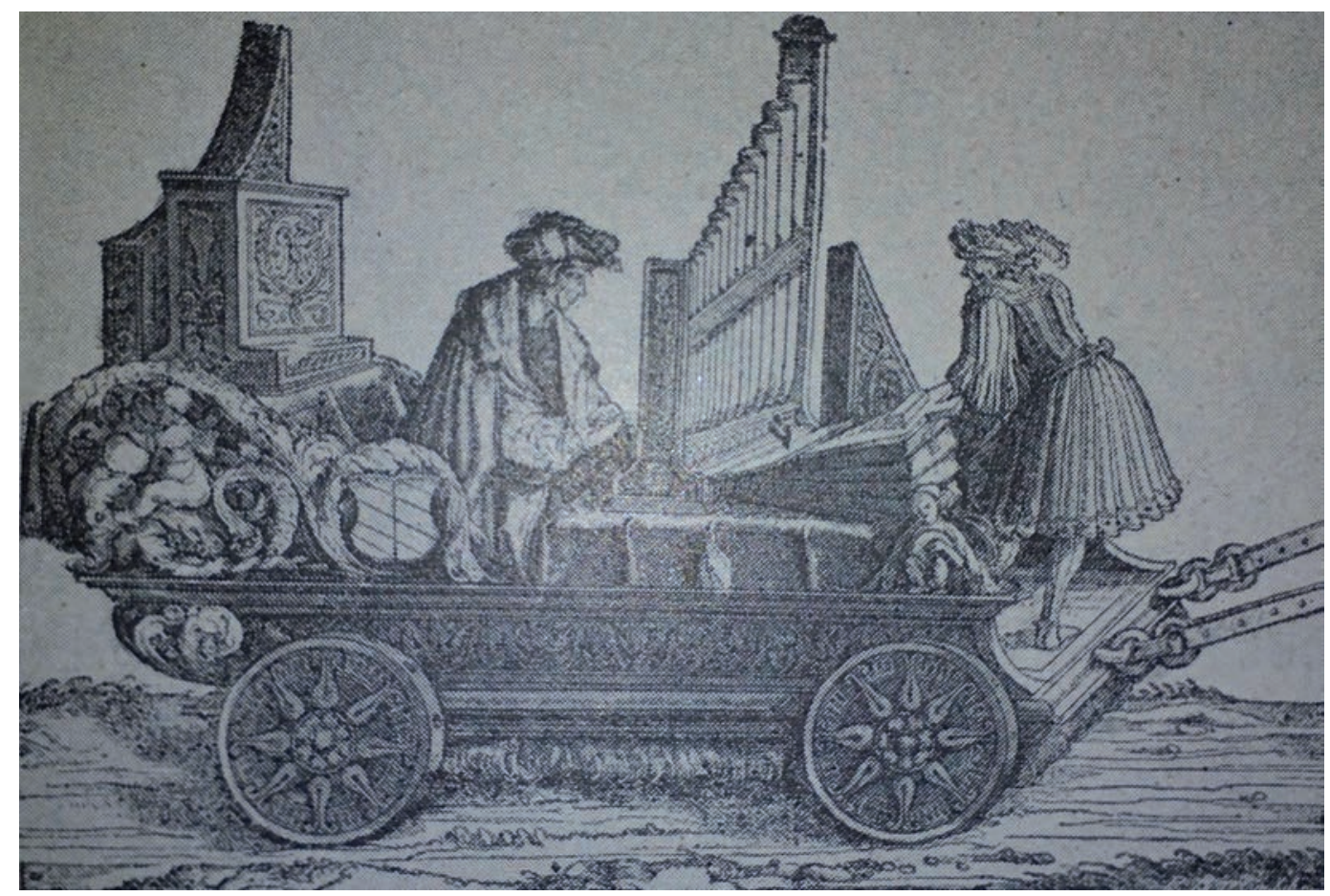

"Órgano portátil perteneciente a Carlos V y con el que tocaba Cabezón"

[según ilustración en: Fernando de ARTEAGA Y PEREIRA; Felipe PEDRELL; y Francisco VIADA: Celebridades musicales ó sea Biografías de los hombres más eminentes en la música. Barcelona, Centro Editorial Artístico de I. T. M. Seguí, Imprenta de Luis Tasso y Serra, 1886, p. 3].

Antonio de Cabezón iba a servir a la capilla real española durante cuarenta años, ya fuera en primer término al cuidado de la emperatriz (desde 1526 y hasta el fallecimiento de la soberana en 1539), ya luego del propio emperador, y por disposición de este último, entre 1539 y 1548 , de las infantas Doña María y Doña Juana, y del príncipe (que ten- dría también como profesor de música a Luis de Narváez). Cabezón residió en ese tiempo cada año, durante seis meses con las hijas del emperador, en el castillo de Arévalo (donde coincidiría con Mateo Flecha), y durante los seis restantes con Don Felipe en Valladolid. 

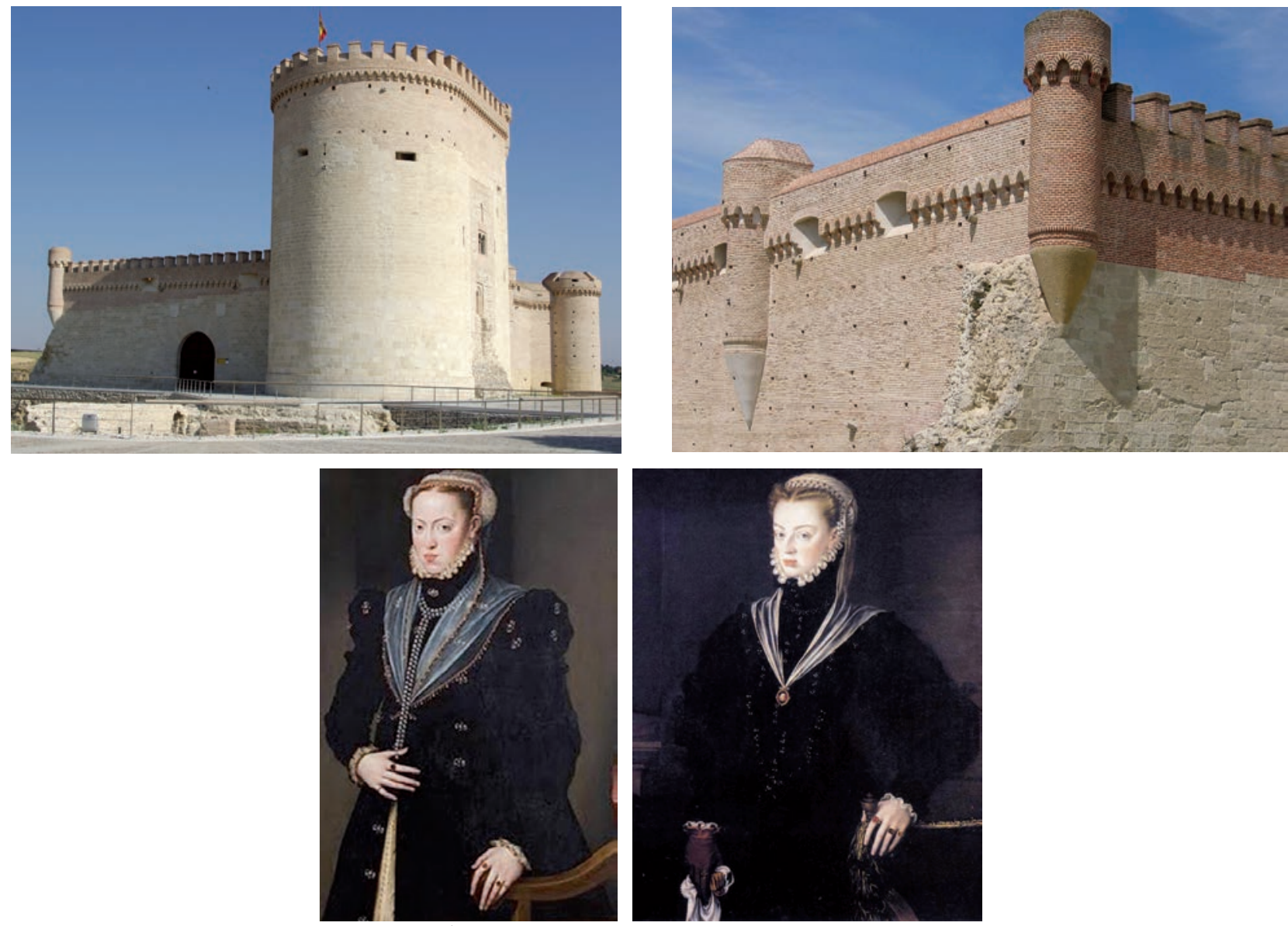

Arriba: murallas del castillo de Arévalo (Ávila), donde Antonio de Cabezón enseñó música a las infantas, hijas del emperador Carlos V (abajo), Doña María (1557) y Doña Juana (por Alonso Sánchez Coello)³.

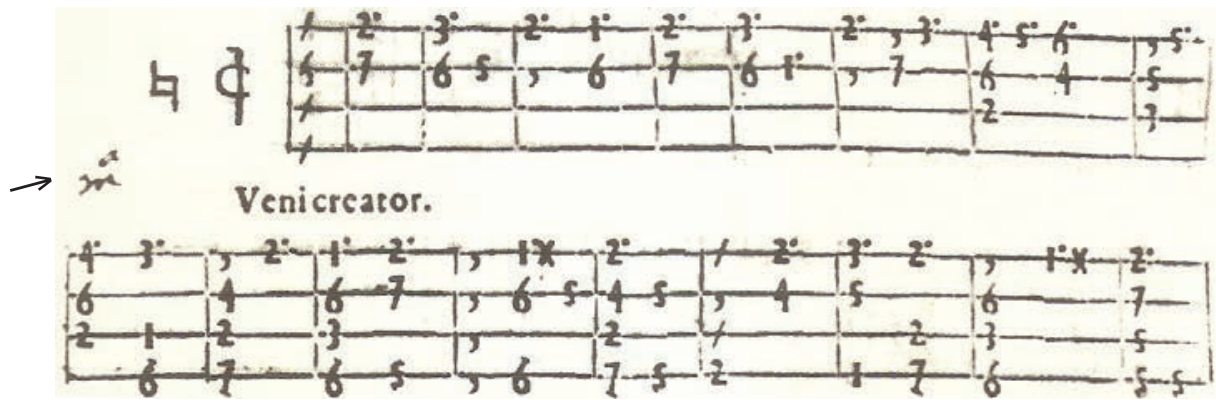

3 Esta última, muy unida y confidente de su hermano Felipe (además de, un tiempo más tarde, la mejor amiga de su cuñada, la reina Isabel de Valois), fue una figura determinante en la corte, que, aunque trató de evitar desempeñar cargos públicos, llegó a ejercer la regencia en 1554-1559. Al año siguiente no obstante, promovió el comienzo de la construcción del convento madrileño de las Descalzas Reales (adonde se retiró en 1564). 

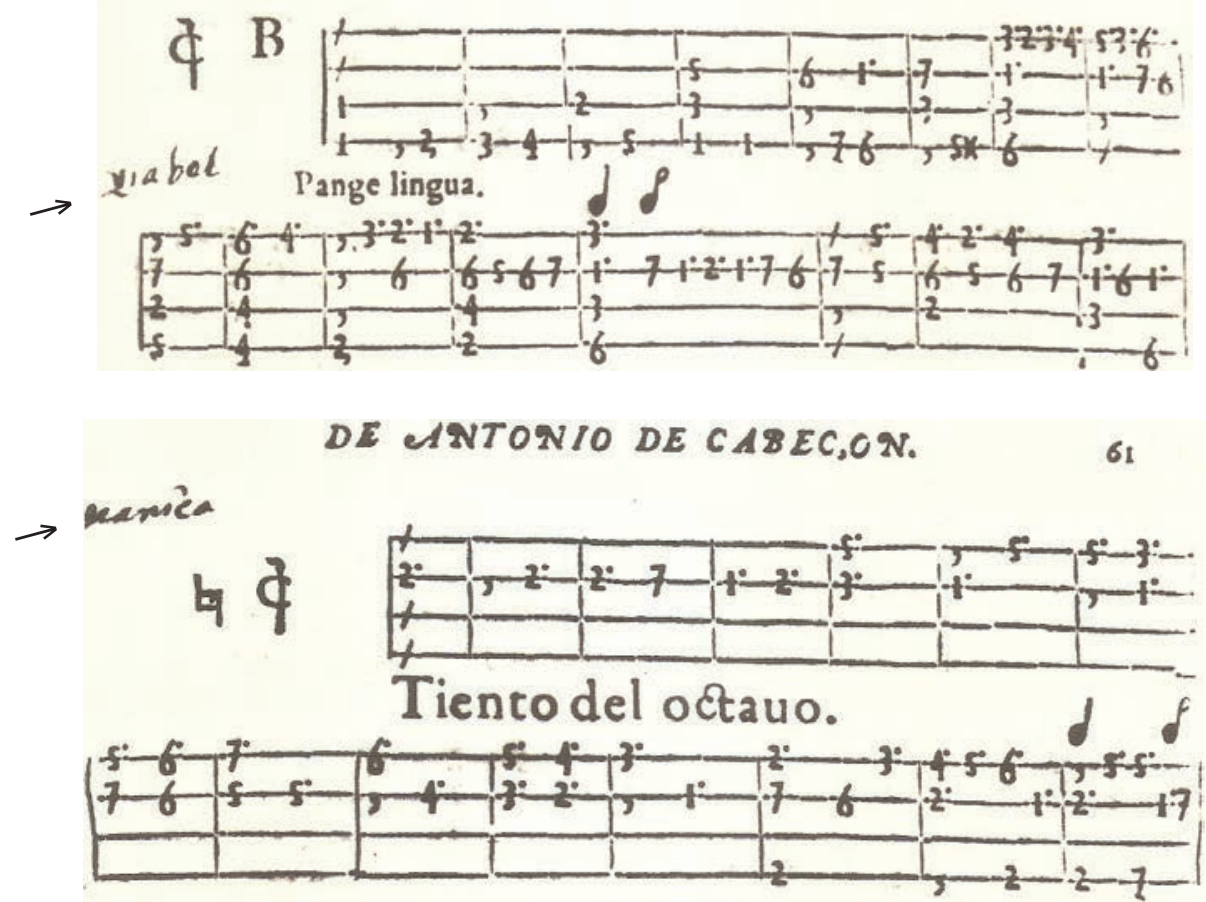

Nombres femeninos añadidos manuscritos al margen ( $M^{a}$, fol.23r; Ysabel, fol.26r; y [J]uanica, fol.61r) en el ejemplar impreso de las Obras de música... de Antonio de Cabezón (Madrid, Francisco Sánchez, 1578), custodiado hoy en la Biblioteca "José María Lafragua" de la Benemérita Universidad Autónoma de Puebla (México). [Alusión probable a sus intérpretes].

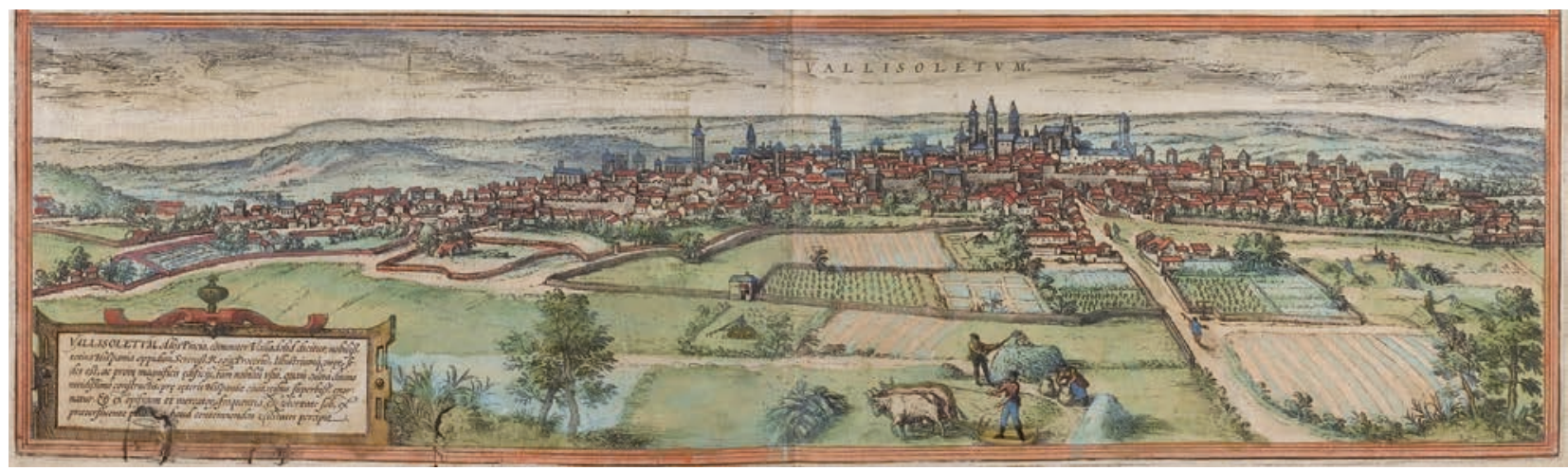

Georges BRAUN y Frans HOGENBERG: "Vista de Valladolid", en Civitates Orbis Terrarum. Colonia, Heinrich von Aich, 1572 [1574]. 

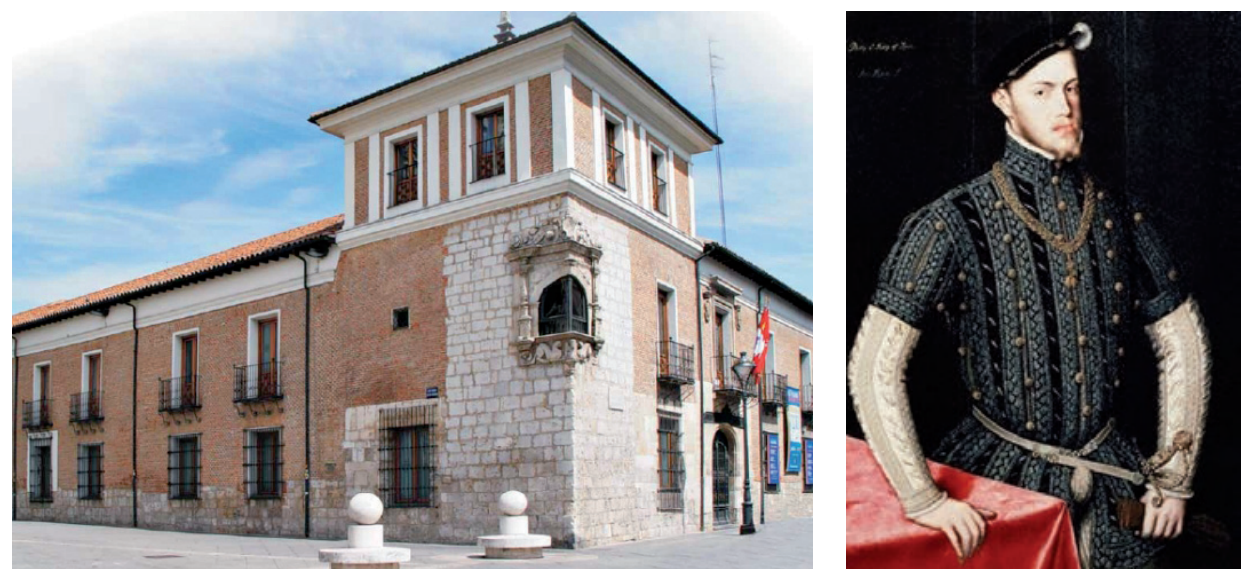

Palacio Pimentel, casa natal de Felipe II en Valladolid, y retrato del joven príncipe Don Felipe, hermano de las infantas María y Juana, a quien también enseñó música A. de Cabezón en dicha ciudad.

A partir de 1543, año en que el príncipe contrae matrimonio con su prima hermana, la infanta María Manuela de Portugal — de la casa de Avís - $(* 1527 ; \dagger 1545)$, éste fue nombrado regente ${ }^{4}$. Y cuando en 1548 , ya viudo, decide em- prender su primer viaje europeo, Cabezón pasa a su servicio, ahora en exclusiva - y hasta su muerte - , como músico de tecla de su capilla y cámara.

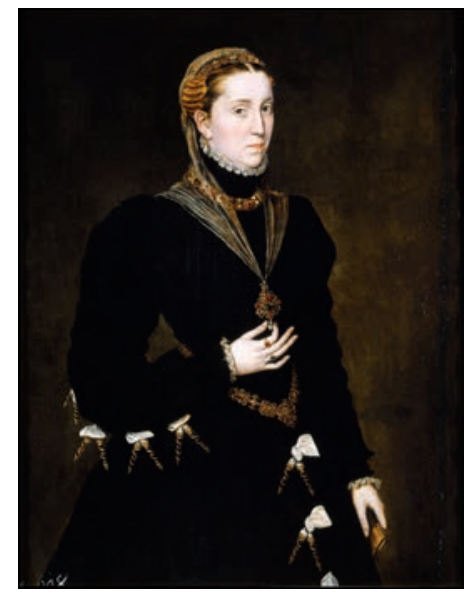

María Manuela de Portugal (*1527; †1545), primera esposa del príncipe Don Felipe, por Antonio Moro.

[Muy resumidamente, podemos avanzar que Antonio de Cabezón acompañó a Don Felipe en su gira, hasta su regreso a Valladolid en 1551. Y marcharía de nuevo con él en 1554, primero a Inglaterra y enseguida a Flandes. El ya monarca,

4 El entonces todavía Príncipe de Asturias, Don Felipe, tuvo con ésta su primera esposa un único hijo, Don Carlos de Habsburgo (*1545; $\dagger 1568$ ), el cual, aunque falleció todavía joven, aún llegaría a ser también Príncipe de Asturias, una vez entronizado su padre.
Felipe II, no volvería a la península hasta 1559 , pero concedió permiso para que regresara con antelación a Antonio de Cabezón en 1556, año que este último pasó en Ávila. Entre 1557 y 1559, Cabezón reside de nuevo en Valladolid, al servicio del príncipe Don Carlos. En 1560 el rey se casa con Isabel de Valois, y al año siguiente la corte se establece en Madrid, transcurriendo esos años nuestro músico en Toledo y Madrid, con la corte, hasta su muerte en 1566]. 

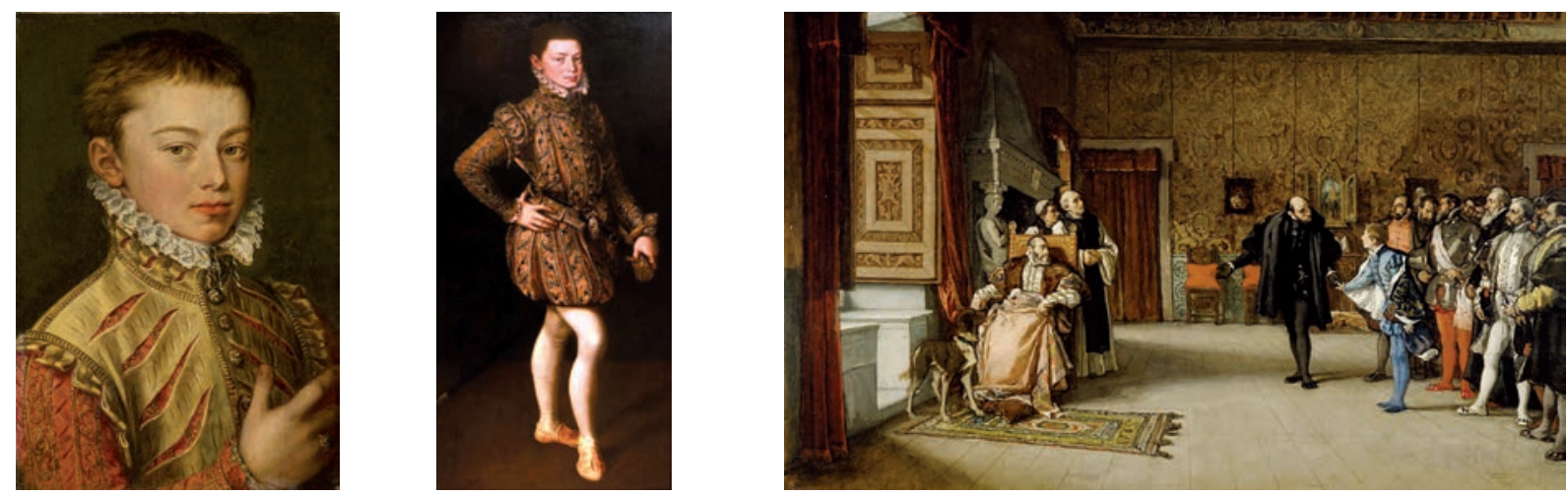

El hermanastro de Felipe II, Don Juan de Austria (*1545 ó 1547; †1578), conocido de joven como "Jeromín”, fue hijo ilegítimo del emperador y de Bárbara Blomberg. Ejerció como militar y diplomático. Izda., retrato de 1559-1560, por Alonso

Sánchez Coello; centro: a los catorce años, por el mismo5. Dcha.: recreación romántica en el cuadro al óleo (1869) de Eduardo Rosales Gallinas: Presentación de don Juan de Austria al emperador Carlos V, en Yuste (Museo del Prado).

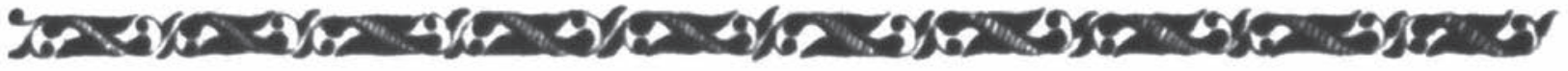

Para el estudio, dos - tal vez tres - son los hitos que marcan su producción musical, internacionalmente conocida. En primer lugar, su presunta intervención en la recopilación impresa de Luis Venegas de Henestrosa (Libro de Cifra Nueva para tecla, harpa, y vihuela... Alcalá, 1557), en donde se incluyen treinta y cuatro com- posiciones atribuidas apenas a "Antonio", compositor que se ha identificado tradicionalmente con Antonio de Cabezón. Como es sabido, se trata aquí de la primera obra impresa en territorio español que se dispuso "en cifra nueva" para cualquier instrumento polifónico (de tecla, arpa o vihuela), la cual supondría posteriormente el modelo

5 Como es sabido, el emperador reconoció a este hijo ilegítimo (tenido con mujer soltera mientras él era viudo), comprometiéndose mediante un sustancioso pago anual a educarle en España, lo que suscribió mediante la firma de un documento a dicho efecto realizada en Bruselas el 13.06.1550, entre su mayordomo Luis Méndez de Quijada y el "violista” de la corte imperial en Bruselas Francisco Massy. El muchacho llegó secretamente a Castilla en 1551 (a Leganés, donde la esposa española de Massy poseía unas tierras) y en verano de 1554 -cuando fue oficial y legalmente reconocido por Carlos V-, el joven pasó al castillo de su tutor, Luis Méndez de Quijada en Villagarcía de Campos (Valladolid), donde, a la sazón, la esposa de este último se hizo cargo de su educación, ayudada por un maestro, un sacerdote y un militar. El soberano ordenó que le llevaran a su presencia, en 1558, en su retiro del Monasterio de Yuste. Mientras, Felipe II se hallaba fuera de España. Eran, precisamente, los años en que Cabezón regresó a España desde su primer viaje europeo, adelantándose al monarca, en un tiempo en que había quedado como regente la princesa Juana, que conoció al muchacho Jeromín en Valladolid en mayo de 1559 (recordemos cómo Cabezón había enseñado música a las infantas varios años en Arévalo, y al príncipe Felipe en Valladolid). También el medio hermano de Jeromín, Felipe II, iba a conocerle en septiembre de 1559, procediendo a reconocerle, según deseo de su padre, como miembro de la familia real. En esas fechas precisamente, Cabezón se hallaba en Valladolid, al servicio del hijo del entonces todavía joven Felipe II, es decir, del príncipe Don Carlos, que había nacido en 1545, y que, por tanto, era casi de la misma edad que su tío Don Juan de Austria. El caso es que, tanto el más tarde malogrado Príncipe de Asturias (Don Carlos), como Jeromín-Don Juan de Austria, se formaron en una floreciente Universidad de Alcalá de Henares, cuna de Miguel de Cervantes, otro personaje con quien, al pasar los años, coincidiría el célebre militar y vencedor en la famosa Batalla de Lepanto (1571), en un entramado de sucesos y personalidades verdaderamente de primera línea internacional, moviéndose en un entorno más bien pequeño, en el que seguramente debieron coincidir, con ocasión de las celebraciones habituales ciudadanas, así como de la corte y la alta nobleza. [Don Juan de Austria, célebre rector de los tercios y armada españoles, al frente de los cuales, y de las tropas cristianas, detuvo el expansionismo mediterráneo de los turcos en Lepanto, llegaría también a ser con el correr de los años Capitán General de la Mar y Comandante de la Flota del Mediterráneo (1568-1576), Capitán General de Granada (1569-1570), Comandante de la Santa Liga de Estados (1571-1573) y Gobernador de los Países Bajos (1576-1578)]. 
principal en el que se basaría la cifra utilizada, a su vez, por Hernando de Cabezón a la hora de editar las composiciones de su padre ${ }^{6}$.
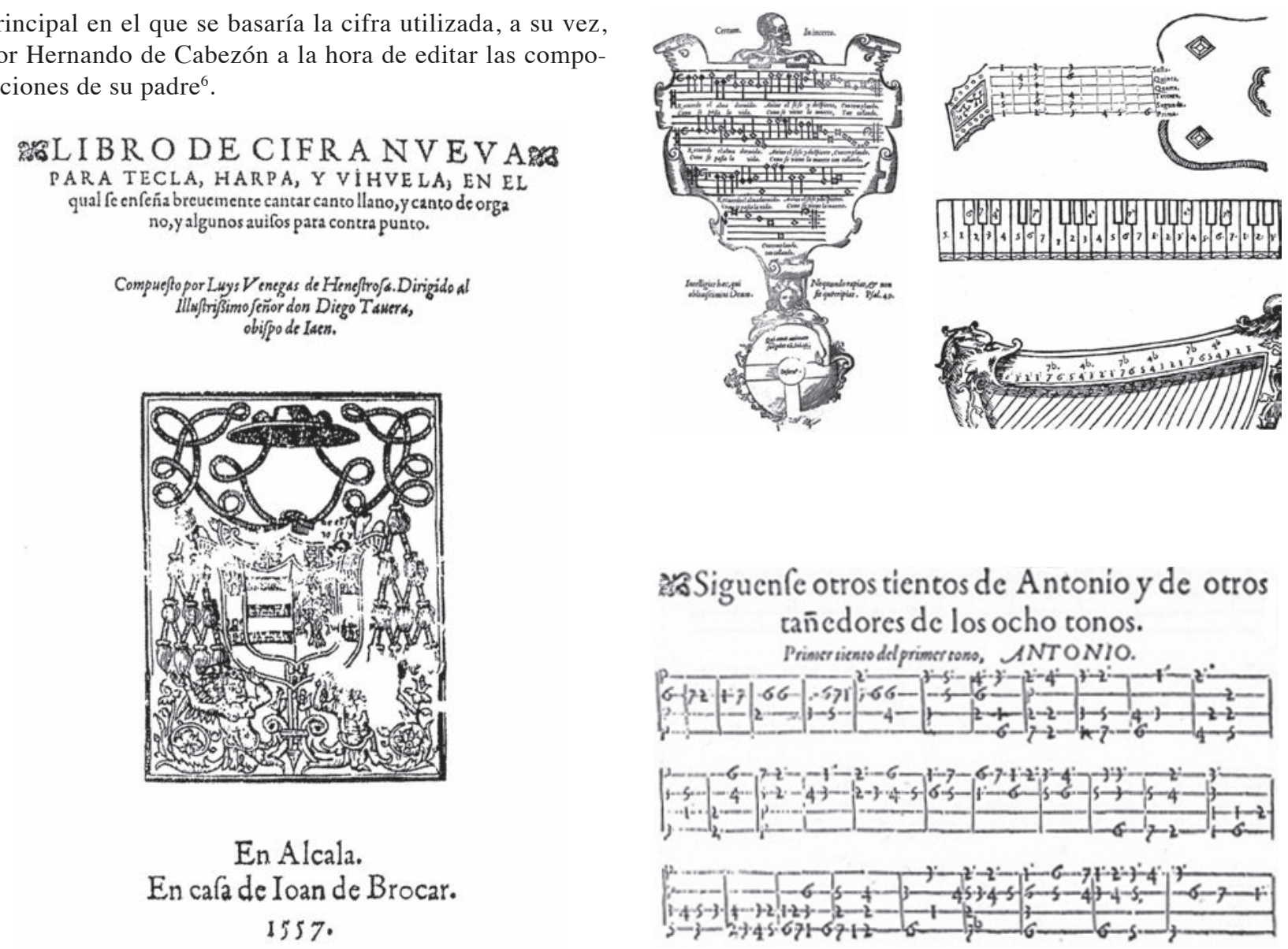

Luis VENEGAS DE HENESTROSA: Libro de Cifra Nueva para tecla, harpa, y vihuela, en el que se enseña breuemente a cantar canto llano, y canto de organo, y algunos auisos para contrapunto. Alcalá de Henares, Juan de Brocar, 1557.

En segundo lugar, la principal fuente que nos ha transmitido la música del organista ciego castellano (242 composiciones) nos la suministra su propio hijo Hernando, en su edición de las Obras de música para tecla, arpa y vihuela,

6 MOLL ROQUETA, Jaime, 1951: 155-178. WARD, John M., 1952a: 105-113. JAMBOU, Louis y François REYNAUD, 1984: 419430. KNISPEL, Claudia, 1994: 23-25. Conviene no obstante precisar que existe otro impreso portugués, algo anterior, a cargo de Gonçalo de Baena, publicado en 1540 y anotado en "otra cifra", que supone el primer impreso para teclado existente en la península ibérica: BAENA, Gonçalo de: Arte nouamente inventada pera aprender a tāger. Lisboa, Germā Galharde, 1540. [Conservado en la Real Biblioteca del Palacio Real de Madrid, cámara de seguridad, signatura VIII / 1816]. Sobre este último impreso, pueden verse: ARTIGAS PINA, Javier, 2004. KNIGHTON, Tess, 2012. FORST, Bruno, 2012. publicadas en Madrid, en las prensas de Francisco Sánchez, en 1578 (doce años después de la muerte de su padre): una colección o Compendio de Música, que organiza sus materiales didácticamente, de menor a mayor dificultad (acaso se corresponda con la música compuesta por Antonio para enseñanza y entretenimiento de las infantas Doña María y Doña Juana en Arévalo) y en la que el proceso editorial fue largo; de hecho, no tuvo mucha venta en España, aunque acabaría siendo una de las obras más decisivas para la evolución de la música instrumental europea. Esta obra constituye sin duda la mejor colección de obras para instrumento polifónico del Quinientos hispano, seguramente debidas, en una altísima proporción, al organista de Carlos V y de Felipe II. 


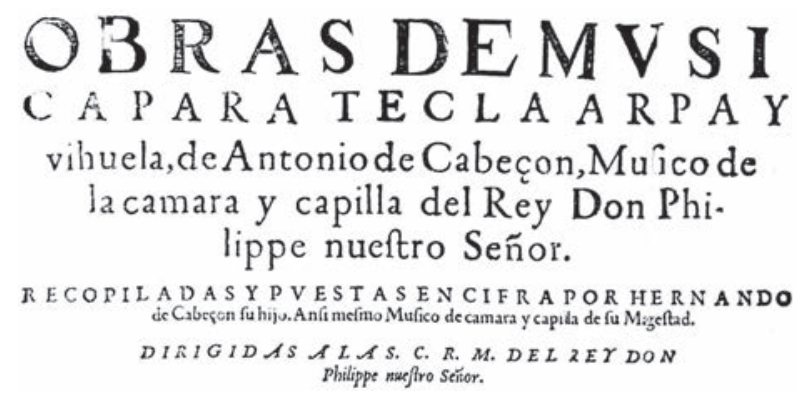

Y finalmente, todavía se encuentran algunas otras

Biblioteca de la Universidad de Coimbra.

obras suyas en Portugal, en los manuscritos 48 y 242 de la

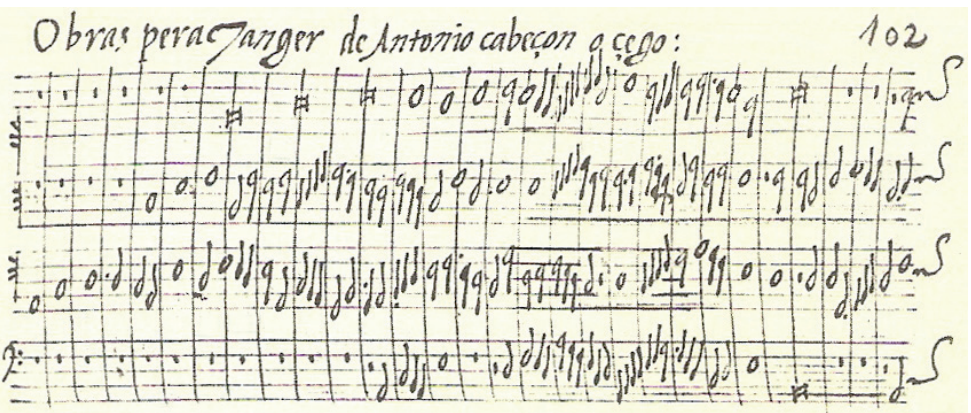

Obras para tañer de Antonio de Cabezón "el ciego", en la Biblioteca General de la Universidad de Coimbra (P-Cug, MM 242, fol.102).

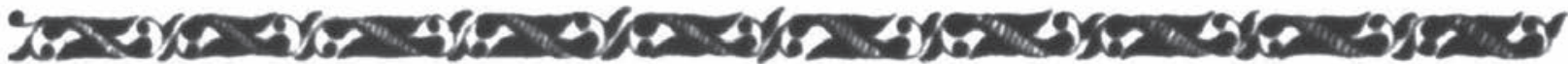

Detenerse en exceso al comentario sobre las afirmaciones de Hernando respecto a los contenidos de su recopilación (en cuya introducción señala que lo que incluye su libro sólo son las migajas que caían de la mesa de su padre y lecciones que daba a sus alumnos y ni siquiera las más importantes, no conforme a su sabiduría, sino a la medida de lo que ellos podrían entender) sería caer, por enésima vez, en el lugar común. Pero reivindicar la figura de Hernando como transmisor y artífice del posterior halo de prestigio de su padre en la profesión organística, no responde sino a justicia: recopilador, transmisor, él mismo compositor de algunas obras y realizador de la puesta musical en cifra de toda la edición.

\section{Dulcememorix.Hernando de Cabeçon.}

En este último sentido, la invención de la cifra utilizada (típicamente española y apenas precedida por la recopilación de Venegas), no sólo supuso un sistema cómodo y barato de reflejar la realidad sonora en forma escrita - no en pauta, sino básicamente mediante números y un código muy sencillo-, sino que resultó un medio bastante eficaz para describir el desarrollo polifónico al servicio de los instrumentos de tecla.

\section{DE C L A R A I ON DE la cifra que enefte libro fe vfa.}


En cualquier caso, difícilmente podríamos comprender adecuadamente la vida y la obra del organista ciego, si no nos acercáramos a la faceta más humana del músico. Casado en 1538 (en facilitar su matrimonio, pudo haber intervenido la mismísima emperatriz), y "por amores", con la jovencísima Luisa Núñez de Moscoso - de la pujante familia abulense de los Núñez-, de Ávila, ciudad en donde desde entonces fijó su casa, tendría cinco hijos: Agustín, Gregorio, Jerónima, María y Hernando. Desde Ávila, Cabezón podría
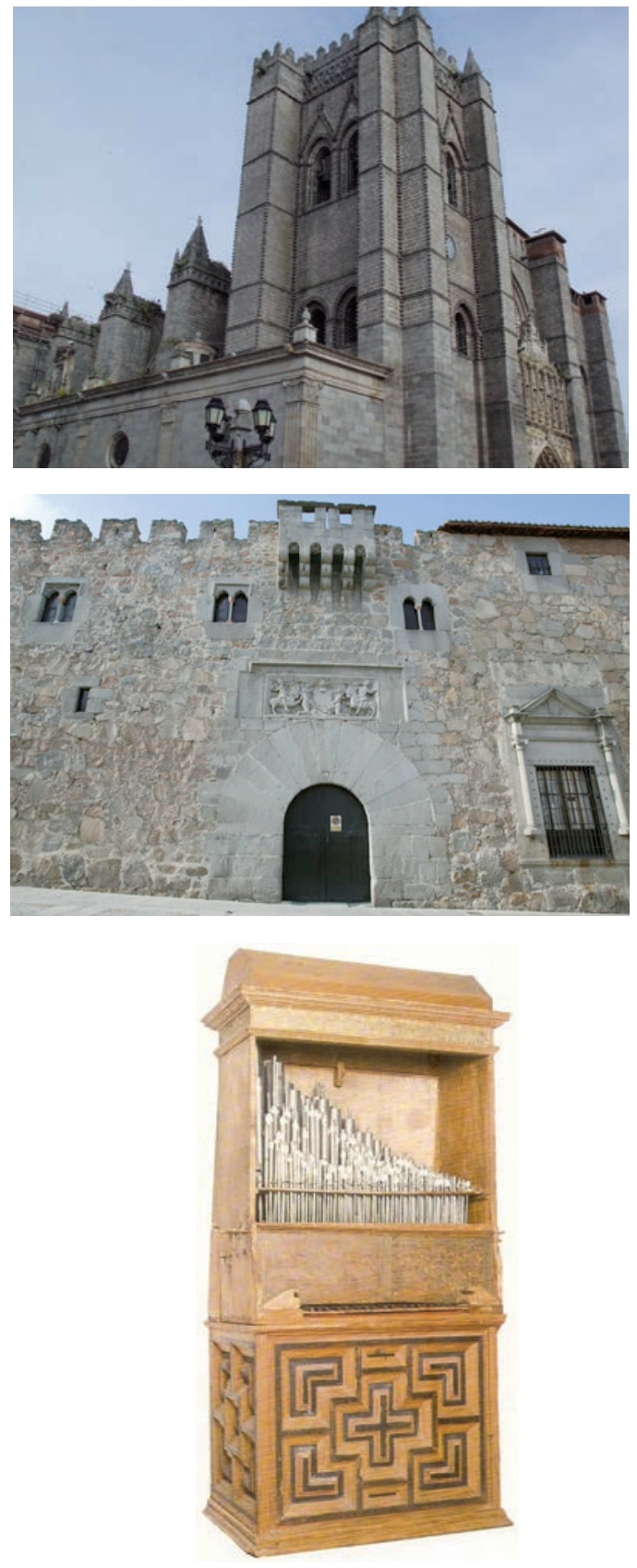

viajar con facilidad a Valladolid, Toledo y Madrid, sedes frecuentes en aquella época de la corte itinerante. Llegó a tener dos casas en Ávila, en el mejor barrio y parroquia, de San Juan, en donde residían los Núñez, los Cepeda, e incluso un niño cantor de la catedral, llamado Tomás Luis de Victoria... En aquella misma iglesia, Francisco Núñez había bautizado años antes a la niña Teresa [Sánchez] de Cepeda [Dávila] y Ahumada: santa Teresa de Jesús $(* 1515 ; \dagger 1582)$.
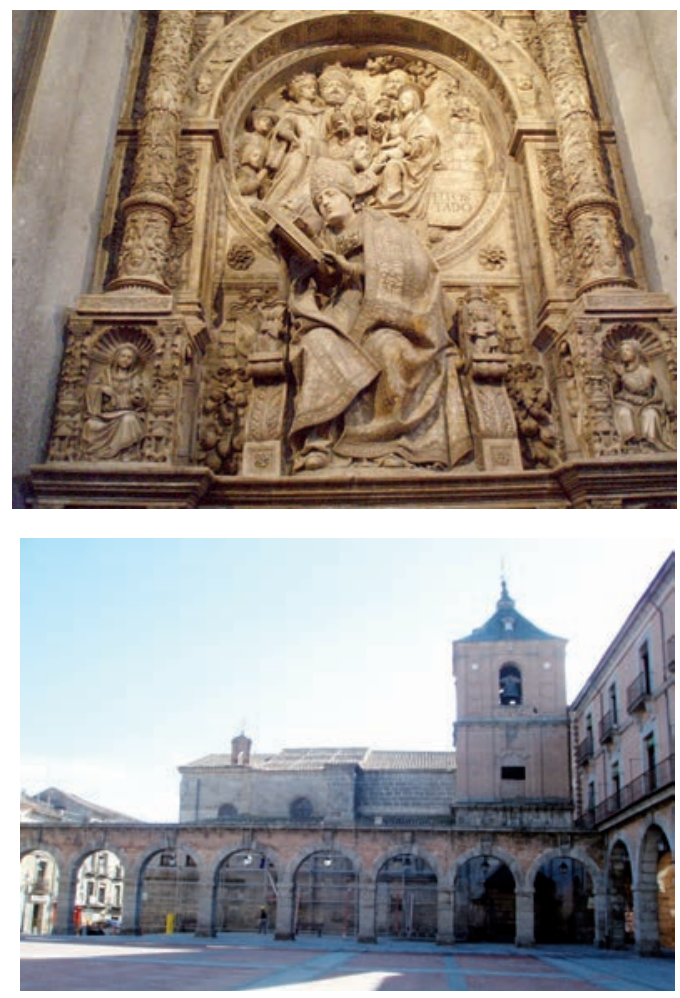

Ávila. Arriba, izda.: exterior de la catedral; dcha.: detalle central del sepulcro del Tostado, Alonso Fernández de Madrigal, obra de Vasco de la Zarza (1520-1524). Centro, izda.: Palacio de los Dávila, de Bartolomé Núñez Dávila; dcha.: iglesia de San Juan Bautista. Abajo: órgano realejo del Convento de la Encarnación, de Ávila (siglo XVI). 
Es un hecho incontestable que la familia debió resultar un apoyo indispensable en la trayectoria de Antonio de Cabezón. Su hija Jerónima entraría al servicio de la reina de Bohemia, su hijo Gregorio llegó a abrazar el sacerdocio, su sobrino Alejo - bachiller enraizado en Castrillollegó a ser uno de los tres curas de su propio pueblo, y él mismo, tras acompañar al monarca en su jornada inglesa, recibió, entre otros regalos, mil ducados de dote para el casamiento de su hija menor, María, admitida como "dama de la cámara de la princesa doña Juana" de Portugal.

Pero, privado de la visión, no sabía escribir. Ello hace que la documentación primaria y directa que sobre él se ha conservado sea exigua y que, incluso en los actos vitales de relevancia en que debía, al menos, firmar su conformidad, tenía que valerse de alguna otra persona. Aparte de la necesidad de algún manchador o levantador de fuelles - requerida entonces por todo organista-, posiblemente precisara también de alguien que le ayudara a llegar hasta la tribuna en que se ubicaban algunos instrumentos, o que le indicara el emplazamiento concreto de los tiradores de los registros, o que le informara del momento exacto en que la liturgia o el ceremonial de corte requería de su intervención. Para ello, nada mejor que el apoyo familiar, del que siempre estuvo rodeado. En primer término, de su propio hermano Juan ${ }^{7}$; y más tarde, de sus hijos, especialmente Hernando y Agustín.

El primero de ellos, Juan, posiblemente menor en edad que nuestro protagonista, fue también organista y compositor de cámara, y acompañó, como su hermano Antonio, al príncipe Don Felipe en alguno de sus viajes. Sólo se conserva de él un Glosado a cinco voces sobre la canción Pues a mí desconsolado, tantos males me rodean, acaso compuesta con motivo de la muerte de su hermano Antonio. Tuvo como discípulo a Cristóbal de León, que aprendiera música con Antonio, a quien acompañó durante años y viajes, y a quien se ha querido ver como uno de los hipotéticos copistas de las obras del organista ciego.

Por su parte, Hernando (*Madrid, 05.09.1541; †Valladolid, 01.10.1602) comenzó ejerciendo como organista sustituto de la Real Capilla, en 1559. Más tarde, fue organista de la catedral de Sigüenza (1564-1566) ${ }^{8}$, hasta que su-

7 Antonio tuvo otro hermano, Diego, que quedó al frente del patrimonio familiar en Castrillo, y a quien el famoso organista iba a alquilar en dos ocasiones unas tierras de labranza de su propiedad.

8 Donde aparece documentado en las Actas del Cabildo de Sigüenza. Años 1549 Á 1563. Constan las primeras gestiones para mandar traerle, debido a sus buenas referencias, el 15.11.1563, y el 29.11.1564 se le concedía licencia "para tañer el órgano y órganos" de la seo seguntina. En la fecha citada de 1563, las actas (tomos 32-33-34, fol.257v), señalaban: "Este dia entendido por sus $\mathrm{m}[$ erce]des $\mathrm{q}[\mathrm{ue}]$ la voluntad de n[ues]tro prelado y S[eño]r [Pedro Gasca] era que sus m[erce]des cedió oficialmente a su padre a la muerte de éste en 1566 (acompañándole antes en alguno de sus viajes por Europa junto a Don Felipe). Siempre alabó a su padre, de quien señalaba que su ceguera no era "sino particular providencia de Dios, para que, acrecentándose la delicadeza del sentido del oír en lo que faltaba la vista [...], alcanzase a lo que su gran ingenio comprendía". El caso es que, muerto su padre, Hernando permaneció en Portugal entre 1580 y 1581, reclamando personalmente su estancia allá el propio monarca Felipe II, quien, en carta escrita a sus hijas desde Lisboa en 1581, decía: "Y no sé si havréis savido que por no aver aquí quien tañese bien los órganos en la capilla, hize venir aquí á [Hernando] Cabeçón". Sirvió también más tarde como músico de cámara en la corte de Felipe III, hasta su fallecimiento.

Finalmente, Agustín (*1541a; †1564a) no llegó a viajar con su padre en el primer viaje europeo de Don Felipe (aduciéndose "que el niño Agustín es tan pequeño, que no es para yr a servir esta jornada"), aunque sí lo hizo ya en el segundo viaje, a Inglaterra, como cantorcico tiple (fue admitido para el servicio de la corte en 1547), junto a su padre y a su tío Juan, que viajaban como organistas y tañedores de tecla.

nombrasen por organista desta S[an]ta Igl[es]ia a Hernando Cabeçon organista de su mag[esta]t, ansi por ver q[ue] [Francisco Hernández] Palero [más tarde, organista de la Capilla Real de Granada] a quien avian embiado llamar a Granada no venía, como por que tenían relaçión de su grande abilidad y q[ue] de çiertas igl[es]ias del reyno le procuraban llevar, unánimes y conformes aviendo votado prim[er]o todos sus merçedes como el uso y costumbre en su Cabi[ld]o ordin[ari]o fueron de parescer y voto, de darle la d[i]cha prebenda y ansi diputaron a los s[eñore]s ar[cedia]no de Aillon y Can[onig]o Çaldivar para q[ue] subiesen a su S[eñori]a II[lustrisim]a y le dixessen la nominación que se avia hecho conforme a la voluntad q[ue] se les avia referido que su S[eñori]a avia mostrado y q[u]e le suplicaba mandasse escrivir a Antonio Cabeçon, padre del d[i]cho Her[nan]do de Cabeçon, para q[ue] con la letra de sus mercedes se le imbiasse, y por quanto el S[eño]r Can[onig]o Andrés de Valdivieso se offrecio q[ue] llevaría estas letras por q[ue] avia de yr [a] otro neg[oci]o suyo a Alcalá, sus merçedes le di[e]ron ocho días de gra[ci]a". Seguramente la respuesta de Antonio de Cabezón fue positiva, pues dos semanas después, el 03.12.1563, consta lo siguiente (Ibidem, fol.260v): "Este dia sus m[erce]des diputaron y nombraron para hacer la información de la genealogía y descendencia de Hernando de Cabeçon, organista desta S[an]ta igl[es]ia, conforme a los estatutos della, al señor can[onig]o Andrés de Valdivieso, al que dieron pleno poder y comisión para yr a su naturaleza a la hazer por el interrogatorio de preguntas y instrucción q[ue] se le dará por el S[eño]r Doctor Suarez, can[onig]o letrado de sus m[erce]des". Finalmente, el 29.11.1564 (ibídem, fols.266r-v) el capítulo otorgaba licencia a Hernando para desempeñar sus funciones: "los S[eñore]s Doctor Suarez y B[eneficiad] o Guijarro salieron fuera, y vieron la información, y refirieron estar muy bastante para exercer el off[ici]o del órgano el d[i]cho Her[nan]do de Cabeçon, y entendido por sus mer[ce]d[e]s dixeron que davan y dieron licen[ci]a al dicho Her[nan]do de Cabeçon para tañer el órgano y órganos desta $\mathrm{S}[\mathrm{an}] \mathrm{ta}$ igl[e]sia [...] y le mandaron assentar en las tablas del puntar y nominas del pan, y de la ma[ne]ra q[ue] se ha hecho y acudido a los demás organistas predecessores suyos". 
Las alusiones elogiosas a Antonio de Cabezón como compositor menudearon desde fecha temprana. Ya en el año 1538 , fecha asimismo de su matrimonio, el escritor y ensayista Cristóbal de Villalón (*16.in; $† 1588$ p) decía de él que "en el arte no se puede más expresar, porque dicen que ha hallado el centro en el componer".
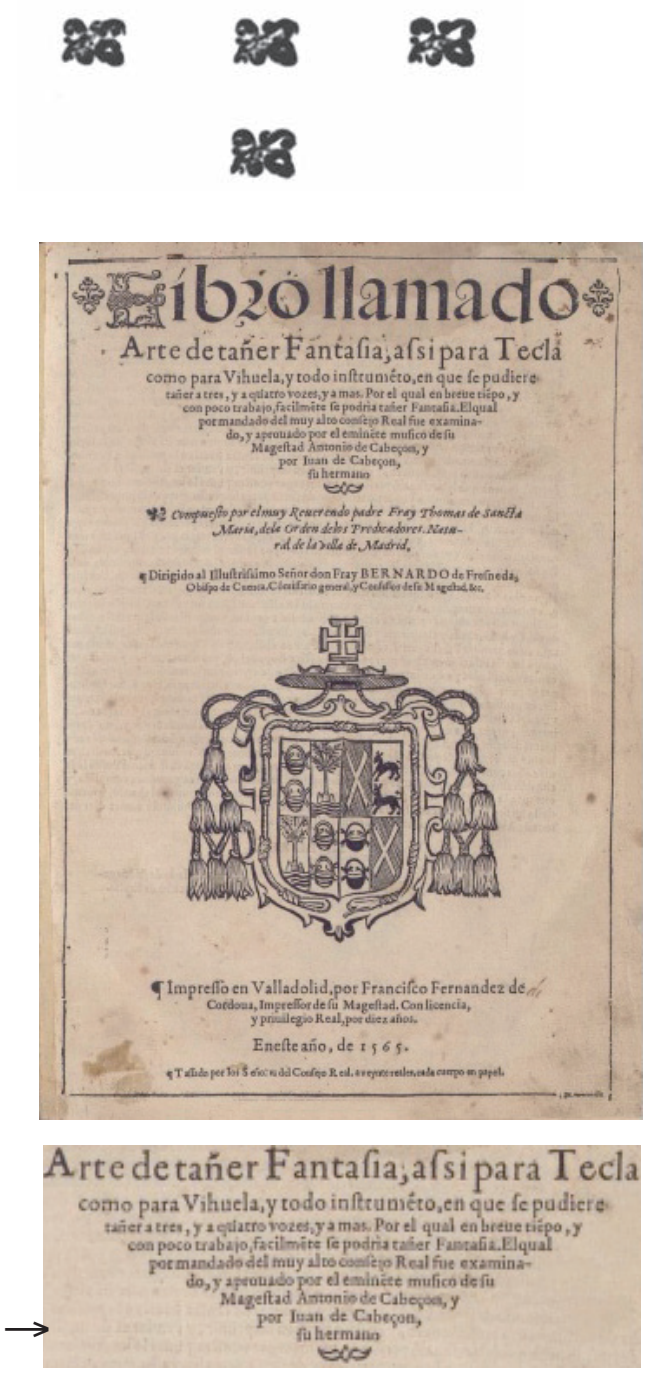

Por lo demás, un año antes de su muerte, Antonio examinó y aprobó (por mandado del muy alto Consejo Real), junto a su hermano Juan, el célebre tratado del dominico fray Tomás de Santa María (*Madrid, 1510; †Ribadavia?, Orense, 1570), Libro llamado Arte de tañer Fantasia... (Valladolid, 1565).
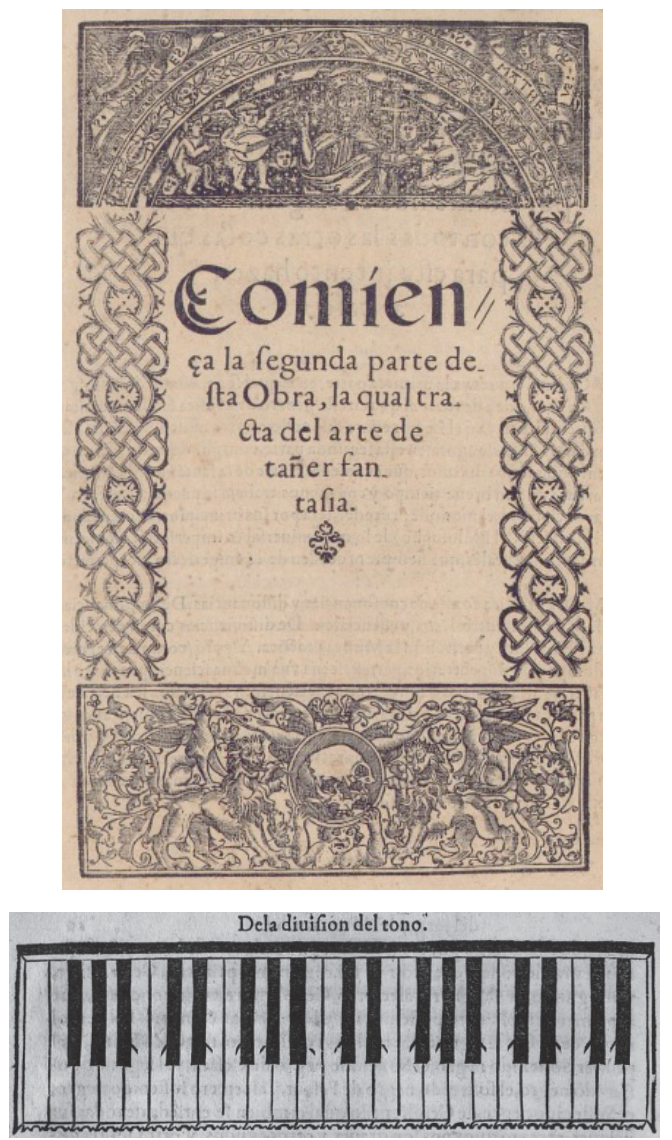

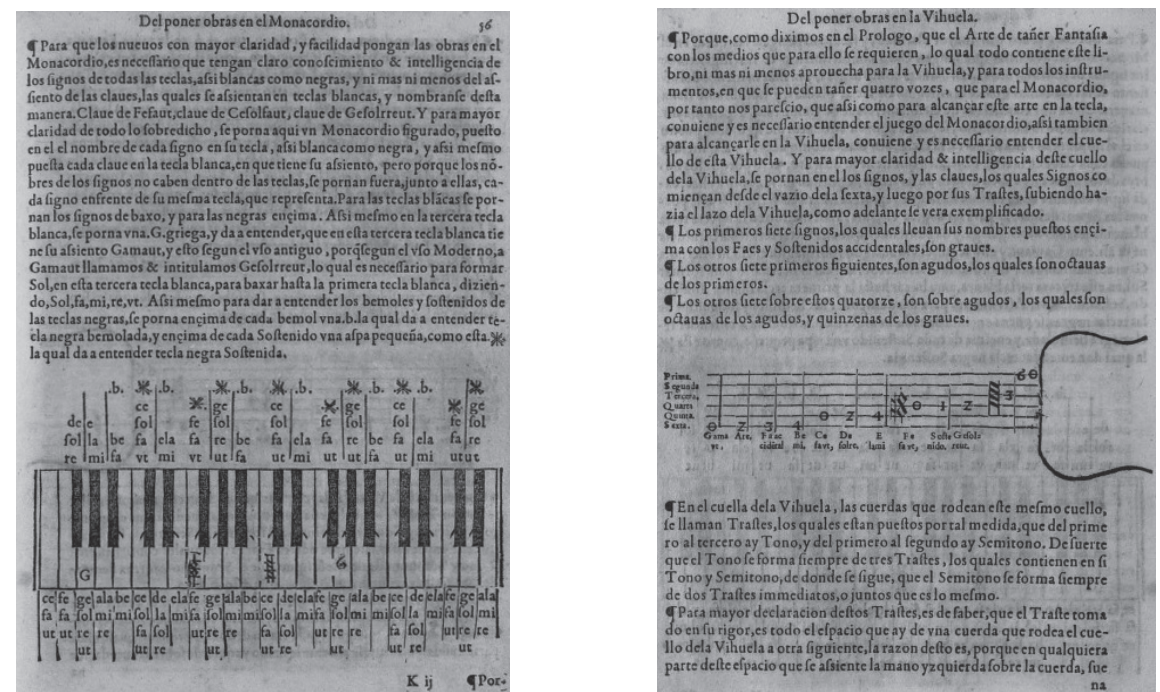

Fray Tomás de SANTA MARÍA: Libro llamado Arte de tañer Fantasia, assi para Tecla como para Vihuela, y todo instrumẽto, en que se pudiera tañer a tres, y a quatro vozes, y a mas. Por el qual en breue tiẽpo, y con poco trabajo, facilmẽte se podria tañer Fantasia. Valladolid, Francisco Fernández de Córdoba, 1565.

Desconocemos cómo pudo haber verificado su examen Don Antonio, "eminente músico de Su Magestad" aparte de por una obvia transmisión oral - , aunque parece que pudo haber coincidido con el dominico en varias ocasiones, pues el teórico, organista y compositor que propugnaba "tañer con buen aire", en su "Prólogo al pío lector", explica que preparar su tratado le había costado dieciséis años de trabajo infatigable, "comunicando cosas con personas diestras, y entendidas en esta facultad, especialmente con el eminente músico de Su Magestad Antonio de Cabeçon". En efecto, parece que Santa María ejercía en 1536 como organista del monasterio madrileño de Santa María de Atocha, desarrollando luego su actividad como instrumentista en el convento de dominicos de San Pablo de Valladolid, para, ya en 1563 - según el contrato de impresión de su libro-, estar en el Monasterio de Santo Domingo de Guadalajara. Posiblemente ambos músicos departieran sobre cuestiones de digitación, de lo que el tratado de Santa María elabora un interesante sistema ${ }^{9}$.

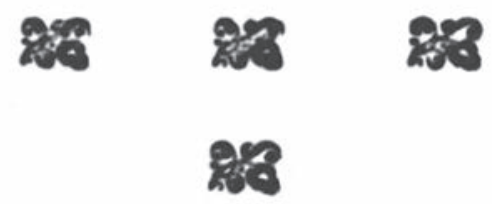

9 KASTNER, Macario Santiago, 1987: 113-127.
Pero, si por algo destaca la personalidad de Antonio de Cabezón, aparte de las siempre posibles conjeturas a que nos vemos obligados por falta de certezas documentales, fue por su proyección internacional. Acompañó con su séquito al príncipe Don Felipe, más tarde monarca con el nombre de Felipe II "el Prudente" (en cuyos dominios - otro lugar común, pero una nueva gran verdad-, "no se ponía el sol") en sus dos viajes más fastuosos alrededor de Europa. Al iniciarse el primero de ellos, Cabezón tenía ya 38 años de edad. Su intrincado recorrido, iniciado en Valladolid el 01.10.1548, le llevó en su primera etapa peninsular, vía Peñafiel, Aranda, Calatayud y Zaragoza, hasta llegar al monasterio de Montserrat y a Barcelona, donde embarcaron rumbo a Génova, adonde arribó una flota principesca de cien navíos el 25.11.1548. 

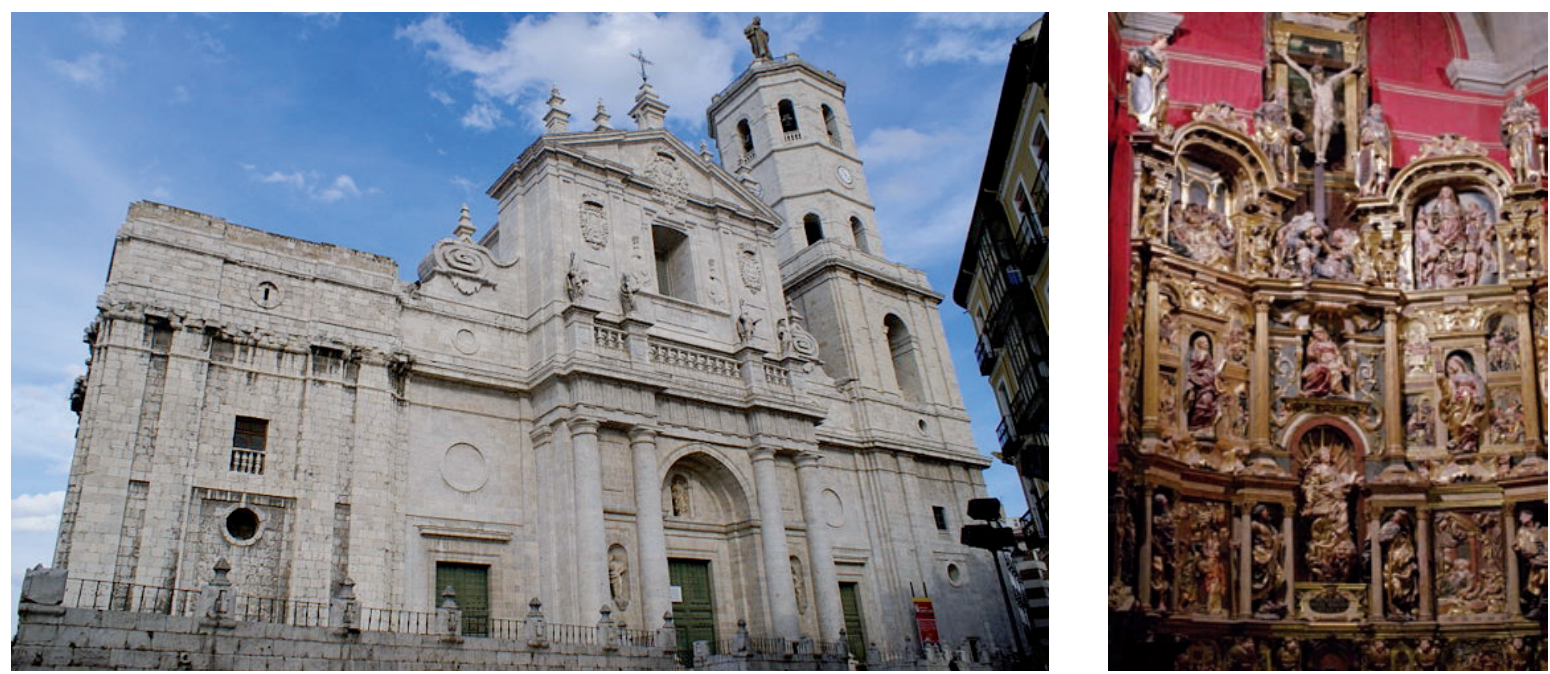

Catedral de Valladolid. Fachada, y retablo mayor, obra de Juan de Juni (1546).

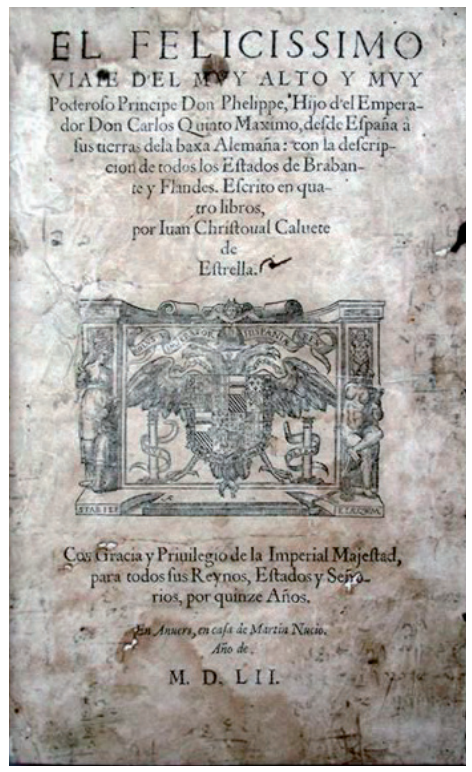

Juan Cristóbal CALVETE DE LA ESTRELLA: El felicísimo viaje del muy alto y muy poderoso Príncipe hijo del Emperador Don Carlos quinto Máximo, desde España a sus tierras de la baxa Alemania: con la descripción de todos los estados de Brabante y Flandes.

Amberes, Martín Nucio, 1552.
El cronista real, Juan Cristóbal Calvete de la Estrella (maestro de pajes, y de latín, de Don Felipe) ${ }^{10}$, que conocía el arte del músico ciego, nos refiere en términos laudatorios la intervención entonces del ciego burgalés en su crónica (El felicísimo viaje del muy alto y muy poderoso Príncipe hijo del Emperador Don Carlos quinto Máximo..., p.18), a propósito del solemne recibimiento del príncipe en la citada ciudad portuaria italiana:

10 (*Sariñena, Huesca, 1520?; †Salamanca, 1593). También poeta erudito, humanista e historiador de amplios conocimientos, ejerció como ayo - maestro de pajes- del joven Don Felipe. Había estudiado lenguas clásicas en Salamanca y humanidades en Alcalá de Henares con Hernán Núñez, siendo discípulo de Jerónimo Zurita. Más tarde desempeñó con eficacia la tarea de cronista del Reino, y en particular, de las Indias, labor que motivó alguno de sus trabajos más señalados, en los que da cuenta de los principales viajes de los descubridores españoles: De Aphrodisio expugnato, quod vulgo Africam vocant, commentarius: cum scholiis Bartholomaei Barrienti Illiberitani: accedunt eiusdem Calveti carmina varia (Amberes, Martín Nucio, 1551), De rebus gestis Ferdinandi Cortesi (manuscrito); Encomio de Fernando Álvarez de Toledo, duque de Alba (Amberes, 1557); o De rebus Indicis; Rebelión de Pizarro en el Perú y vida de D. Pedro Gasca escritas por Juan Cristóbal Calvete de Estrella. Compuso asimismo algunos poemas religiosos y latinos (El Túmulo Imperial, adornado de Historias y Letreros y Epitaphios en Prosa y verso latino, Valladolid, Francisco Fernández de Córdoba, 1559) y un tratado de métrica griega y latina (De versuum genere epitome, manuscrito, 1586). 
"Llegada á Génova. - Llegado el Príncipe á la iglesia mayor, fue recibido con una solemne procesión de la clerezía. Estaban á la puerta esperándole el Príncipe Doria y los de la Señoría, celebróse la Misa de Pontifical. Oficiáronla los Cantores y capilla del Príncipe (D. Felipe), con gran admiración de todo el pueblo, de ver la

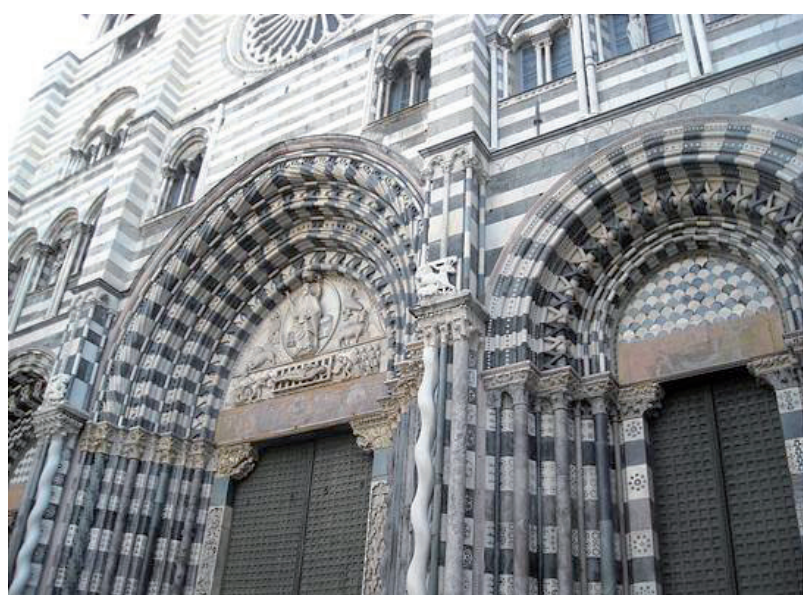

solemnidad con que se hacía, y con tan divina música y de tan escogidas voces; y de oir la suavidad y extrañeza con que tocaba el órgano, el único en este género de música, Antonio de Cabezón, otro Orfeo de nuestros tiempos".

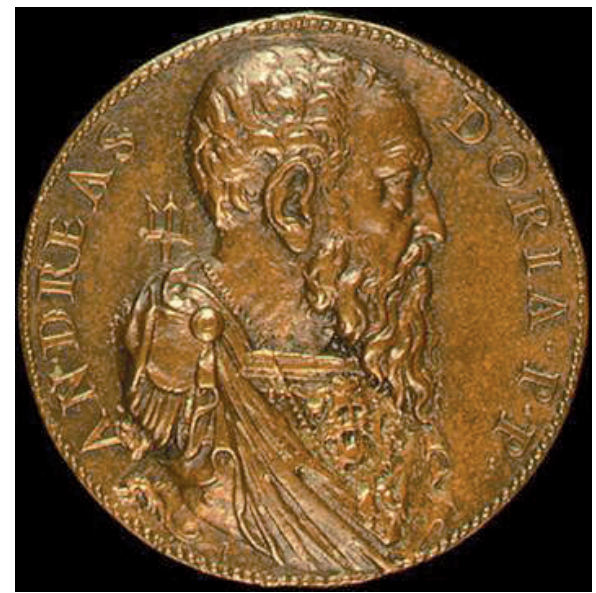

Entrada a la catedral de San Lorenzo, de Génova. A la dcha., el almirante genovés Andrea Doria, en una medalla realizada por León Leoni (1541).

Desde ahí, la comitiva se dirigió hacia territorio centroeuropeo en una marcha realizada casi toda — en su primera parte - a caballo. Atravesaron Milán, Mantua y Trento, desde donde alcanzaron tierras de Austria y Alemania (Innsbruck, Múnich, Ulm — donde se encontraron con las tropas españolas del emperador, que se les unieron en su camino hasta Flandes - , Espira, Heidelberg...), para dirigirse finalmente a Flandes, donde realizarían una estancia más prolongada, en la que visitaron multitud de lugares (Bruselas, Brabante, Lovaina, Amberes, Gante, Brujas, Namur, Tournai, Malinas, Luxemburgo...).
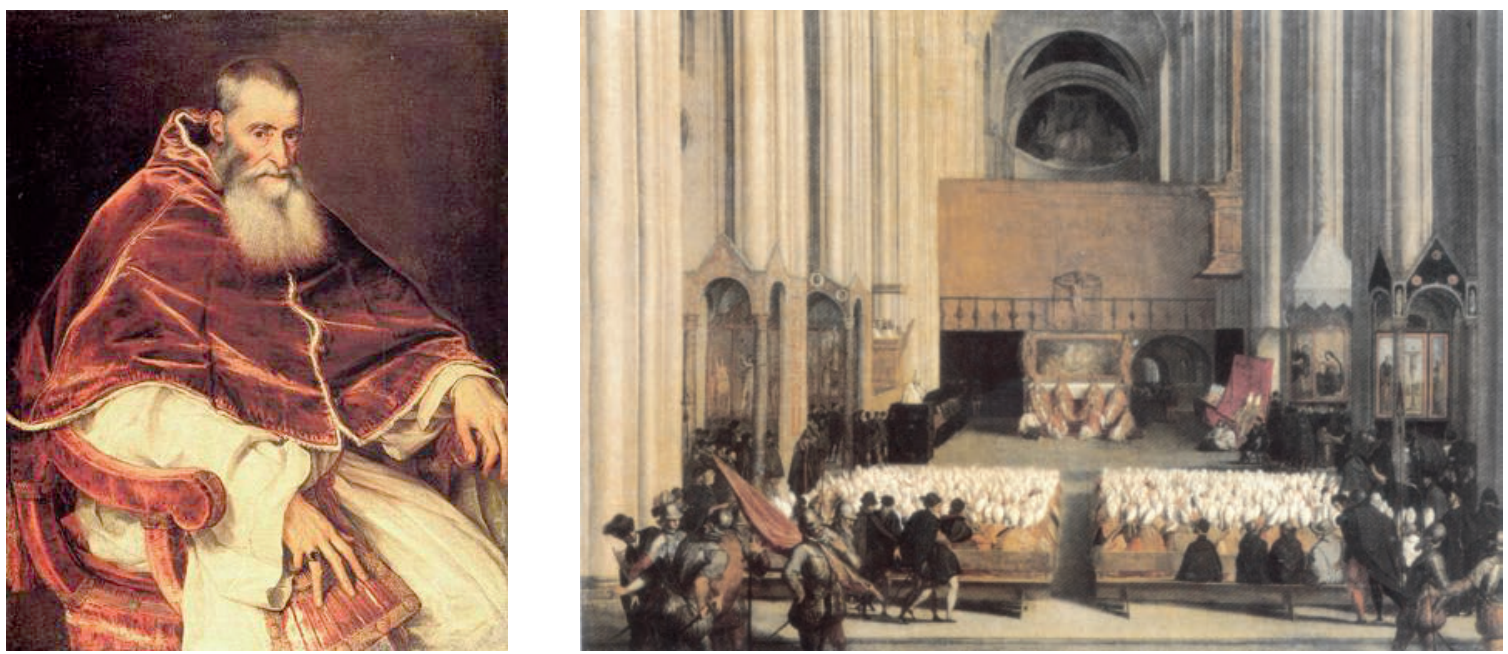

El primer viaje europeo (1548-1551). Izda.: el papa Pablo III Farnesio, por Tiziano.

Dcha.: El Concilio de Trento (1545-1563), por Tiziano (Museo del Louvre). 
De su temprana y breve estadía en Milán, sabemos que la Iglesia agasajó al príncipe con unas ceremonias "cantadas con música de voces y de órgano", y que, tras el banquete nocturno en casa de Ferrante Gonzaga,

"el príncipe y la princesa de Molfeta y su hija y las damas se salieron desde a poco a los estrados y començaron caballeros a dançar con las damas milanesas

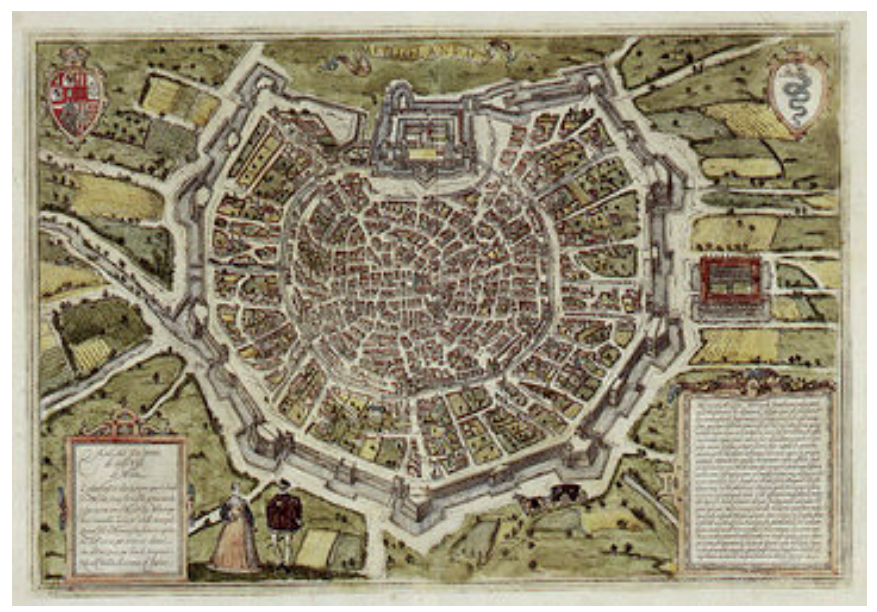

que allí había. El príncipe danzó con la princesa y con su hija, y después de haber dançado algunos muy bien pavanas y gallardas, se començó la danza de el hacha, donde salieron damas y caballeros a dançar por su orden, y el príncipe, después de haber dançado con la hija de la princesa, hizo que sacase al Duque de Alba y al Marqués de Astorga".

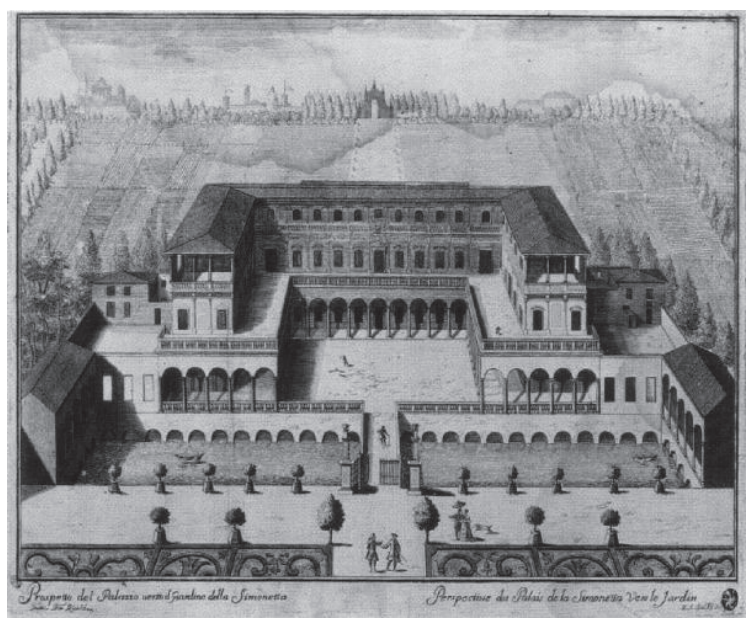

Mapa de la ciudad lombarda de Milán del siglo XVI, sede del gobierno español de la época, donde se ubicaba el Palacio Real y casa del entonces gobernador, Ferrante Gonzaga.

Dcha.: Villa Simonetta, residencia de verano de F. Gonzaga (Milán).
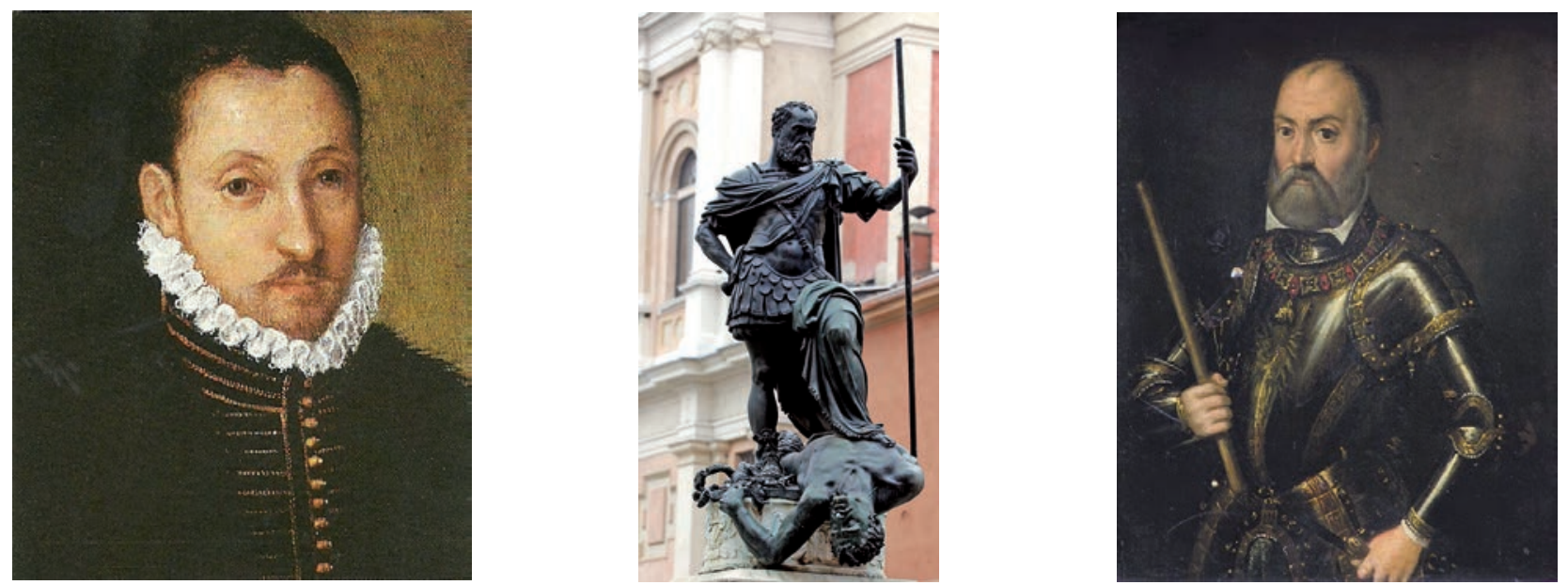

Ferrante I Gonzaga (*1507; †1557), conde de Guastalla y Príncipe de Molfetta. Izda.: 1544 (Castillo de Ambras); centro: estatua póstuma en bronce con el Triunfo de Ferrante Gonzaga sobre la envidia, en la Plaza Roma de Guastalla (Italia), a cargo de su artista protegido, León Leoni (1564); dcha.: como gobernador de Milán (1546-1555), con la orden del Toisón de Oro. 

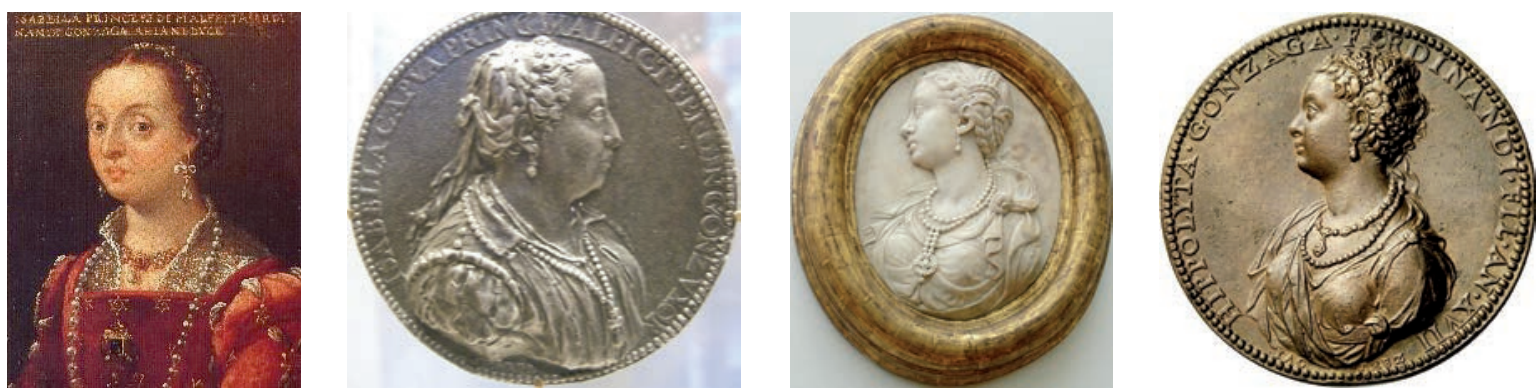

Dos imágenes de la princesa de Molfetta (esposa de Ferrante I Gonzaga), Isabella di Capua $(* 1510 ; \dagger 1559)$ - a la $d c h a$., en una medalla, por Jacopo da Trezzo (1550c) - . A la $d c h a$., otras dos imágenes de su hija, Hipólita Gonzaga $(* 1535 ; \dagger 1563)$, a la edad de 17 años — a la izda., por Jacopo da Trezzo - [¿la "gallarda milanesa"?].
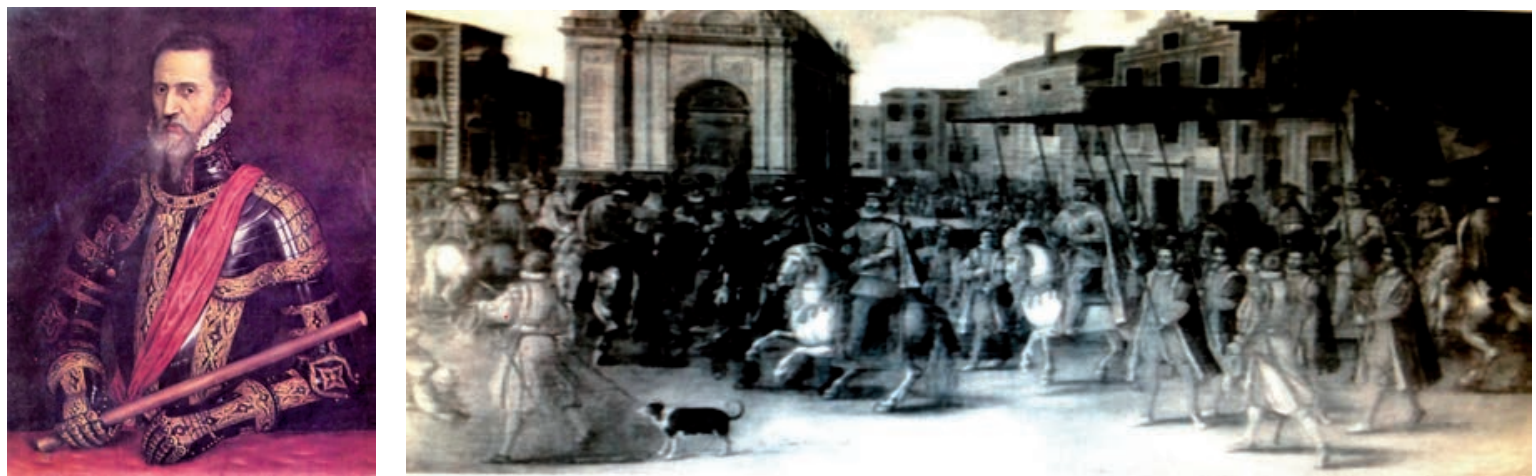

Izda.: Fernando Álvarez de Toledo y Pimentel (*1507; †1582), III Duque de Alba de Tormes, más conocido como el Gran Duque de Alba, que sería gobernador del ducado de Milán (1555-1556). Dcha.: Pedro Álvarez Osorio (*1515c; †1560), IV Marqués de Astorga, sostiene el cetro de Carlos V, durante su coronación como emperador, en Bolonia (1530).

Allí mismo, sin duda, Cabezón habría escuchado y/o tocado la música de pavanas y gallardas milanesas que más tarde serían incluidas entre sus obras editadas. Acompañaba al séquito principesco una nutrida capilla musical: 3 "cantorcicos tiples", más 4 tiples, 4 contraltos, 3 tenores, 4 bajos, dos organistas - Antonio y Juan de Cabezón - , 10 trompetas y 10 ministriles.

Obedeciendo los deseos del emperador, el príncipe (y con él, sus músicos) pasó buena parte de 1549 y hasta fines de mayo de 1550 , descansando y trabajando junto a su padre. Salieron a caballo desde Bruselas el 31.05.1550, con la intención de llegar a Augsburgo hacia finales de julio, para reunirse con el parlamento alemán. Atravesaron Aquisgrán y Colonia, embarcándose luego a Espira, para llegar a Augsburgo el 08.07.1550.

Los músicos de Don Carlos realizaron el mismo viaje, alternando con los de Don Felipe durante más de dos años. Estos últimos regresaron a España tras recibir el príncipe los amplísimos poderes otorgados por su padre en la Dieta de Augsburgo (el 23.06.1551), y pasando por Génova desembarcaron en Barcelona el 12.07.1551. Complicados desplazamientos y trayectos para un ciego, a caballo, en barco, y en interminables jornadas. 

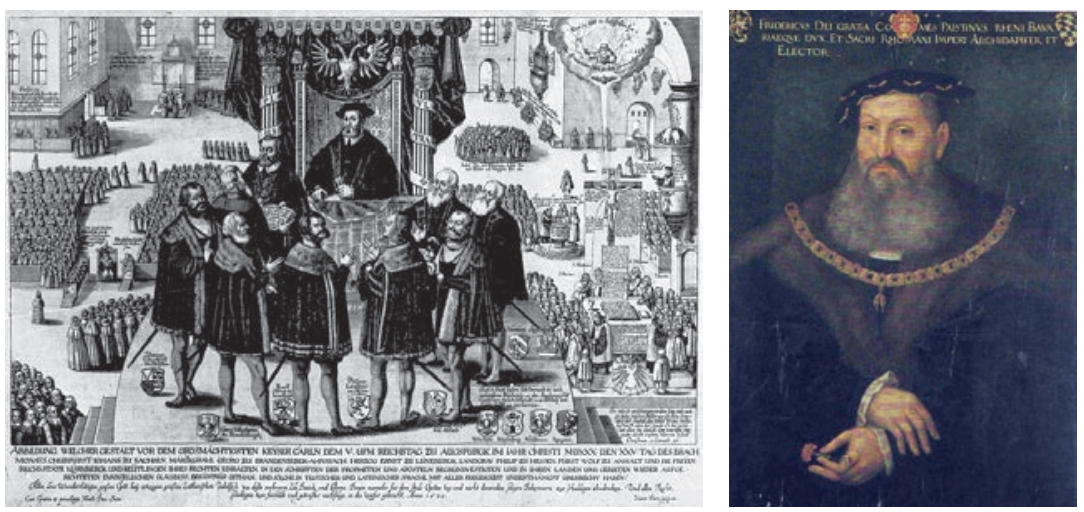

Izda.: Carlos V recibiendo la Confessio Augustana en la sesión del 25.06.1530 de la Dieta (reuniones del Reichstag del Sacro Imperio) de Augsburgo. Allí se celebró una nueva Dieta en 1547-1548, con el llamado "Ínterim de Augsburgo" o decreto imperial del 15.05.1548, promulgado tras la victoria imperial católica en Mühlberg frente al ejército protestante.

Dcha.: el príncipe elector de Renania-Palatinado, Federico II (Federico de Wittelsbach, 1544).

Este primer gran viaje europeo supuso un conjunto de vivencias e intercambios culturales y artísticos verdaderamente singulares. Así, la estancia de Cabezón en Heidelberg, en el palacio y corte del conde palatino o príncipe elector del Sacro Imperio, Federico, le supuso recibir el regalo - supuestamente por sus servicios como músico- de una reli- quia (que todavía hoy se venera en la iglesia parroquial de Castrillo de Matajudíos, donde se depositó, encerrada en un relicario policromado): el cráneo de Santa Laura y dos bulas de legitimación, firmadas por los cardenales Giovanni Poggio, nuncio papal en España y tesorero de Julio III, y Cristoforo Madruzzo, obispo de Trento.
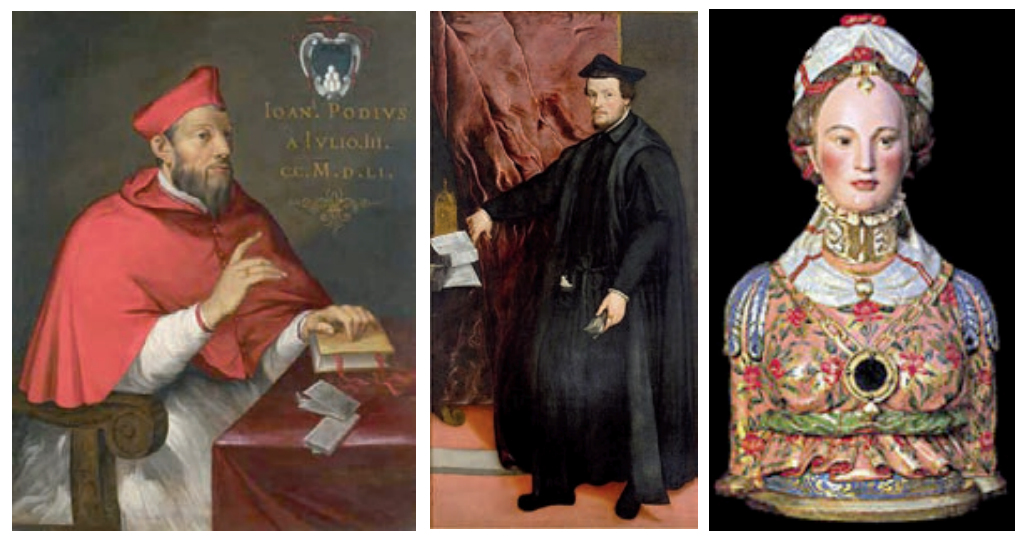

Izda.: El cardenal Giovanni Poggio (1551). Centro: El cardenal Cristoforo Madruzzo (1552), por Tiziano (Museo de Arte de São Paulo). Príncipe obispo de Trento (1539), desempeñó importantes misiones al servicio del emperador, y de su hijo

Don Felipe. Dcha.: Relicario de Santa Laura (iglesia de San Esteban, de Castrillo de Matajudíos).

Ya de regreso en España, se sabe que en 1552 Don Antonio pulsó los órganos de la catedral de Ávila, donde mantenía su casa.

Al cabo de un tiempo, se planteó de nuevo la realización de un segundo viaje europeo de la corte, esta vez a Inglaterra, con motivo de celebrar la boda de Estado del prín- cipe Felipe con María Tudor. Para entonces, Cabezón habría alcanzado ya plena madurez en su música. Tras los acuerdos diplomáticos previos, el 05.01.1554 se firmaba en Londres el pacto matrimonial regio, y al día siguiente se celebraban nupcias "per procuratorem". Había que organizar la partida, que se dispuso vía Benavente y Santiago de Compostela, de 
manera que el 13.07.1554 zarpaba desde La Coruña la flota que iba a acompañar a Don Felipe, compuesta por 125 barcos.

El enlace matrimonial, al que el príncipe se avino por mandato de su padre el emperador ("ya que soy un hijo obediente y no tengo más deseo que el suyo, especialmente en asuntos tan importantes"), fue una mera cuestión de Estado. El fogoso Don Felipe, ante la idea de unirse a una mujer (su tía segunda) doce años mayor que él, pero animado ante la idea de que Inglaterra abrazara el catolicismo, diría en aquella ocasión la célebre frase de "Yo no parto para una fiesta nupcial, parto para una cruzada".
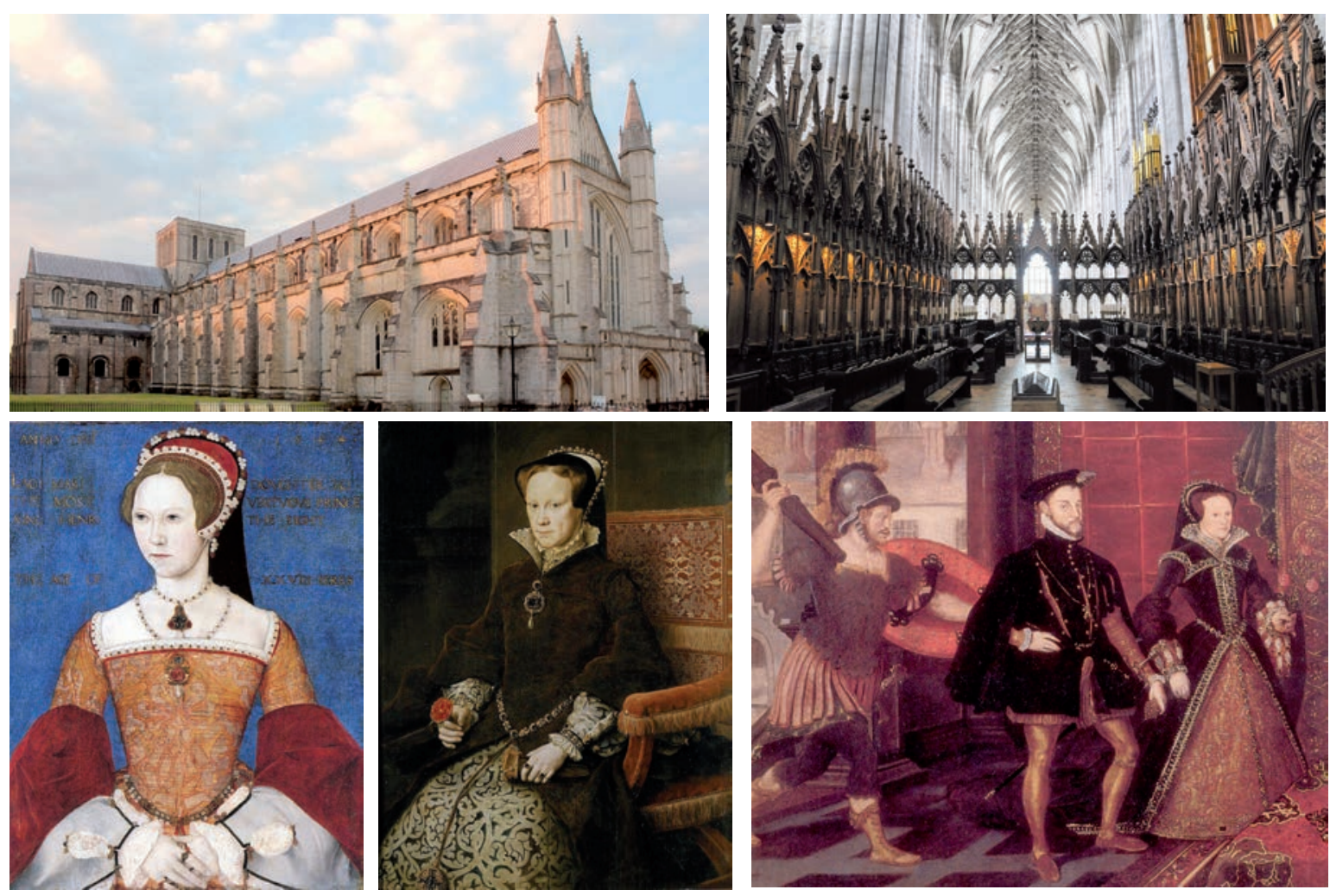

Tía segunda de Don Felipe, María (Tudor) I de Inglaterra se convirtió en su segunda esposa, en la catedral de Winchester (arriba). Abajo, izda., de joven (como Lady Mary), por el Maestro John (1544); centro, por Antonio Moro; dcha., alegoría.

Lo cierto es que la experiencia fue poco satisfactoria para nadie: una vez casados, al cabo del tiempo, y creyendo que la reina estaba embarazada - el objetivo ansiado-, se descubrió que María no tenía más que una retención de líquidos; para salvar las apariencias, el obispo de Londres hizo creer que todo había sido un castigo divino por no proseguir la persecución de herejes, de modo que la propia María ordenó quemar vivas en los tres meses siguientes a más de cincuenta personas, de donde le sobrevino su hoy célebre apodo de "Bloody Mary" (de donde el nombre actual de un conocido cóctel). Felipe y su séquito sólo querían abandonar Inglaterra, donde no les complacía ni el clima, ni la cerveza, ni las mujeres, ni las inclinaciones protestantes. Se populari- zó entonces la copla "Que yo no quiero amores en Inglaterra pues otros mejores tengo en mi tierra ¡Ay, Dios de mi tierra, saquéisme de aquí!, ¡ay, que Inglaterra ya no es para mí!’.

De hecho, como algunos músicos no podían soportar tan larga estancia en aquellas tierras, el rey les concedió licencias para que pudieran visitar a sus familiares en España. Unos, la obtuvieron por un año, como Antonio de Cabezón y su hijo Agustín; y otros, la consiguieron tan sólo por tres o cuatro meses. Entretanto, el goloso y mujeriego príncipe español se entretenía en otros amores (con Catalina Leney, con la doncella de honor de la reina - Magdalena Dacre - , e incluso con una panadera), aunque se rumoreaba que en realidad estaba enamorado - siendo muy posiblemente corres- 
pondido - de su cuñada (hija de Enrique VIII y Ana Bolena, y más tarde, reina), la joven y guapa Isabel.

La cuestión es que, el 29.08.1555, Felipe, reclamado por su padre (que pretendía abdicar a su favor y proclamarle rey de España y de sus colonias, además de señor de Flandes y de los estados de Italia - rey de Nápoles y Sicilia, y duque de Milán-), embarcó en Dover, y por Calais, se dirigió a Bruselas, dejando sola a su esposa.

El 23.10.1555, estando en el castillo de Bruselas Don Felipe y muchos de sus servidores, entre ellos sus músicos, abdicó a su favor Carlos V. Con ello, el príncipe recibió de su padre los Reinos de España, lo que trajo una recompensa del nuevo monarca a sus criados, entre ellos, Antonio de Cabezón y su familia, a quienes, como acabamos de decir, permitió regresar a España. Felipe II continuaba en Flandes y su enamorada esposa, la reina María, le reclamaba desde Inglaterra. El ya monarca volvió a las islas británicas el 20.03.1557, pero tampoco consiguieron la deseada descendencia. Finalmente, Felipe decidió volver a España en julio de 1557, comunicándole María Tudor al poco tiempo un nuevo embarazo, que resultó tan falso como el primero. Abandonada y depresiva, contrajo la gripe y empeoró lentamente su salud, hasta que falleció, sin hijos, el 17.11.1558.
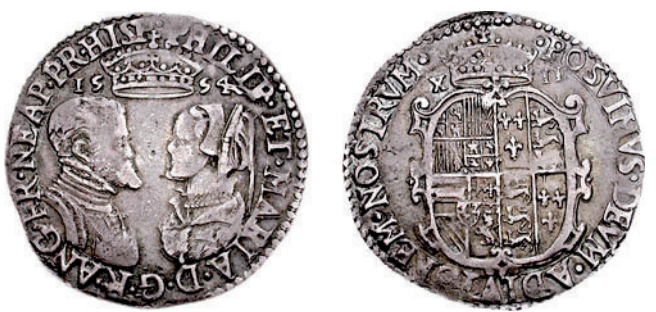

Moneda inglesa (chelín de 12 peniques) con imagen de Felipe II y María Tudor (Londres, 1554).

La estancia de Cabezón en la corte londinense se había prolongado del 13.07.1554 al 29.08.1555, y la presencia del músico castellano, con su "lindo aire de tañer" (basado en un alarde de destreza para ejecutar puntos doblados y reiterados, redobles - trinos - , quiebros - grupetos y mordentes - , y aleados) y con su dominio del arte de las variaciones (diferencias) pudo haber servido de modelo e impulso técnico para Thomas Tallis $(* 1505$ c; $† 1585)$, para la posterior y entonces incipiente escuela de virginalistas y organistas ingleses (de Thomas Morley a Orlando Gibbons, pasando por el sacerdote católico Peter Philips, John Bull o Giles Farnaby, entre otros), o incluso para William Byrd $(* 1543 ; \dagger 1623)$.
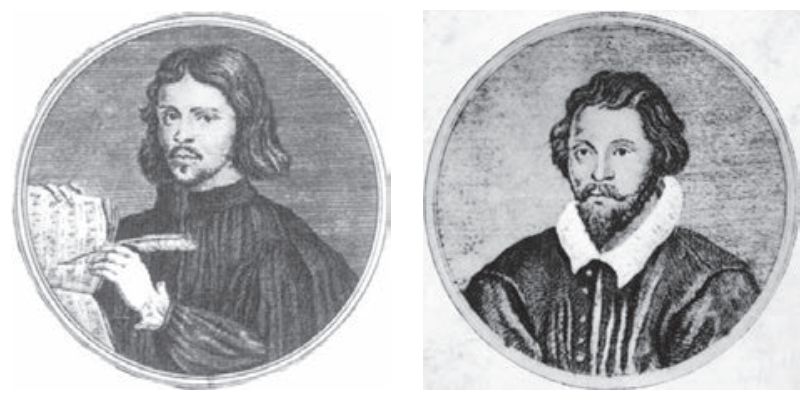

Thomas Tallis $(* 1505 \mathrm{c} ; \dagger 1585)$ y William Byrd $(* 1543 ; \dagger 1623)$.

Según parece, Antonio de Cabezón dejó su gira europea en enero de 1556, al cabo de dieciocho meses escasos de su partida, habiendo transcurrido la última etapa de aquel segundo viaje en los Países Bajos, donde ya había estado en el viaje anterior. Esta vez, iba acompañado por su hermano Juan, y también por su hijo Agustín. Nuestro biografiado se iba a instalar primero en Ávila (1556), y más tarde, en Valladolid (1557-1559), al servicio del príncipe Don Carlos. 

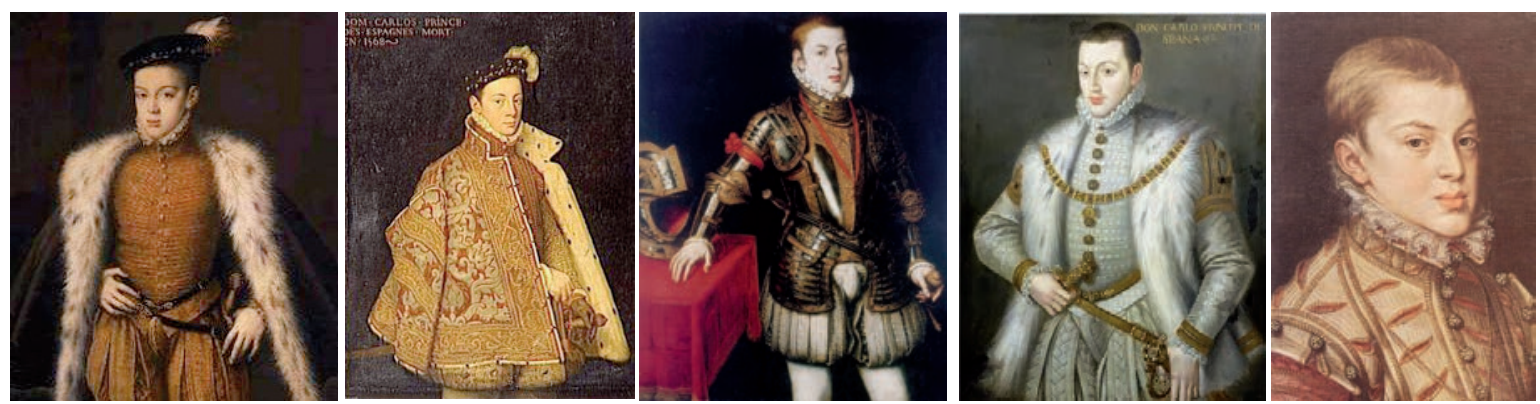

Retratos del único hijo del primer matrimonio de Felipe II con María Manuela de Portugal, Don Carlos de Austria (*1545; $\dagger 1568$ ), que llegaría a ser Príncipe de Asturias. El segundo, atribuido a Antonio Moro, y el tercero (con armadura, 1560c) y quinto, por Alonso Sánchez Coello. [Protagonizaría, ya en el siglo XIX, la célebre ópera Don Carlo de Giuseppe Verdi].

Los viajes y disponibilidad de Antonio de Cabezón le granjearon el reconocimiento de Felipe II, quien, en una cédula en que le concede una pensión vitalicia, declara recompensarle extraordinariamente, "y es de mi voluntad acatando lo que nos ha serbido y sirbe". De hecho, el monarca le asignó un salario fijo de 180.000 maravedíes, que le iba a permitir poder dedicarse por entero a su tarea como músico de tecla y compositor.
Como ya hemos adelantado, a pesar de que el monarca había concedido con antelación licencia para regresar a España a Antonio de Cabezón en 1556, el propio monarca no volvería a territorio peninsular español hasta 1559. Y al año siguiente, el rey contraía nuevas nupcias, esta vez con Isabel de Valois, residiendo al principio la pareja real en Toledo, para establecerse posteriormente la corte, en 1561, en Madrid. En este tiempo pues, una vez más, Antonio de Cabezón hubo de residir junto a los monarcas, en Toledo y Madrid, hasta el fatal momento de su fallecimiento, en 1566.
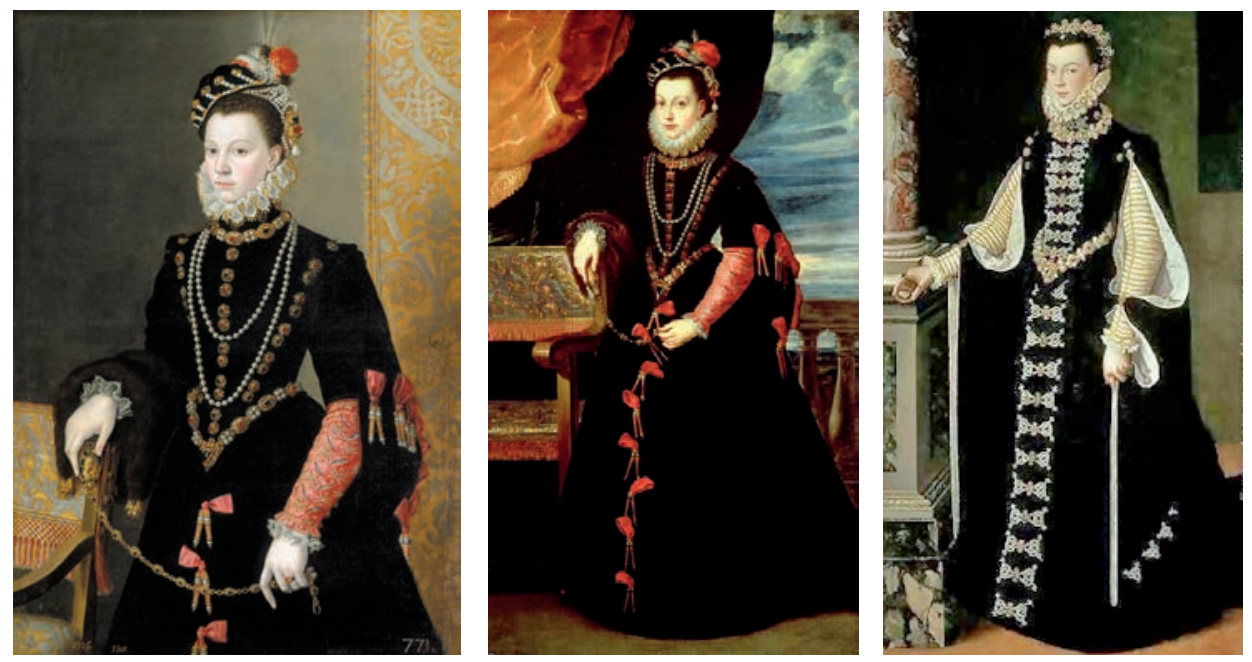

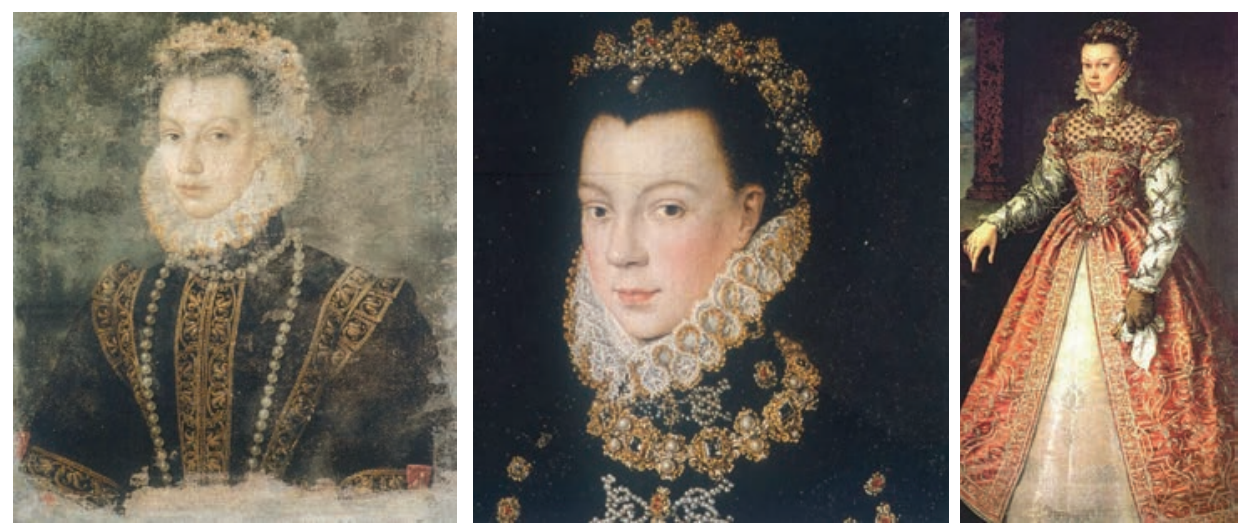

Isabel de Valois $(* 13.04 .1546 ; \dagger 1568)$, tercera esposa de Felipe II, reina consorte (1559-1568). Casada por razón de Estado, y por poderes (el 22.06.1559, en Notre Dame de París), cuando apenas tenía 13 años, entró en territorio peninsular en 1560. De formación plenamente francesa y carácter alegre (todavía jugaba con muñecas), su corta edad obligó, pues aún era núbil, a posponer su posible descendencia (el rey tenía entonces 33 años). Primera fila, izda: óleo atribuido a Sofonisba de Anguissola (1565); centro: retrato, por Peter Paul Rubens; dcha.: retrato, por Sofonisba Anguissola. Segunda fila: otros tres retratos, el de la izda., también por Sofonisba de Anguissola.

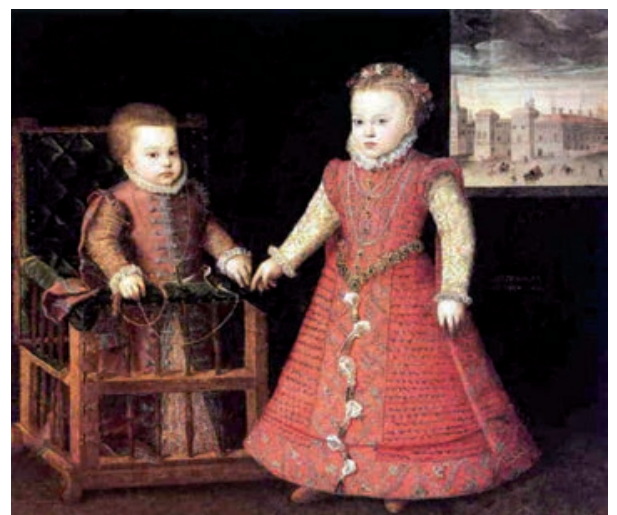

Finalmente, en 1566, nació la infanta Isabel Clara Eugenia. La reina Isabel de Valois proporcionó al monarca sus años más felices (y una segunda hija, Catalina Micaela), aunque fallecería al poco, prematuramente, con sólo 22 años ${ }^{11}$. Óleo atribuido a Alonso Sánchez Coello, en el Monasterio de las Descalzas Reales de Madrid (1568c), con Catalina Micaela en un andador e Isabel Clara Eugenia, niña ${ }^{12}$.

11 La joven y refinada reina de origen francés ("Isabel de la Paz", así llamada por la firma del tratado de Cateau-Cambresis entre Francia y España), gustaba del lujo y la diversión, a la que arrastraba, con un alegre círculo de amigos (los hermanos del rey, el príncipe Carlos y cortesanos como la princesa de Éboli o Alejandro Farnesio), a un monarca que hasta entonces no había podido disfrutar de la vida (doblemente viudo y con un hijo de la edad de su nueva esposa, su madre murió pronto, su padre abdicó en él, y hubo de afrontar muy temprano la responsabilidad y gestión de gobierno de amplísimos y muy diversos territorios). Juntos se iban de excursión o de caza, representaban farsas y bailaban, entreteniéndose la reina con el dibujo (su maestra fue la gran pintora Sofonisba de Anguissola) y con la música: en sus habitaciones, tenía un órgano, dos arpas, una cítara, y un clavicordio traído de Francia. En tal contexto, Felipe II vivió unos años felices, apenas alertado por la falta de descendencia: en 1564 la reina sufrió un aborto de gemelos, que la hundió en una gran depresión. Pero el 12.08.1565 nacía finalmente, para alegría de todos, Isabel Clara Eugenia. Y todavía daría a luz a Catalina Micaela. Entretanto, Isabel de Valois era la única capaz de calmar al heredero príncipe Don Carlos, por entonces físicamente enfermo y psicológicamente trastornado, el cual acabaría recluido y falleciendo tras su cautiverio. Otra vez, embarazada, la reina tuvo un aborto, que esta vez la llevaría a la muerte, en un año, 1568, en el que Felipe II perdió a su primogénito y a su esposa más amada.

12 Como es conocido, Felipe II, nuevamente viudo en 1568, todavía se casaría una cuarta vez, con Ana de Austria (*1549; †1580), en el año 1570, si bien ya no trataremos aquí de ella por exceder cronológicamente las fechas que afectan a Antonio de Cabezón, protagonista del presente artículo. No obstante, sirva decir que ambos tuvieron cinco hijos: Fernando $(* 1571 ; \uparrow 1578)$, Carlos Lorenzo $(* 1573$; $† 1575)$, Diego Félix $(* 1575$; $\dagger 1582)$, Felipe - futuro rey Felipe III $-(* 1578 ; \dagger 1621)$ y María $(* 1580 ; \dagger 1583)$. 

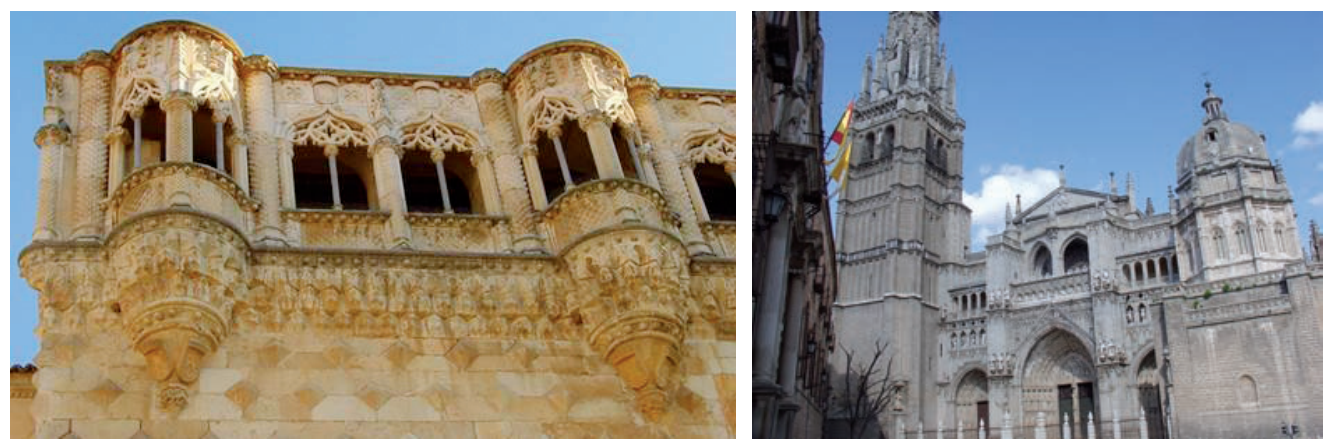

Palacio del Infantado (Guadalajara), donde se confirmó el enlace, ahora presencial, de los contrayentes reales (31.01.1560), y fachada de la Catedral de Toledo.

Sería durante los últimos años del músico de Castrillo, cuando Felipe II se embarcaría en un proyecto constructivo que le tomaría largo tiempo: la erección del Real Monasterio de San Lorenzo de El Escorial, donde se ubicaría el panteón real y donde, en breve tiempo, se dotaría una magnífica biblioteca y se proveería su iglesia de unos órganos excelentes.
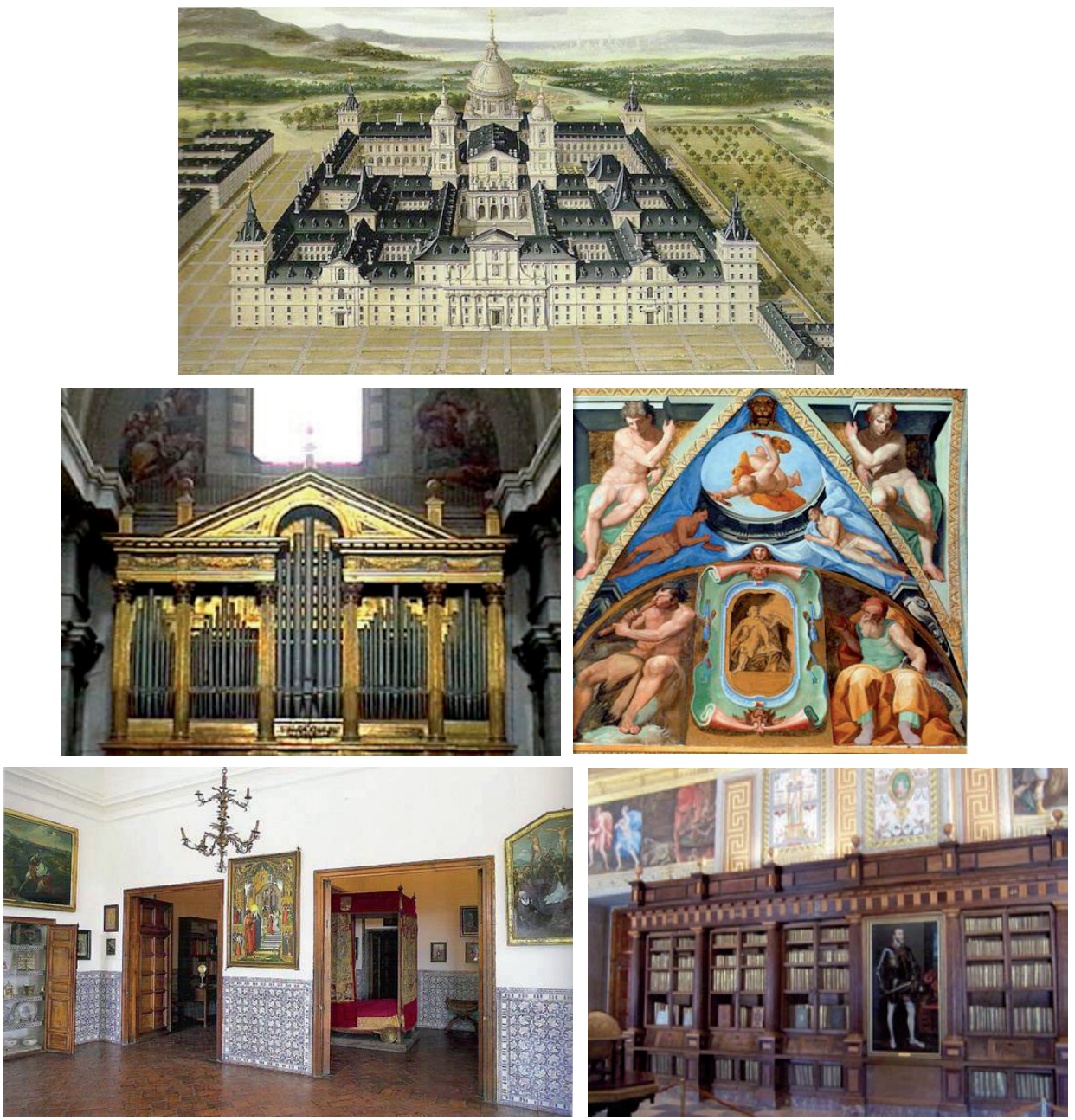

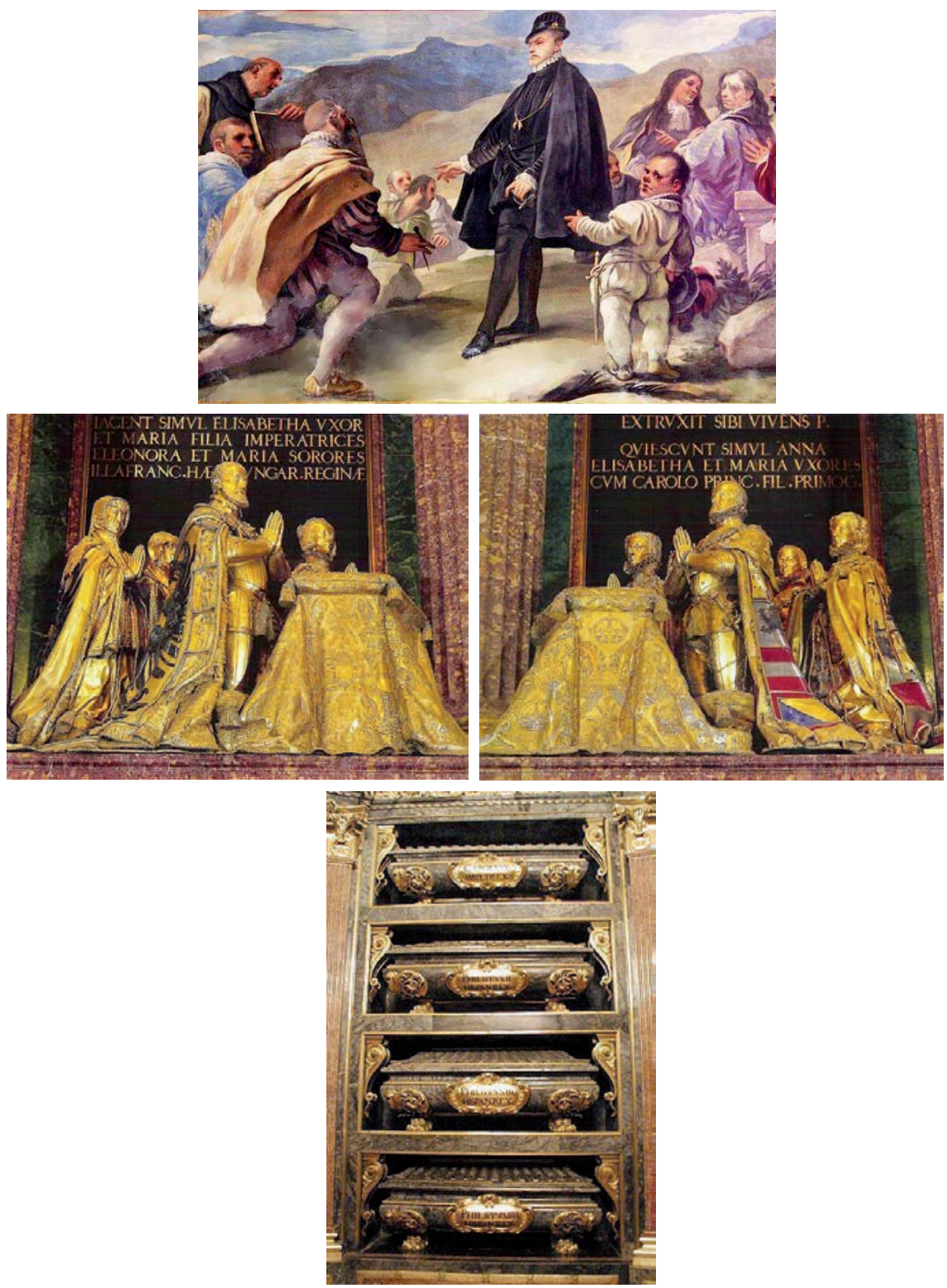

El Escorial. (De arriba abajo y de izda. a dcha.): vista del monasterio; uno de los órganos; pintura de la biblioteca (Alegoría de la música, por Pellegrino Tebaldi, 1588-1595); cámara del rey (Palacio de los Austrias); Real Biblioteca; Lucas Jordán, Felipe II con sus arquitectos inspecciona las obras de El Escorial (detalle: Felipe II y el Velasquillo, su bufón); Pompeo Leoni, Cenotafios de Carlos V (lado del Evangelio) y de Felipe II (lado de la Epístola), en bronce dorado (capilla mayor de la basílica); y Panteón de reyes, con los sepulcros de Carlos V, Felipe II, Felipe III y Felipe IV.

En su testamento, Cabezón manifestaba su deseo de ser enterrado junto a su mujer en el monasterio de San Francisco de Ávila, pero, fallecido en Madrid, se le dio sepul- tura en la iglesia del antiguo convento de San Francisco el Grande. 

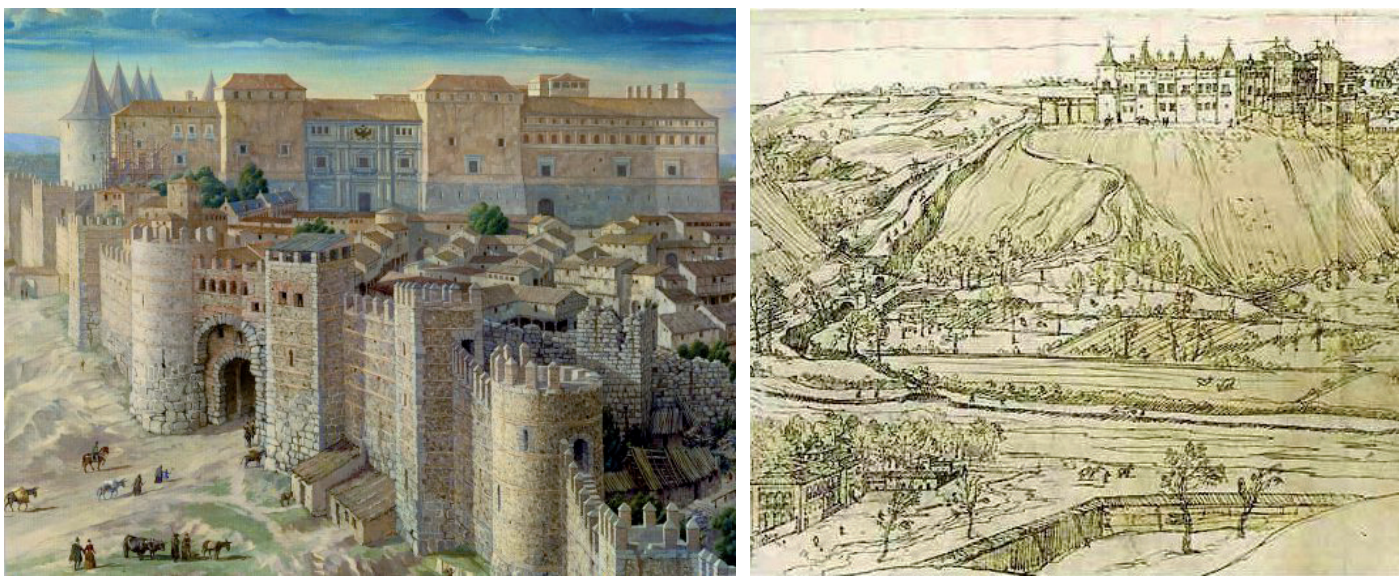

Izda.: Madrid en 1561, con el Real Alcázar, residencia de Felipe II. Dcha.: fragmento de un dibujo de Madrid de Antoon Van den Wijngaerde (1562), con el Real Alcázar.

Desgraciadamente, sólo se ha conservado el texto de su epitafio latino (recogido en el siglo XVII por el erudito y bibliógrafo Nicolás Antonio), que Felipe II ordenó grabar en su tumba, pero que se perdió definitivamente en la construcción de la nueva fábrica del templo: "En este sepulcro descansa aquel privilegiado Antonio que fue el primero y el más glorioso de los organistas de su tiempo. Cabezón, su apellido, ¿a qué nombrarlo, si su noble fama vive en toda la tierra, mientras su espíritu vive en los astros? Murió, ¡ay!, llorándole toda la corte del rey Felipe: por haber perdido tan rara joya".

Lamentablemente, tampoco se conoce hoy su retrato (desaparecido en el incendio del Real Alcázar de Madrid en 1734), que fuera pintado por Alonso Sánchez Coello por encargo de Felipe II, quien lo puso en sus aposentos de palacio.

Seguramente, los viajes fueron el medio más eficaz para dar a conocer su propia música y extender su influencia musical, no sólo sobre los músicos españoles (para quienes significó un primer eslabón en la gran tradición organística ibérica de los siglos XVI y XVII, siendo Francisco Correa de Arauxo y Pablo Bruna los casos posteriores seguramente más directamente destacados), sino también sobre los europeos: Italia conoció pronto la música para tecla de Cabezón, y pueden rastrearse huellas de ello en la producción del napolitano Giovanni Maria Trabaci $(* 1575$ c; $† 1647)$, o en los Países Bajos, pueden buscarse ecos de su música en la obra de autores como Jan Pieterszoon Sweelinck $(* 1562 ; \dagger 1621)$, entre otros.

Estricto coetáneo del franciscano y teórico musical Fray Juan Bermudo, que conocía sus obras, fue compañero de músicos como Miguel de Fuenllana, Diego del Castillo, Fray Tomás de Santa María, Luis Venegas de Henestrosa, Mateo Flecha, Luis de Narváez, Nicolás Payen, Pierre de Manchicourt, y Michael de Boch, y tuvo contacto personal con Nicolás Gombert, Pathie, Jean Mouton y Thomas Crecquillon. Conoció muy posiblemente al burgalés Francisco de Salinas, a Cristóbal de Morales, Juan Navarro y, acaso, como niños cantores en la catedral de Ávila, a Tomás Luis de Victoria y a Sebastián de Vivanco, entre otros muchos músicos con quienes, por razón de fechas y lugares de actividad, pudo haber coincidido (?), en una nómina que se antoja interminable: Cornelius Canis, Henry van Worst, Buus, Jean de Bonmarchié, Melchor de Valdés, Antonio Carreira, Macedo, Paiva, Yepes, Jerónimo Saledo, Manuel de Barbanza, Francisco de Soto, Cipriano de Soto, Marco Houterman, Van Gheeraerdsberghe, Van de Meulen, Bernardino de Ribera, Pedro de Pastrana, Juan García de Basurto, Alonso Ordóñez, Francisco de Ceballos, Guido Godefroy, Enríquez de Valderrábano, Esteban Daza, Jerónimo del Espinar, Juan Peraza, Jerónimo López, Pedro de Escobar, Bartolomé de Quevedo, Pedro Ordóñez...

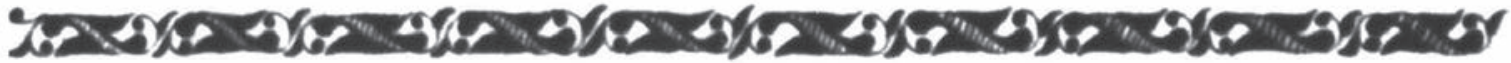


En cuanto a la producción musical de Antonio de Cabezón, aunque de estilo claro, y muy imbuida de la tradición hispánica (de gran expresividad y con un singular empleo de la disonancia y de la explotación de las tensiones entre armonía y melodía), está muy influida, en la armonía y el contrapunto, por la obra polifónica del franco-flamenco Josquin Desprez. Siendo paradójicamente, muy español, desgrana un lenguaje, al tiempo, internacional, como puede apreciarse por otra parte en buena parte de sus composiciones, basadas en obras de otros autores, siguiendo a menudo en sus glosas y paráfrasis de canciones y motetes foráneos, al citado Josquin, pero también a Thomas Crecquillon, a Philippe Verdelot, Nicolás Gombert, Adrian Willaert, Clemens non Papa, Juan de Urreda, Jean Mouton, Jean Richafort, Jacquet de Mantua, Lupus, u Orlando di Lasso ${ }^{13}$.

13 En este sentido, los modelos vocales utilizados en la edición de Hernando de Cabezón (1578), como ahí mismo se señala, son los siguientes:

Himnos: Urreda - Pange lingua.

Tientos: Clement Janequin - Qui la dira. / Josquin Desprez Missa De Beata Virgine ("Cum Sancto Spiritu").

Canciones glosadas y motetes a 4: [Cipriano da Rore] - Ancol que col partire / Clemens non Papa - Canción francesa. / Crecquillon Ie pres en grei. / Crecquillon - Por un plasir. / Crecquillon - Prenes pitie. / Crecquillon - Si par sufrir. / Crecquillon - Un gai bergier. / [Pierre Sandrin] - Douce mémoire. / Josquin Desprez - Clama ne ceses [tercer Kyrie de la Missa De l'homme armé super voces musicales] / Josquin Desprez - Misa De l'homme armé ("Benedictus"). / Missa De Beata Virgine ("Cum Sancto Spiritu"). / Missa De l'homme armé ("Osana"). / Mouton-Queramus.

Motetes a 5 y canciones glosados: Adrian Willaert - Je fille quanile medona. / Adrian Willaert - Qui la dira. / Clemens non Papa - Sana me Domine. / Crecquillon - Je suys ayme. / Crecquillon - Pis ne me pulvenir. / Gombert - Ay me qui voldra. / Gombert - Triste de par. / Jaquet - Aspice Domine. / Josquin Desprez - Inviolata. / Josquin Desprez - Inviolata. / Josquin Desprez - Stabat Mater. / Josquin Desprez - Stabat Mater. / Lupus - Aiule vos sola verdura. / Orlando - Susana un jur. / Quien llamo al partir partir. / Richafort - Jerusalem luge. / Verdelot Durmendo un jorno. / Verdelot - Si bona suscepimus.

Motetes y canciones a 6: Josquin Desprez - Ave Maria. / Josquin Desprez - Benedicta es caelorum Regina. / Verdelot - Ardente mei suspiri. / Verdelot - Sancta Maria. / Verdelot - Ultimi mei suspiri.

Discantes: Dubiensela (D'ou vien cela?). / [Gombert?] - El canto del caballero. / Gallarda milanesa. / Las vacas. / Madama le demanda. / Pavana italiana. / Quien te_me enojo.

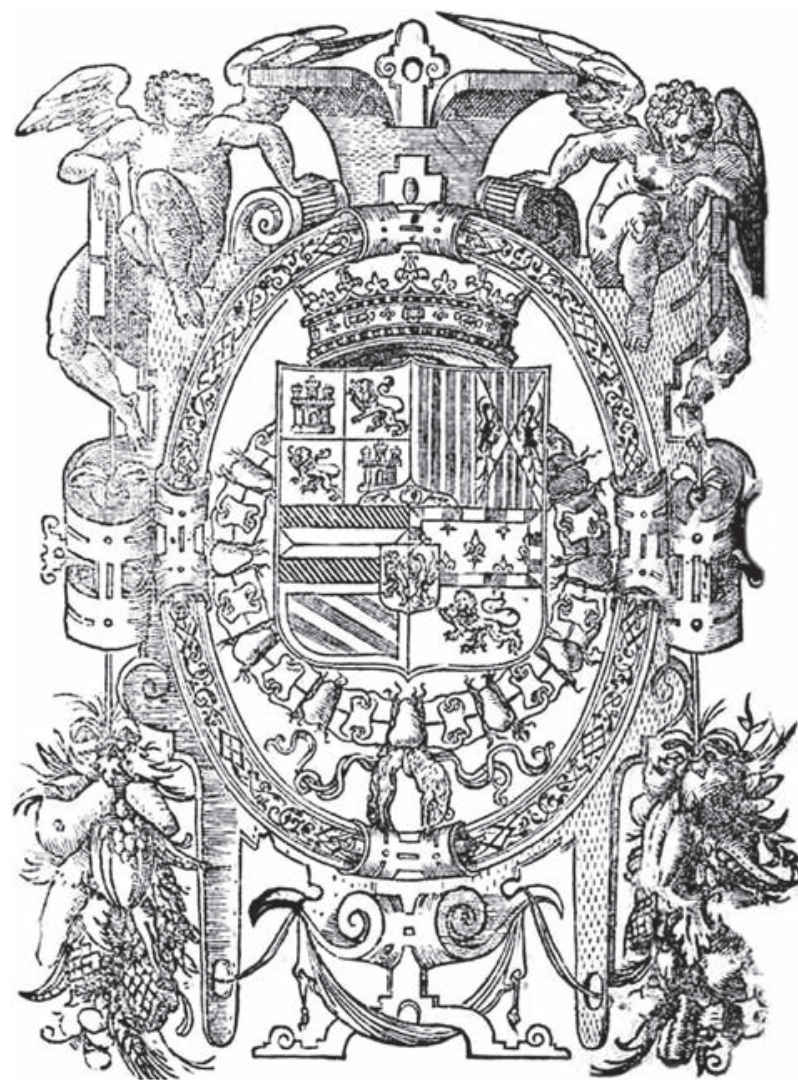

Escudo del monarca español Felipe II, insertado en la portada de las Obras de música para tecla, arpa y vihuela, de Antonio de Cabezón, editadas en 1578 por su hijo Hernando. [= RISM $1578^{24}$.

Su obra, presenta una de las disposiciones seguramente más meditadas de la época, ordenando las composiciones de menor a mayor dificultad y procurando en todo momento facilitar el aprendizaje a quienes, a través del estudio, quisieran adentrarse, con comodidad, en los secretos de la composición y en la práctica de los instrumentos polifónicos, incluidos los "curiosos ministriles"14.

14 Hernando de Cabezón en su famosa edición de las obras de su padre en 1578, hacia el final de su "Declaracion de la cifra que en este libro se vsa", señala lo siguiente "[...] Tambien se podran aprovechar del libro los curiosos menestriles, en ver inuenciones de glosas tratadas con verdad sobre lo compuesto, y ver la licencia que tiene cada voz, sin perjuyzio de las otras partes, y esto toparan en muchos motetes canciones y fabordones que ellos tañen, que con poca dificultad podran sacar desta cifra en cãto de organo. [...]". 


\title{
DESDE A \\ QVI SE DA \\ PR INC I P IO
}

C O M P E ND I O

DE M V S C A D E A N

TONIO DECABEC, ON.

\section{EL ORDEN QVE SE HA DE TENER}

\author{
Aduertimientos.
}

\section{paralos que comiençan}

\section{E X E M P L O.}

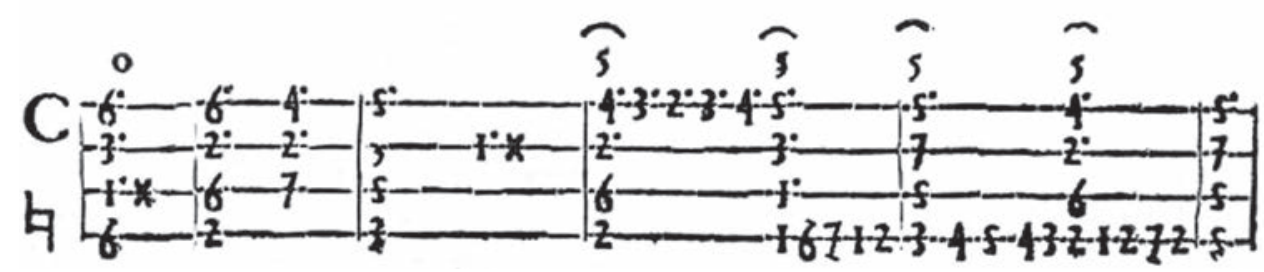

\section{todaslas bozes porvna}

\section{Buslta al principio.}

Más que la intención, la vocación pedagógica del libro editado por Hernando de Cabezón aparece constantemente a lo largo de toda la publicación.

En concreto, el orden que sigue la recopilación de Hernando de Cabezón para exponer sus materiales, se divide en los siguientes apartados: 1.- Dúos para principiantes. / 2.- Obras de a tres para principiantes. / 3.-Obras de a cuatro [versos de los ocho tonos del canto llano sobre el saeculorum]. / 4.- Fabordones de todos los ocho tonos. / 5.- Himnos. / 6.- Versos de Magnificat sobre todos los ocho tonos. / 7.- Cuatro Kyries de cada tono. / 8.- Tientos. / 9.- Cancio- nes glosadas y Motetes a cuatro. / 10.- Motetes de a cinco y Canciones glosados. / 11.- Motetes y Canciones a seis. / y 12.- Discantes [y Diferencias].

Pero la obra de Cabezón, según se organiza en la edición de su hijo Hernando, no es, a nuestro juicio, música "de consumo", para ser escuchada de un tirón, debido a su densidad, a su intrincada complejidad intelectual, aun a pesar de su sólo aparente sencillez. Como los poemarios, o como 
la buena música de Bach con la que Pedrell tan encomiásticamente la comparó, debe ser degustada, aprehendida, poco a poco, pieza a pieza, debe ser reflexionada. Cada una de sus sonoridades, que pudieran parecer en ocasiones y en una primera impresión arcaicas - imbuidas de un paisaje plenamente modal-, están todas bien meditadas: son músicas de un siglo XVI ferviente y convencidamente católico, descubridor de nuevos mundos, en expansión. Son músicas para el cultivo del espíritu y el intelecto, para la meditación.
Muy probablemente, por alguna de esas ideas es por lo que esta música debió complacer tanto a Felipe II, hombre de su tiempo, que hoy, alejados de leyendas negras y tópicos distorsionadores, comenzamos a conocer un poco mejor, alegre, amigo de dulces y mujeriego siendo príncipe, y sólo paulatinamente, más prudente y decididamente responsable (con un imperio, a su cargo, que gobernar), a caballo entre un estado anímico taciturno o solitario, y exacerbadamente religioso, hacia sus últimos días.
Por lo demás, la música de Antonio de Cabezón abarca todos los géneros organísticos característicos del Quinientos, tanto sacros como profanos. Si alguna de sus composiciones más afamadas fueron El canto del caballero, La gallarda milanesa, o La pavana italiana, conviene decir que cultivó también algunas piezas litúrgicas (una treintena de himnos, y piezas breves del tipo de kyries, versos y fabordones).
Pero trabajó igualmente numerosas piezas de diversa índole, algunas, versátiles, para ser interpretadas tanto en ámbito cortesano como en otros contextos (dúos, tres, finales...). Y trabajó también, siguiendo la moda del momento, las glosas de romances, es decir, comentarios, versiones ornamentadas o adaptaciones para teclado de obras originalmente polifónicas - canciones - de otros compositores.

\section{E X E M P L O.}

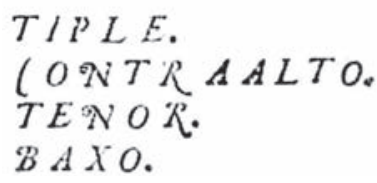

\section{cō differēte eq glofla.}

Pero si en algo destacó Cabezón fue por la influencia que iba a ejercer en el desarrollo posterior de los géneros instrumentales de la época, particularmente en la composición de tientos (que alcanzan casi la treintena), así como en las series de diferencias (en torno a una decena), que tienen una importancia esencial en la historia de la variación.

Sus tientos, verdaderas obras de arte que exhiben el gran oficio compositivo de su autor, son obras polifónicas imitativas no estrictamente litúrgicas (a la manera del motete vocal), que parecen anunciar ya, con muchísima antelación, a partir de la composición trabada de "pasos" contrapuntísticos, el posterior desarrollo de la fuga. Se caracterizan por ser piezas de gran virtuosismo (a la manera de la compleja polifonía franco-flamenca) y de una gran dificultad técnica, estando generalmente organizadas en torno a unas estructuras formales y tonales relativamente sencillas, que exhiben una enorme y variada riqueza de recursos, propiamente concebidos para el teclado. Sus tientos están dotados, además, de un cierto carácter reflexivo, tal vez para ser interpretados de modo introspectivo, acaso en algunos momentos concretos de la Misa, o bien, en contextos civiles que requirieran un ambiente sereno, creando un ambiente intimista que sería particularmente factible a partir de instrumentos sencillos, pequeños, áulicos o de cámara, tales como órganos realejos o portativos, espinetas o monocordios. 


\section{T A B L A.}

\section{Ellongo fepinta afsi}

Breue

Semibreue.

Semibreue con puntillo.

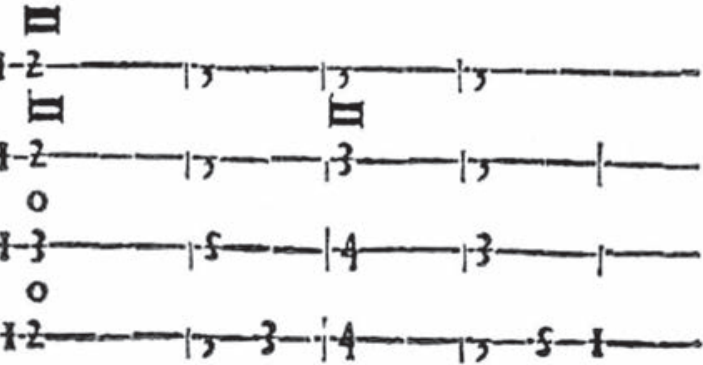

Por otra parte, para aproximarnos a lo que pudo haber sido el espíritu del órgano renacentista del tiempo de Antonio de Cabezón, se ha de tener bien en cuenta que, una corte itinerante como la castellana - que cambiaba frecuentemente de ubicación - en la que Cabezón ejerció su actividad, no contó antes de 1561 con ningún órgano de gran tamaño, pues su traslado habría sido enormemente complejo. Como organista cortesano (más aún como clavicordista), Cabezón habría tocado básicamente para ofrecer un entretenimiento musical de cámara, o bien en el marco de pequeñas funciones litúrgicas - en una cotidianeidad alejada de los fastos extraordinarios - en la capilla de la corte. Aunque, naturalmente, en otro tipo de ocasiones, Cabezón pudo haber tocado algún gran órgano, catedralicio o no. Pero no son muchos los instrumentos que hoy quedan en los que hubiera podido tañer nuestro organista ciego. Entre ellos, podríamos citar casi a modo de excepciones que confirman la regla - el órgano de la capilla del Condestable de la catedral de Burgos, el realejo conservado en el monasterio de la Encarnación de Ávila, o el órgano del emperador de la catedral de Toledo, construido por Gonzalo Hernández de Córdoba y Juan Gaitán en 1543-1549 .

15 Así por ejemplo, en el Aragón de la época sin ir más lejos, hay que considerar también la presencia de organeros alemanes ya desde el siglo XV, luego imitados - en ocasiones con participación de constructores franceses y flamencos - por los maestros locales, frente al órgano tradicional castellano, en situación expansiva y espoleado por la construcción de numerosos instrumentos en territorios anteriormente musulmanes y ahora reconquistados (lo que suponía la creación de numerosos puestos de trabajo como organistas), así como por su exportación a los extensos territorios americanos y de ultramar. (Entre los constructores foráneos del Quinientos, aparte algunos italianos y portugueses, destacaron el francés Guillaume de Lupe, activo en Aragón a partir de 1565, y los flamencos Maese Jorge, en Sevilla desde 1567, así como los diversos miembros de la familia Brebos, en la corte).
Repárese en que, por ejemplo, los propios instrumentos realizados en España por los organeros Brebos (para la Casa Real, para El Escorial), son posteriores al tiempo de Don Antonio, quien, precisamente, aprovechando el viaje a Flandes en 1561 para el que se había comisionado a su colega el organista real Michael de Boch (para que trajera a la Real Capilla buenos cantores), encargó personalmente a su compañero que contratara la construcción de dos órganos pequeños para dicha Real Capilla al maestro organero de la localidad de Mons - a quien sin duda debía conocer de sus anteriores viajes - , Jean Crynon. Sin embargo, sin fortuna finalmente en la ejecución de este último encargo, de Boch tuvo que contactar en Amberes con los maestros organeros Brebos, de donde su posterior llegada y actividades en la península. Dichos dos instrumentos, pequeños, llegaron a Madrid en 1562, y debieron ser aprobados por Antonio de Cabezón, y por su discípulo y a la sazón organero real, Cristóbal de León, permitiendo así que la producción de Brebos fuera introducida en España. Enseguida, Gilles Brebos construiría los órganos de las catedrales de Malinas (1564) y de Amberes (1565-1568), que servirían como modelos para otros instrumentos posteriores levantados ya en territorio español.

Pero, al margen de lo que sucediera en la corte, el órgano ibérico del tiempo de Felipe II se encontraba en una fase de desarrollo extraordinario, experimentando en nuevos instrumentos (con, por ejemplo, el inicio del proceso de implantación del registro partido en Castilla) y recibiendo constantes influencias que serían esenciales para su conformación y evolución posterior, encaminada a sus funciones básicas: como instrumento solista, como elemento de alternancia con el cantollano y la polifonía (particularmente, en los versos para salmos), y como acompañante de cantores y ministriles (en la posterior realización protagonista del bajo continuo). 


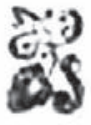

En cuanto a Antonio de Cabezón y su producción musical, maestro también en la composición de diferencias (variaciones sobre canciones y danzas francesas y españolas), éstas suelen estar basadas en un cantus firmus o bajo ostinato, y una melodía sencilla - bien conocida en la época-, que se desarrollan y varían extensamente (haciendo gala en tal proceso de gran virtuosismo e invención interpretativa, contrapuntística y compositiva), en estilo improvisado. En esta faceta, Cabezón, junto a Narváez y Mudarra, se adelantaron al resto de Europa. Los temas elegidos podían tomarse del Guárdame las vacas, la pavana italiana, o de canciones como ¿Quién te me enojó, Isabel?, La gallarda milanesa, o el Canto del Caballero.

\section{Divino Antonio,oriamento y gloria}

Finalmente, conviene recordar que la reivindicación musicológica de la obra de Antonio de Cabezón se inicia con Hilarión Eslava, ya en la segunda mitad del siglo XIX, a quien siguieron Jesús de Monasterio, y con mucha menor relevancia, Mariano Soriano-Fuertes, Baltasar Saldoni, José
Parada y Barreto, o el belga François Joseph Fétis. Pero, en realidad, no sería hasta que Felipe Pedrell fijara su atención en él y revalorizara su entonces casi olvidada figura, publicando alguna de sus composiciones, cuando la personalidad de Cabezón adquirió nuevamente fama mundial.

\section{ANTONIOCABEC,ONE MVSICOREGIO.}

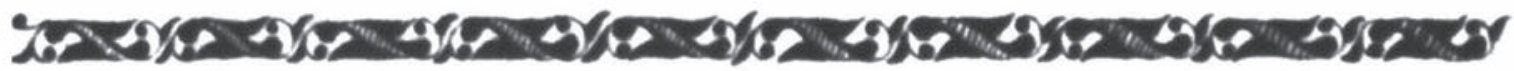

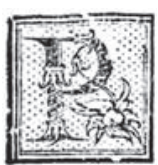

edrell le ensalzó, así, como el "Bach español”, en un elogio por demás anacrónico, aunque, ciertamente, bien elocuente. Muchas otras aportaciones vendrían, afortunadamente, más tarde (H. Anglés, M. S. Kastner, Ch. Jacobs, M. Ester-Sala...). Según el musicólogo José Subirá, Cabezón "se adelantó en dos siglos a los grandes maestros", mientras que para el germano-estadounidense Willi Apel, sus tientos "demuestran una grandeza de concepción y una lógica constructiva muy por encima de todas las obras crea- das en el campo de la música instrumental hasta el tiempo de Frescobaldi”. Sin embargo, más allá de apologías escasamente contrastadas, o de la subjetividad natural de los gustos personales, es un hecho que, su obra, hoy más viva que nunca por sus bondades intrínsecas, y transcurrido ya más de medio milenio desde su nacimiento, canta, se proyecta y se puede disfrutar, a diario, como una de las maravillas sonoras que nos legó el Renacimiento español, desde la tribuna de numerosos órganos distribuidos por todo el mundo.

\section{Antonio mucho mas feferialaua}

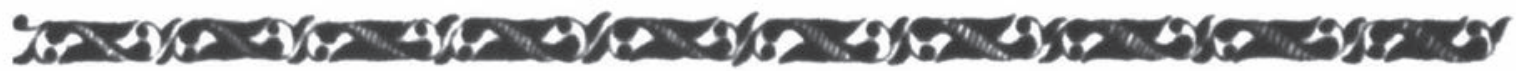


Por lo que se refiere a los preliminares que se incorporan a la edición de 1578 realizada por Hernando de Cabezón, importa reseñar que todos ellos estuvieron relacionados con el ámbito literario alcalaíno, en el que, precisamente, Miguel de Cervantes iba a ser su máximo representante. No cabe duda de que, si tales cuatro poetas, se decidieron a estampar con su firma algunas de sus composiciones líricas en la edición de Hernando, debían conocerle bien, por cuanto no sería en absoluto descabellado sospechar que hubiera conocido al autor del Quijote. Aparte del ya mencionado Juan Cristóbal Calvete de Estrella, poeta que abre con sus escritos elogiosos la edición de Hernando de Cabezón, aparece también en la edición musical hernandiana de 1578 Pedro Laínez (*Alcalá de Henares, 1538c; †Madrid, 1586), autor - conocido por el sobrenombre poético de "Damón"- de un soneto en el que califica a Antonio como "fénix en todo el orbe", "templo famoso", "fábrica adonde el arte al pensamiento es igual", "divino Antonio, ornamento y gloria", e incluso parece referirse a su hijo Hernando y su tarea de reivindicar la obra de su padre entonces ya fallecido, cuando alude a que "en el presente lo restaura a pesar del tiempo y muerte, el claro sucesor, que tu memoria ha vuelto viva y clara, eternamente". Queda claro, por tanto, que Laínez conoció tanto a Antonio, como a Hernando. Este poeta palatino, adscrito a la escuela toledana renacentista y que trabajó tanto la temática amorosa como la tradición pastoril (coplas castellanas tradicionales, glosas, paráfrasis, églogas, canciones, epístolas...), destacó especialmente por su composición de elegías (Elegía a la muerte del emperador Carlos $V$ y Elegía a la muerte de doña Isabel de Valois), así como por sus sonetos y villancicos. Influido por la obra de Petrarca y Garcilaso de la Vega, se le califica no obstante desde el punto de vista estrictamente literario poco más que como un mediocre escritor. En ocasiones mezcló el español y el italiano, siguiendo la moda poética de su tiempo. Procedía de una familia acomodada y poseía una más que notable fortuna. Dejó no obstante su obra sin publicar, a pesar de que su viuda, Juana Gaitán, quiso editar - sin éxito a pesar de la ayuda de Miguel de Cervantes-, un Cancionero suyo, así como sus Engaños y desengaños de amor. Desempeñó cargos secundarios en Palacio y fue ayudante de cámara del príncipe Don Carlos, hijo de Felipe II, primero en Madrid y luego en Alcalá (hacia 1563), donde residió hasta la muerte de Don Carlos en 1568. Cultivó la amistad de grandes literatos como Francisco de Figueroa ("el divino"), Vicente Espinel (que le cita en sus Rimas de 1591) o Ramírez Pagán, y fue elogiado por alguno de sus contemporáneos y amigos (como el también citado Luis Zapata, en su poema Carlo famoso; Cervantes en los versos del "Canto de Calíope" de $\mathrm{La}$ Galatea ${ }^{16}$; o Lope de Vega en La hermosura de Angélica con otras diversas rimas, La Dorotea, La Arcadia o El laurel de Apolo). Apenas imprimió algunos sonetos aislados, como el que aparece en la traducción de Las Luisiadas de Camoens (1580), u otro en el Tesoro de Poesía de Pedro de Padilla (1580).

El siguiente y tercer poeta en cantar las alabanzas de Antonio de Cabezón en las composiciones encomiásticas que preceden a la célebre edición de Hernando, es el licenciado Juan de Vergara (*Alcalá de Henares, $1545 ; \dagger 1620$ ), quien, aparte de destacarse como poeta, desarrolló una intensa actividad profesional - buena parte de ella en Segovia - como médico (bachiller en Medicina en 1576, Cirujano Mayor del Ejército, Cirujano de Cámara de Felipe II y de la Casa Real con Felipe III) ${ }^{17}$, además de poseer otras titulaciones académicas como Licenciado en Artes y Maestro en Filosofía por la universidad complutense alcalaína. A mediados de la década de 1580 vivía en Madrid, donde frecuentaba diversos círculos literarios y de la corte. Sus versos fueron premiados en distintas justas poéticas, y figuran al inicio de obras tales como el Tesoro de varias poesías de Pedro de Padilla (Madrid, Francisco Sánchez, 1580) - curiosamente, impreso por el mismo tipógrafo que realizara la publicación del Compendio de música de Cabezón-; Isidro y La hermosura de Angélica de Lope de Vega (Madrid, Luis Sánchez, 1599 y Madrid, Pedro Madrigal, 1602); o el Romancero historiado con mucha variedad de glosas y sonetos y al fin una floresta pastoril de Lucas Rodríguez (Alcalá de Henares, Hernán Ramírez, 1579-1580?).

\section{CONPRIVILEGIO. Impreffas en Madrid en cafa de Francifeo Sanchez.Año de M.D. L XX}

\footnotetext{
16 Cervantes señalaba: "Por ellos hasta el cielo me levanto y sin ellos me corro y me avergüenzo: tal es Laynez, tal es Figueroa, dignos de eterna y de incesable loa".

17 Publicó en 1575 unos sonetos iniciales al Compendio de Cirugía de su colega médico Francisco Díaz (cirujano de Felipe II). Y se sabe que asistió como médico a Felipe II en su lecho de muerte.
} 
Del licenciado Vergara, el propio Cervantes señalaba (en El viaje del Parnaso, 1614): "De Esculapio y de Apolo gloria ilustre, / si no, dígalo el santo bien partido, / y su fama la misma envidia ilustre", y nuevamente, en una octava (de su "Canto de Calíope", en $L a$ Galatea) decía que "El alto ingenio y su valor declara / un licenciado tan amigo vuestro / cuanto ya sabéis que es Juan de Vergara / honra del siglo venturoso nuestro. / Por la senda que él sigue, abierta y clara, / yo mesma el paso y el ingenio adiestro, / y adonde él llega, de llegar me pago, / y en su ingenio y virtud me satisfago". También fue alabado por el historiador, poeta y teólogo que era curiosamente hijo de un sochantre - padre fray José de Sigüenza (*1544; †1606) en su Historia de la Orden de San Jerónimo, aunque años después sería criticado por Lope de Vega, que le tildó de "maldiciente" y "murmurador", pues Vergara debía integrar el círculo más cercano a Cervantes, formado por poetas alcalaínos.
Finalmente, el cuarto poeta encargado de alabar con sus composiciones la figura y la obra dada a luz por Hernando de Cabezón en 1578 fue Alonso de Morales Salado, de quien apenas se conocen dos sonetos. Cervantes, en el mismo poema ya citado (su "Canto de Calíope", en $L a G a$ latea - Alcalá, Juan Gracián, 1585-), dice de él: "[...] Y es este que me fuerza y que me oprime / a decir sólo dél, y cantar cuanto / canto de los ingenios más cabales, / el licenciado Alonso de Morales". Precisamente, de Morales Salado sabemos que compuso el soneto titulado "Edad felice, siglo venturoso", que se imprimió al comienzo de un Methodo de la collection y reposicion de las medicinas simples, y de su correction y preparación (Madrid, Alonso Gómez, a costa de Gaspar de Ortega, 1581), obra médica realizada por el boticario vecino de Madrid, Luis de Oviedo.

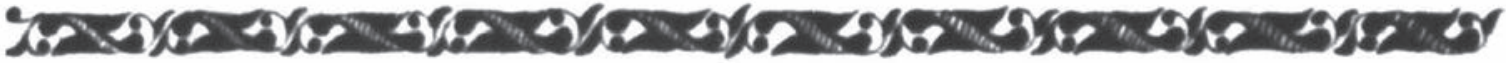

\section{PROYECCIÓN DE LAS OBRAS DE MÚSICA PARA TECLA, ARPA O VIHUELA, O LO QUE ES LO MIS- MO, DE SU COMPENDIO DE MÚSICA}

Ya hemos comentado en algún otro foro y ocasión anterior, que del impreso editado por Hernando con la producción musical de su padre, se conocen cada vez más ejemplares conservados, pues no son pocos los que van apareciendo poco a poco para el estudio, con el transcurso del tiempo y el avance de las investigaciones, especialmente en el extenso ámbito panhispánico.

Citemos las siguientes fuentes originales impresas conocidas para la investigación a día de hoy: cuatro ejemplares (tres en realidad) conservados en España, en la Biblioteca Nacional de España (Madrid) $(\boldsymbol{E}-\mathbf{M n})$ [ejemplar legado por Francisco Asenjo Barbieri], en la Biblioteca del Real Monasterio de San Lorenzo de El Escorial (Madrid) $(\boldsymbol{E}-E)$, Biblioteca de Francisco Zabálburu (Madrid), y Biblioteca de la Universidad de Barcelona [desaparecido en 1936]; otros tres ejemplares (dos en realidad) en Alemania, en la Sección de música de la Biblioteca del Duque Augusto en Wolfenbüttel (Estado de Baja Sajonia) [ejemplar registrado como desaparecido en la década de 1950], en la Sección de música de la Biblioteca del Estado alemán en Berlín $(\boldsymbol{D}-B)$, y en la Colección musical "Carl Proske" de la Biblioteca episcopal de Ratisbona ( $\boldsymbol{D}-\boldsymbol{R} p)$. Y un ejemplar en cada uno de los siguientes lugares: uno en Bélgica, en la Biblioteca Real "Alberto I" de Bruselas $(\boldsymbol{B}-\boldsymbol{B r})$ [ejemplar legado por François Joseph Fétis]; otro en los Estados Unidos de América, en la Sección de música de la Biblioteca del Congreso en Washington $(\boldsymbol{U} \boldsymbol{S}-\boldsymbol{W c})$; otro en Francia, en la Biblioteca "Geneviève Thibault" de París (F-Pthibault) [en la Biblioteca Nacional de Francia, $\boldsymbol{F}-P n$ ]; en Gran Bretaña, en el Museo Británico de Londres - Biblioteca Británica- $(\boldsymbol{G B}-L b l)$ [ejemplar incompleto]; en Italia, en la Biblioteca del Conservatorio de Música de "San Pietro a Maiella" de Nápoles $(\boldsymbol{I}-N c)$; y en México, en la Biblioteca "José María Lafragua" de la Benemérita Universidad Autónoma de Puebla, en Puebla. Por tanto, 11 ejemplares conservados y localizados en total actualmente, de los 1.200 ejemplares que se llegaron a tirar en origen ${ }^{18}$.

El profesor Gustavo Mauleón ha documentado el envío por barco desde Sevilla y su recepción en las Indias (en el puerto de Veracruz, en el virreinato de la Nueva España), en el año 1586, de al menos siete ejemplares, cifra que no sería extraño hubiera podido incrementarse en años sucesivos, de donde la esperanza de poder localizar nuevos ejemplares conforme avancen las crecientes y prometedoras investigaciones musicológicas en México.

Por otro lado, es conocido el hecho de que a raíz del término de vigencia del privilegio real para impri-

18 LESURE, François (dir.), 1960: 307. SCHLAGER, Karlheinz, 1972, vol.2, p.1. KINDERMANN, Ilse y Jürgen KINDERMANN (eds.), 1986, vol.11 (Addenda et Corrigenda): 205. 
mir concedido a Hernando de Cabezón, el cual expiraba en 1575 , se pudo liberar su licencia de venta. Pero todo parece indicar que en 1581 únicamente se habían vendido 400 ejemplares y, acaso, que cinco años más tarde no se hubiera vendido ninguno más, pues su distribuidor adeudaba exactamente la misma cantidad que se había comprometido a abonar anualmente, que cuando se hizo cargo de la partida de los 800 ejemplares restantes cinco años atrás.

Ninguna de las naciones estranjeras podrá tal vez presentarnos en el siglo XVI un profesor tan eminente en este ramo como D. Felix Antonio Cabezon, organista de la Real capilla y clavicordista de cámara de S. M. Felipe II: él es el primer eslabon de la no interrumpida cadena de nuestros grandes organistas : él es autor de dos obras muy notables, una de ellas es el método de órgano con el titulo de Misica para tecla, de que hace mencion la bibliografía de D. Nicolás Antonio, y la otra un tratado de composicion cuyo título es Musica teórica y práctica. Estas obras, que no habia yo podido hallarlas en España, las encontré en la Real Biblioteca musical de Berlin, donde tuve la satisfaccion de verlas y examinarlas, haciéndome notar el sábio y ama.

Por su eminente mérito fue invitado con una plaza de organista de la Real capilla de S. M. y habiéndola aceptado, la disfrutó hasta su muerte.

Florecieron tambien en este mismo siglo y principios del siguiente otros varios organistas de nombradia, entre ellos D. Antonio y D. Hernando Cabezon, y don Bernardo Clavijo. Los dos primeros, hijos del mencionado D. Felix, publicaron, como llevo dicho, las obras de su padre, y trabajaron con esmero en esparcir las escelentes doctrinas que de él habian aprendido.
Por otro lado, para realizar con garantías una valoración de la transmisión e influencia de la obra cabezoniana conviene tener en cuenta que su recuperación musicológica se inició de la mano de Hilarión Eslava $(* 1807 ; \dagger 1878)$, ya en la segunda mitad del siglo XIX (en 1854), cuando publicó algunas noticias sobre el músico burgalés en la primera parte de su célebre Museo orgánico español.

\footnotetext{
bilisimo Cusles de dicha biblioteca, $\mathrm{Sr}$. Dhen, que en ellas es donde se encuentra la primera pieza escrita en Europa para cuarteto de cuerda, cuyo hecho se habia atribuido á autores estranjeros mucho mas modernos. Ambas producciones fueron publicadas por sus hijos don Antonio y D. Hernando en 1578, despues de la muerte de su padre, acaecida en 26 de marzo de 1566 , á los 56 años de edad. Es de notar, que en la época que floreció este célebre organista, habia en la Real capilla varios profesores flamencos de gran reputacion, y entre ellos el maestro D. Felipe Rogier; y sin embargo fué tal la estimacion en que se tuvo á nuestro compatriota, y tan grande el sentimiento de la Corte por su muerte, que á espensas del Sr. D. Felipe II se le erigió un monumento sepulcral en la iglesia de S. Francisco el Grande, donde fué enterrado, gravándose en la tápida que lo cubria el siguiente epitafio.

Hic situs est Felix Antonius ille sepulcro, Organici quondam gloria prima chori:

Cognomen Cabezon cur eloquar? inclita quando

Fama ejus terras, spirilus astra colit.

Occidit, heu! tota Regis plangente Filipi

Aula: tam rarum perdidit illa decus.

Desgracia es que este monumento, que tal vez sea el único que se ha erigido en Espana al mérito de un artista músico, desapareciese á una con el antiguo templo del convento citado al reedificarse el nuevo que hoy existe.
}

Contrayéndome ahora al ramo de organistas acerca de esta grave falta, se vé que los antiguos ninguna obra de interés han publicado para ilustrar este importante ramo, si se esceptua el método Música para tecla por Cabezon, y el tratado Facultad orgánica por Correa, que he mencionado.

Si de las obras teóricas y fundamentales se pasa a las prácticas ó composiciones orgánicas, se vé la misma falta de publicaciones.

Miguel Hilarión ESLAVA Y ELIZONDO: Museo Orgánico Español. (Parte Primera). Madrid, s.n., 1854. 
A él le siguió el compositor y violinista cántabro Jesús de Monasterio $(* 1836 ; \dagger 1903)$, que transcribió la obra cabezoniana titulada en el impreso de Hernando Fuga a quatro todas las bozes por una sexto tono, fol. 84. Y a éste todavía le siguieron, aunque apenas ya limitándose a meras menciones, el belga François Joseph Fétis $(* 1784 ; \uparrow 1871)$, Baltasar Saldoni $(* 1807 ; \dagger 1889)$, Mariano Soriano-Fuertes $(* 1817$; $\dagger 1880)$, o José Parada y Barreto $(* 1834 ; \dagger 1886)^{19}$. Por esos mismos años apareció también un - para la época- minucioso trabajo académico, a cargo de C. Krebs, que realizó diversos extractos de la digitación indicada por Hernando en su tesis doctoral, del año 1893, y un interesante artículo a cargo de Cristóbal Pérez Pastor ${ }^{20}$.

Pero todas estas noticias eran todavía francamente limitadas, de modo que no sería hasta Felipe Pedrell (*1841; $\dagger 1922$ ) cuando se iba a proceder a un verdadero rescate de la figura del organista ciego de Castrojeriz, en sus pioneros trabajos - por su tratamiento, contenidos y novedad $-{ }^{21}$, que le valieron convertirse en el verdadero descubridor, y primer editor, de las obras de Cabezón en tiempos modernos.

Con dichos autores se cierra el interesante período que va desde fines del siglo XIX hasta los primeros años del siglo XX. Y tras ellos, durante un largo período, poco más, salvo alguna noticia aislada o alguna incorporación de sus obras en antologías y misceláneas, generalmente de escaso valor y novedad, hasta que Higinio Anglés $(* 1888$; $† 1969)$ continuara la tarea emprendida años atrás por su maestro, Felipe Pedrell. De hecho, Anglés dedicó muchos esfuerzos a dar a conocer la obra del organista ciego castellano ${ }^{22}$, que contaron, no obstante, con dos grandes hitos que jalonaron su producción al respecto: la edición, en el Instituto Español de Musicología del CSIC, del Libro de Cifra Nueva de Venegas de Henestrosa, y la edición en tres volúmenes de la edición de 1578 de Hernando de Cabezón ${ }^{23}$. Y entonces sí, con este trabajo, monumental, y el primero verdaderamente dedicado en exclusiva y con detenimiento a sus composiciones, se abrió una nueva etapa en la recuperación del autor castellano y en la reivindicación de su obra.

A partir de ahí, los trabajos musicológicos se diversificaron y se amplió considerablemente el número de estudiosos

19 FÉTIS, François Joseph, 1835-1844 [1866]. SORIANOFUERTES, Mariano, 1855-1859. SALDONI, Baltasar, 1868. PARADA Y BARRETO, José, 1868.

20 KREBS, Carl, 1893 [(1892)]: 307-388. PÉREZ PASTOR, Cristóbal, 1897: 363-371.

21 PEDRELL, Felipe (ed.), vols. III y IV, 1895; vols. VII y VIII, 1896. PEDRELL, Felipe, 1897. PEDRELL, Felipe (ed.), 1908.

22 ANGLÉS, Higinio, 1926: 227-231. ANGLÉS, Higinio y José SUBIRÁ, 1951, vol. 3. ANGLÉS, Higinio, 1966a: 3-15; 1966c: 87-104. 23 ANGLÉS, Higinio (ed.), 1944. ANGLÉS, Higinio (ed.), 1966 b. que se dedicaron con ahínco a dar a conocer su producción, entre quienes caben destacar algunas ediciones de referencia, de autores como Santiago Kastner ${ }^{24}$, Charles Jacobs (con la edición de sus obras completas en cinco volúmenes) ${ }^{25}$, Howard Mayer Brown ${ }^{26}$, Willi Apel ${ }^{27}$, Maria Ester-Sala (cuya publicación de los "glosados" completaba y complementaba la anterior edición en tres tomos realizada por Anglés sobre la edición de Hernando de 1578$)^{28}$, o Louis Jambou ${ }^{29}$, entre otros $^{30}$. Incluso esta misma revista, Anuario Musical, dedicó un número especial al músico burgalés, inaugurando así una ya casi tradición, que hoy retomamos aquí de nuevo ${ }^{31}$.

A partir de ahí, han aparecido múltiples trabajos ${ }^{32}$, que han contribuido verdaderamente a que la obra de Cabezón

24 KASTNER, Macario Santiago, 1941. KASTNER, Macario Santiago, 1950: 78-96. KASTNER, Macario Santiago (ed.), 1951. KASTNER, Macario Santiago, 1952: 77-115. KASTNER, Macario Santiago, 1954 y 1965. KASTNER, Macario Santiago, 1955: 84-108. KASTNER, Macario Santiago (ed.), 1958. KASTNER, Macario Santiago, 1959: 115-164. KASTNER, Macario Santiago, 1960: 49-69. KASTNER, Macario Santiago, 1966a: 171-190. KASTNER, Macario Santiago, 1966b: 105-121. KASTNER, Macario Santiago, 1968: 3-33. KASTNER, Macario Santiago, 1973. KASTNER, Macario Santiago, 1977. KASTNER, Macario Santiago, 1981: 213-235.

25 JACOBS, Charles G., 1957. JACOBS, Charles G., 1959. JACOBS, Charles G., 1962. JACOBS, Charles G., 1964-1966. JACOBS, Charles G. (ed.), 1967-1972-1976-1986-1986, vols. 1-5. [Vol. 1: Duos, Kyrires, Variaciones, Finales; vol. 2. Tientos; vol. 3. Versos y Fugas; vol. 4. Himnos, Arreglos de Cantus firmus y Fabordones; y vol. 5. Tabulaturas y obras dudosas]. JACOBS, Charles G., 1968: 277-298. JACOBS, Charles G., (BECQUART, Paul y Henri VANHULST, eds.), 1988: 115138. JACOBS, Charles G., (GILLINGHAM, Bryan y Paul MERKLEY, eds.), 1990: 350-359. JACOBS, Charles G., 1999, vol. 2: 835-839; JACOBS, Charles G., 2000, vol. "Personenteil, 3": cols.1525-1529.

26 BROWN, Howard Mayer, 1965. BROWN, Howard Mayer, (LOWINSKY, Edward, ed.), 1976a: 475-522. BROWN, Howard Mayer, 1976b; 1976c. BROWN, Howard Mayer y Stanley SADIE (eds.), 1989. 27 APEL, Willi, 1938: 419-437. APEL, Willi, 1947. APEL, Willi, 1967. APEL, Willi, 1971.

28 ESTER SALA, Maria, 1974. ESTER SALA, Maria, 1980.

29 JAMBOU, Louis, 1982. JAMBOU, Louis, 1994: 27-38. JAMBOU, Louis, 1998: 453-476. JAMBOU, Louis, (WEBER, Edith, ed.), 1999. JAMBOU, Louis, 2001, vol. 4: 764-766. JAMBOU, Louis, 2011: 11-42.

30 NELSON, Robert Uriel, 1948. WARD, John M., 1952: 8898. LEVY, Kenneth Jay, 1953: 375-408. CARPENTER, Hoyle, 1957. HORSLEY, Imogene, 1959: 118-132. BARBER, Elinore Louise, 1959. ÁLVAREZ SOLAR-QUINTES, Nicolás, 1960: 195-217. YOUNG, William, 1963: 163-193. HOWELL Jr., Almonte C., 1964: 18-30. TERNI, Clemente, 1966: 25-41. HOWELL Jr., Almonte C., 1967: 377-396. AGULLÓ Y COBO, Mercedes, 1969: 205-225. FERGUSON, Howard, 1971: 402-406; y también: 53/3 (1972): 351-352; y 54/2 (1973): 256. IFE, Barry y Roy TRUBY, 1986. ROBLEDO ESTAIRÉ, Luis, 1987: 753-796.

31 Entonces se publicaron, además de algunos otros ya mencionados, los siguientes artículos: LÓPEZ MARTÍNEZ, Nicolás, 1966: 17-21. SAGASTA, Julián, 1966: 23-26. REIMANN, Margarete, 1966: 27-38. RUBIO CALZÓN, Samuel, 1966: 45-59. QUEROL GAVALDÁ, Miguel, 1966: 61-86.

32 GÖLLNER, Marie Louise, 1990: 275-290. ARIAS, Enrique Alberto, 1992: 87-95. VEGA CERNUDA, Daniel, 2006: 653-675. 
se internacionalizara definitivamente, consolidándose en el marco de los estudios musicológicos ya casi como un "clásico". Hay que citar en este apartado los trabajos de Miguel Ángel Roig-Francolîi3 , Claudio Astronio ${ }^{34}$ y los de Gerhard Doderer-Miguel Bernal ${ }^{35}$, o de Andrés Cea Galán ${ }^{36}$, entre otros (sin olvidar las aportaciones al volumen monográfico dedicado por la Revista de Musicología al músico de Castrillo en su V centenario) ${ }^{37}$, para pasar a centrarnos en dos publicaciones recientes, que creemos fundamentales: la primera de ellas se trata de la edición mexicana a cargo del profesor Gustavo Mauleón, que ofreció la reproducción facsimilar de la obra editada por Hernando en 1578, con buena calidad y un tamaño excelente para facilitar su estudio y manejo ${ }^{38}$. Un tiempo después de dicha edición facsímil, la Biblioteca Nacional de España colgó, libre de costes, imágenes completas digitalizadas del ejemplar que ahí se conserva ${ }^{39}$.

Por su parte, la segunda publicación reciente y definitivamente de referencia sobre la obra de Cabezón, pues reúne en cuatro volúmenes la transcripción crítica completa del impreso madrileño de 1578 , ha surgido fruto de la colaboración de un equipo de investigación formado por Javier Artigas, Gustavo Delgado, Antonio Ezquerro, Luis Antonio González-

33 ROIG-FRANCOLÍ, Miguel Ángel, 1990. ROIG-FRANCOLÍ, Miguel Ángel, 1992: 55-85. ROIG-FRANCOLÍ, Miguel Ángel, 1995: 437-449.

34 ASTRONIO, Claudio, 2001.

35 DODERER, Gerhard (ed.), 1973. BERNAL RIPOLL, Miguel, 2004: 841-894. DODERER, Gerhard y Miguel BERNAL (eds.), 2010, 4 vols. BERNAL RIPOLL, Miguel, 2011: 63-108. DODERER, Gerhard, 2011: 43-62.

36 CEA GALÁN, Andrés, 1997: 165-175. CEA GALÁN, Andrés, (MORALES, Luisa, ed.), 2007: 169-194. CEA GALÁN, Andrés, 2010: 67-98

37 ROA ALONSO, Francisco Javier, 2011: 109-132. ZALDÍVAR GRACIA, Álvaro, 2011: 133-156. ASENSIO PALACIOS, Juan Carlos, Esther BURGOS BORDONAU y Antonio CARPALLO BAUTISTA, 2011: 157-183. CAPDEPÓN VERDÚ, Paulino, 2011: 203-221. CEA GALÁN, Andrés, 2011: 223-234. PALACIOS SANZ, José Ignacio, 2011: 285-316. PEDRERO ENCABO, Águeda, 2011: 317-332. ROCHA, Edite, 2011: 357-373. ROTH, Dietmar, 2011: 375-392.

38 LIMÓN GONZÁLEZ, Miguel y Gustavo MAULEÓN RODRÍGUEZ (eds.), 2008. Cfr. ahí mismo: MAULEÓN RODRÍGUEZ, Gustavo, "Libros de "música para tañer"” y "Las Obras de música de Antonio de Cabezón en Puebla, México": XV-XXIV. Respecto al ejemplar poblano del impreso renacentista madrileño (hoy conservado en la biblioteca "José María Lafragua" de la Benemérita Universidad Autónoma de Puebla), el profesor Gustavo Mauleón localizó en la mencionada biblioteca universitaria la parte de la cifra (editada ya en 1999, en formato facsímil digital). Este mismo profesor identificó recientemente, en el archivo de la catedral de Puebla, un manuscrito del siglo XVII muy estropeado, con la transcripción de los preliminares del libro de Hernando de Cabezón, los cuales faltaban al ejemplar de la biblioteca universitaria poblana, de modo que ahora ambas fuentes poblanas reúnen el total de los contenidos de las Obras de música...

39 Vid.: http://bibliotecadigitalhispanica.bne.es (http://bdh-rd. bne.es/viewer.vm?id=0000037786 ).
Marín, José Luis González-Uriol y José Vicente González-Va$1 \mathrm{l}^{40}$. Dicha edición con la transcripción completa en partitura del volumen originalmente anotado en cifra, se completa, ahora, con el presente volumen misceláneo en Anuario Musical, de modo que se cumple con lo entonces anunciado, y se cierra en cierto modo una iniciativa que se ha prolongado a lo largo de varios años, a cargo de diversos especialistas ${ }^{41}$.

En todo caso, son muchas las preguntas que todavía hoy quedan sin resolver por parte de la investigación. Una de ellas, acaso la más importante, es si el "Antonio" citado como autor de diversas composiciones en la obra de Luis Venegas de Henestrosa será el mismo que el del volumen de 1578, como también resulta todavía un enigma el por qué del cambio de títulos en la propia publicación de Hernando, llamada Obras de música para tecla, arpa y vihuela en su portada, pero impresa como Compendio de música en la sanción del monarca (que firma "por orden" Antonio de Erasso en El Pardo en 1575), así como en el encabezamiento de cada folio. Muy posiblemente, lo primero se deba a la enorme fama alcanzada por el organista real, que en su momento era de tal calado entre los profesionales que no precisaba de la adición de su apellido para ser enseguida reconocido por todos; y lo segundo, tal vez se deba a los años transcurridos entre 1575 y 1578 , que hubieran podido motivar un cambio de título (inicialmente apenas identificado como un "compendio"), muy probablemente para potenciar sus ventas y publicitarlo como de utilidad para el máximo de instrumentos posibles. De todo ello se ha tratado en reiteradas ocasiones. Pero lo cierto es, que todavía se carecen de certezas al respecto. Muy posiblemente, sean precisamente esas dudas las que hacen a estas composiciones - obviamente aparte su calidad intrínseca-, tan interesantes para la investigación y, de la unión de ambas facetas (calidad artística, y un cierto halo de misterio, en una obra supuestamente dictada - ya que no directamente copiada - por un ciego a otras personas), una recopilación tan apasionante, que se proyecta con intensidad, después de más de quinientos años, hacia las generaciones venideras.

40 ARTIGAS PINA, Javier, Gustavo DELGADO PARRA, Antonio EZQUERRO ESTEBAN, Luis Antonio GONZÁLEZ MARÍN, José Luis GONZÁLEZ URIOL y José Vicente GONZÁLEZ VALLE (eds.), 2010, 4 vols. [nueva edición crítica completa].

41 En este sentido, la presente colección de estudios monográficos sobre la obra de Cabezón, hoy incluida en Anuario Musical a modo de miscelánea, ha pretendido abarcar en la medida de lo posible los siguiente epígrafes o apartados: - Status quaestionis sobre Antonio de Cabezón. Bio-bibliografía crítica. / - Los instrumentos de teclado en la época de Cabezón. / - Música y lenguaje. El ritmo y el compás en tiempo de Cabezón. / - Tonos y modos en Cabezón. / - El Compendio de música de Cabezón en el contexto de la tratadística para la enseñanza de la música de tecla. Y/ - Recepción y circulación de la música de Cabezón. 


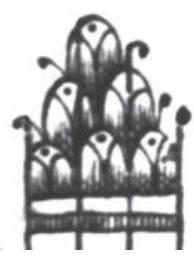

\section{BIBLIOGRAFÍA}

AGULLÓ Y COBO, Mercedes, "Documentos para las biografías de músicos de los siglos XVI y XVII", Anuario Musical, 24 (Barcelona, 1969): 205-225.

ÁLVAREZ SOLAR-QUINTES, Nicolás, "Nuevas noticias de músicos de Felipe II, de su época, y sobre impresión de música", Anuario Musical, 15 (Barcelona, 1960): 195-217.

ANGLÉS, Higinio, "Orgelmusik der Schola Hispanica vom XV. bis XVII. Jahrhundert", en Peter Wagner-Festschrift. Leipzig, Breitkopf und Härtel, 1926, pp.227231.

ANGLÉS, Higinio (ed.), La música en la corte de Carlos V. Con la transcripción del "Libro de Cifra Nueva para tecla, arpa y vihuela" de Luys Venegas de Henestrosa (Alcalá de Henares, 1557). 2 vols. Barcelona, Instituto Español de Musicología del CSIC, col. "Monumentos de la Música Española, II", 1944.

ANGLÉS, Higinio; y José SUBIRÁ, Catálogo Musical de la Biblioteca Nacional de Madrid. Vol.III "Impresos: Música práctica". Barcelona, Instituto Español de Musicología del CSIC, 1951.

ANGLÉS, Higinio, "Antonio de Cabezón: su vida y su obra", Anuario Musical, 21 (Barcelona, 1966a) [1968]: 3-15.

ANGLÉS, Higinio (ed.), Antonio de Cabezón (1510-1566). Obras de música para tecla, arpa y vihuela ... recopiladas y puestas en cifra por Hernando de Cabezón, su hijo. Madrid, 1578. [1 $1^{\mathrm{a}}$ ed. por Felipe Pedrell; nueva ed. corregida por Mons. Higinio Anglés]. 3 vols. Barcelona, Instituto Español de Musicología del CSIC, col. "Monumentos de la Música Española", XXVII, XXVIII, XXIX, 1966b [Existe reimpresión disponible: Madrid, CSIC, 1996].

ANGLÉS, Higinio, "Supervivencia de la música de Cabezón en los organistas españoles del siglo XVII", Anuario Musical, 21 (Barcelona, 1966c) [1968]: 87-104.

APEL, Willi, "Neapolitan links between Cabezón and Frescobaldi", Musical Quarterly, 24 (Oxford, 1938): 419437.

APEL, Willi, Masters of the Keyboard. Cambridge (Massachussetts), Harvard University Press, 1947.
APEL, Willi, Geschichte der Orgel- und Klaviermusik bis 1700. Kassel, Bärenreiter, 1967.

APEL, Willi, Spanish Organ Masters after Antonio de Cabezón. Neuhausen-Stuttgart, American Institute of Musicology, "Corpus of Early Keyboard Music, 14", Hänssler Verlag, 1971.

ARIAS, Enrique Alberto, "Cabezón's Ave Maria: Parody, arrangement or fantasia?", Revista de Musicología, 15/1 (Madrid, 1992): 87-95.

ARTIGAS PINA, Javier, Una nueva visión del repertorio para teclado de los impresos musicales ibéricos publicados en la mediación del siglo XVI: la "reciente" aportación de Gonzalo de Baena en su Arte nouamente inventada per a aprender a tāger (Lisboa, 1540). Madrid, Trabajo de Investigación (DEA), Universidad Autónoma de Madrid, 2004.

ARTIGAS PINA, Javier; Gustavo DELGADO PARRA; Antonio EZQUERRO ESTEBAN; Luis Antonio GONZÁLEZ MARÍN; José Luis GONZÁLEZ URIOL; y José Vicente GONZÁLEZ VALLE (eds.), Antonio de Cabezón (*1510; †1566). Obras de Música para tecla, arpa y vihuela (Madrid, Francisco Sánchez, 1578). 4 vols. Barcelona-Zaragoza, CSIC, Institución "Fernando el Católico", 2010 [nueva edición crítica completa].

ASENSIO PALACIOS, Juan Carlos; Esther BURGOS BORDONAU; y Antonio CARPALLO BAUTISTA, "Los post-incunables de Cisneros en la época de Antonio de Cabezón”, Revista de Musicología, 34/2 (Madrid, 2011): 157-183.

ASTRONIO, Claudio, Antonio de Cabezón Obras de Música para Tecla, Arpa y Vihuela. Vol. 1 [incompleta]. Bolonia, Ut Orpheus Edizioni, 2001.

BARBER, Elinore Louise, Antonio de Cabezón's CantusFirmus Compositions and Transcriptions. Tesis doctoral, Ann Arbor, University of Michigan, 1959.

BERNAL RIPOLL, Miguel, "Rythmón y arithmón. Influencia de la métrica poética en la construcción rítmica en la música española del Renacimiento tardío", Revista de Musicología, 27/2 (Madrid, 2004): 841-894.

BERNAL RIPOLL, Miguel, "Compás y proporciones en la música española de tecla del siglo XVI, y en especial 
en la de Cabezón", Revista de Musicología, 34/2 (Madrid, 2011): 63-108.

BROWN, Howard Mayer, Instrumental Music Printed Before 1600: a Bibliography. Cambridge, Massachussetts, Harvard University Press, 1965.

BROWN, Howard Mayer, "Accidentals and Ornamentation in sixteenth-century intabulations of Josquin Motets", en Josquin des Prez. Proceedings of the International Festival-Conference held at the Julliard School at Lincoln Center in New York City, 21-25 June 1971. (LOWINSKY, Edward, ed.). Londres, Oxford University Press, 1976a, pp.475-522.

BROWN, Howard Mayer, Embellishing Sixteenth-Century Music. Londres, Oxford University Press, "Early music series, 1", 1976b.

BROWN, Howard Mayer, Music in the Renaissance. Englewood Cliffs (Nueva Jersey), Prentice Hall, 1976c.

BROWN, Howard Mayer; y Stanley SADIE (eds.), Performance Practice, I: Music before 1600. Londres, Macmillan, 1989.

CAPDEPÓN VERDÚ, Paulino, "La organistía en la época de Antonio de Cabezón: formas de acceso y funciones", Revista de Musicología, 34/2 (Madrid, 2011): 203-221.

CARPENTER, Hoyle, The Works of Antonio de Cabezón. Tesis doctoral, Chicago, University of Chicago, 1957.

CEA GALÁN, Andrés, "Diferencias sobre el tañer con buen ayre: Aproximación a un problema en la interpretación de la música ibérica de tecla del siglo XVI", en Los instrumentos musicales en el siglo XVI, I Encuentro Tomás Luis de Victoria y la Música Española del siglo XVI. Ávila, UNED, 1997, pp.165-175.

CEA GALÁN, Andrés, “¿Quién te me enojó Isabel?... y otras preguntas sin respuesta en las Obras de música de Antonio de Cabezón", en Cinco siglos de música de tecla española, Actas de los Symposia FIMTE 20022004. (MORALES, Luisa, ed.). Garrucha (Almería), Asociación Cultural LEAL, 2007, pp.169-194.

CEA GALÁN, Andrés, "Nuevos pasajes corruptos en Obras de música de Antonio de Cabezón", Diferencias, 1 (Sevilla, 2010): 67-98.

CEA GALÁN, Andrés, "Nuevas rutas para Cabezón en manuscritos de Roma y París", Revista de Musicología, 34/2 (Madrid, 2011): 223-234.

DODERER, Gerhard (ed.), Antonio de Cabezón: Altiberische Versos: Orgel-Cembalo-Klavier. W. Müller, "Organa Hispanica, 3", 1973.

DODERER, Gerhard; y Miguel BERNAL (eds.), A. de Cabezón. Ausgewälte Werke für Tasteninstrumente. 4 vols. Kassel, Bärenreiter, 2010.
DODERER, Gerhard, "Os manuscritos MM 48 e MM 242 da Biblioteca da Universidade de Coimbra e a presença de organistas ibéricos”, Revista de Musicología, 34/2 (Madrid, 2011): 43-62.

ESTER SALA, Maria, Antonio de Cabezón: Glosados (1510-1566). Madrid, Unión Musical Española, 1974 [con Prólogo de Macario Santiago Kastner].

ESTER SALA, Maria, La ornamentación en la música de tecla ibérica del siglo XVI. Madrid, Sociedad Española de Musicología, 1980.

FERGUSON, Howard, "Corrupt passages in diferencias by Cabezón”, Music \& Letters, 52/4 (Oxford, 1971): 402406. [Y también: 53/3 (Oxford, 1972): 351-352; y 54/2 (Oxford, 1973): 256].

FÉTIS, François Joseph, Biographie universelle des musiciens et bibliographie générale de la musique. Bruselas, Leroux, 1835-1844 [2 2a ed., París, Firmin Didot, 1866].

FORST, Bruno, Gonçalo de Baena. Arte nouamente inuentada pera aprender a tāger (Lisboa, 1540). Madrid, Editiones Dairea, 2012.

GÖLLNER, Marie Louise, "The intabulations of Hernando de Cabezón", en De musica hispana et aliis, Miscelánea en honor al Prof. Dr. José López-Calo. Santiago de Compostela, Universidad de Santiago de Compostela, 1990, pp.275-290.

HORSLEY, Imogene, "The 16th Century Variation: A New Historical Survey", Journal of the American Musicological Society, 12/2-3 (Richmond, 1959): 118-132.

HOWELL Jr., Almonte C., "Cabezón: An Essay in Structural Analysis", Musical Quarterly, 50/1 (1964): 18-30.

HOWELL Jr., Almonte C., "Paired Imitation in 16th Century Spanish Keyboard Music", Musical Quarterly, 53 (Oxford, 1967): 377-396.

IFE, Barry; y Roy TRUBY, Early Spanish Keyboard Music, vol. 1. Oxford, Oxford University Press, 1986.

JACOBS, Charles G., The Transcription Technique and Style of Antonio de Cabezón as Shown in his 13 Intabulations by Josquin des Prez. Tesis doctoral, Nueva York, New York University, 1957.

JACOBS, Charles G., La interpretación de la música española para instrumentos de tecla. Madrid, Dirección General de Relaciones Culturales, 1959.

JACOBS, Charles G., The Performance Practice of Spanish Renaissance Keyboard Music. Tesis doctoral, Nueva York, New York University, 1962.

JACOBS, Charles G., Tempo Notation in Renaissance Spain. Brooklyn, Nueva York, Institute of Mediaeval Music, 1964-1966.

JACOBS, Charles G. (ed.), The Collected Works of Antonio de Cabezón. [Gesamtausgabe / Obras Comple- 
tas]. 5 vols. Brooklyn, Nueva York, The Institute of Mediaeval Music Ltd., 1967-1972-1976-1986-1986. [1: Duos, Kyrires, Variaciones, Finales; 2. Tientos; 3. Versos y Fugas; 4. Himnos, Arreglos de Cantus firmus y Fabordones; 5. Tabulaturas y obras dudosas].

JACOBS, Charles G., "Spanish Renaissance Discussion of Musica Ficta", Proceedings of the American Philosophical Society, 112 (Philadelphia, 1968): 277-298.

JACOBS, Charles G., "Sixteenth-Century Instrumental Music: Interrelationships between Spain and the Low Countries", en Musique des Pays-Bas Anciens, Musique Espagnole Ancienne (1450-1650). Acta Colloqui Bruxellensis 28-29.X.1985 (BECQUART, Paul; y Henri VANHULST, eds.). Lovaina, Peeters, "Colloquia Europalia, 3”, 1988, pp.115-138.

JACOBS, Charles G., "An Inquiry into Cabezón's Treatment of Modes I and II", en Beyond the Moon: Festschrift Luther Dittmer. (GILLINGHAM, Bryan; y Paul MERKLEY, eds.). Ottawa, Wissenschaftliche Abhandlungen (Institute of Medieval Music) 53, 1990, pp.350-359.

JACOBS, Charles G., "Cabezón. 1. Antonio de. 2. Juan. 3. Agustín de. 4. Hernando [Fernando]", en Diccionario de la Música Española e Hispanoamericana. Madrid, SGAE, vol.2, 1999, pp.835-839.

JACOBS, Charles G., "Cabezón. 1. Antonio de. 2. Juan de. 3. Hernando de.", en Die Musik in Geschichte und Gegenwart. Vol."Personenteil, 3”. Kassel-BaiselaLondres-Nueva York-Praga, Bärenreiter / StuttgartWeimar, J. B. Metzler, 2000, cols.1525-1529.

JAMBOU, Louis, Les origines du tiento. París-Burdeos, Centre National de la Recherche Scientifique-Maison des Pays Ibériques, 1982.

JAMBOU, Louis; y François REYNAUD, "Doble Enigma en torno a la figura de Luis Venegas de Henestrosa", Revista de Musicología, 7/2 (Madrid, 1984): 419-430.

JAMBOU, Louis, "Le cantus firmus dans le tiento", en Itinéraires du cantus firmus, I: Paris 1992, París, Presses Universitaires de Paris-Sorbonne, 1994, pp.27-38.

JAMBOU, Louis, "Los músicos de tecla en tiempos de Felipe II: viaje entre lo aldeano y lo cortesano", Revista de Musicología, 21/2 (Madrid, 1998): 453-476.

JAMBOU, Louis, "Le cantus firmus Pange lingua more hispano: affirmation et oubli d'une identité", en Itinéraires du cantus firmus, III, De la théorie à la pratique. (WEBER, Edith, ed.). París, Presses Universitaires de Paris-Sorbonne, 1999.

JAMBOU, Louis, "Cabezón [Cabreçon]. (1) Antonio de Cabezón. (2) Juan de Cabezón. (3) Agustín de Cabezón. (4) Hernando de Cabezón", en The New Grove Dictio- nary of Music and Musicians. $2^{\mathrm{a}}$ edición. Oxford-Nueva York, Oxford University Press, 2001, vol.4, pp.764-766.

JAMBOU, Louis, "El órgano europeo en tiempos de Cabezón”, Revista de Musicología, 34/2 (Madrid, 2011): 11-42.

KASTNER, Macario Santiago, Contribución al estudio de la música española y portuguesa. Lisboa, Editorial Ática, 1941.

KASTNER, Macario Santiago, "Los manuscritos musicales núms. 48 y 242 de la Biblioteca General de la Universidad de Coimbra", Anuario Musical, 5 (Barcelona, 1950): 78-96.

KASTNER, Macario Santiago (ed.), Antonio de Cabezón: Obras de música para tecla, arpa y vihuela. I. Claviermusik. Maguncia, Schott, 1951.

KASTNER, Macario Santiago, "Parallels and Discrepancies between English and Spanish Keyboard Music of the 16th and 17th Century", Anuario Musical, 7 (Barcelona, 1952): 77-115.

KASTNER, Macario Santiago (ed.), Silva ibérica de música para tecla de los siglos XVI, XVII y XVIII. 2 vols. Maguncia, Schott, 1954 y 1965.

KASTNER, Macario Santiago, "Relations entre la musique instrumentale française et espagnole au XVIe siècle", Anuario Musical, 10 (Barcelona, 1955): 84-108.

KASTNER, Macario Santiago (ed.), Antonio de Cabezón: Obras de música para tecla, arpa y vihuela. II. Tientos und Fuguen aus den 'Obras'. Maguncia, Schott, 1958.

KASTNER, Macario Santiago, "Palencia, encrucijada de los organistas españoles del siglo XVI", Anuario Musical, 14 (Barcelona, 1959): 115-164.

KASTNER, Macario Santiago, "Il soggiorno italiano di Antonio e Juan de Cabezón", L'Organo, 1 (Brescia, 1960): 49-69.

KASTNER, Macario Santiago, "La estancia de Antonio y Juan de Cabezón en Italia", Boletín de la Institución Fernán González, 45/166 (Burgos, 1966a): 171-190.

KASTNER, Macario Santiago, "Vestigios del arte de Antonio de Cabezón en Portugal", Anuario Musical, 21 (Barcelona, 1966b): 105-121.

KASTNER, Macario Santiago, "Semitonia-Probleme in der Iberischen Claviermusik des 16. Und 17. Jahrhunderts", Anuario Musical, 23 (Barcelona, 1968): 3-33.

KASTNER, Macario Santiago, Antonio de Cabezón und Zeitgenossen: Kompositionen für Tasteninstrumente. Frankfurt am Main, Wilhelm Zimmermann, 1973.

KASTNER, Macario Santiago, Antonio und Hernando de Cabezón: eine Chronik dargestellt am Leben zweier Generationen von Organisten. Tutzing, Hans Schneider, 1977. 
KASTNER, Macario Santiago, "Sobre las diferencias de Antonio de Cabezón contenidas en las Obras de 1578", Revista de Musicología, 4/2 (Madrid, 1981): 213-235.

KASTNER, Macario Santiago, "La teoría de Tomás de Santa María comparada con la práctica de algunos de sus contemporáneos", Nassarre, 3/1 (Zaragoza, 1987): 113-127.

KINDERMANN, Ilse; y Jürgen KINDERMANN (eds.), RISM. A/I/11. Einzeldrucke vor 1800. Band 11. Addenda et Corrigenda. (Redaktion:). Kassel-BasileaLondres, Bärenreiter, 1986, p.205.

KNIGHTON, Tess, Gonçalo de Baena. Arte para tanger (Lisboa, 1540). Lisboa, Universidade Nova de Lisboa, Centro de Estudos de Sociologia e Estetica Musical, Ediçoes Colibri, 2012.

KNISPEL, Claudia, "Welche 'Verwandten' hat die Vihuela? Die Tabulaturen von Luys Venegas de Henestrosa und Antonio de Cabezón für Tasteninstrumente, Harfe und Vihuela", Concerto, 11/94 (Colonia, Junio 1994): 23-25.

KREBS, Carl, Girolamo Diruta's Transilvano: Ein Beitrag zur Geschichte des Orgel- und Klavierspiels im 16. Jahrhunderts. Tesis doctoral, Universidad de Rostock, 1893 [publicada en: Vierteljahrsschrift für Musikwissenschaft, 8 (1892), pp. 307-388].

LESURE, François (dir.), RISM. B/1. Recueils imprimés XVIe-XVIIe siècles. I: Liste Chronologique. MunichDuisburgo, G. Henle, 1960, p. 307.

LEVY, Kenneth Jay, "Susanne un Jour: The History of a 16th Century Chanson", Annales Musicologiques, 1 (Neuilly-sur-Seine, 1953): 375-408.

LIMÓN GONZÁLEZ, Miguel; y Gustavo MAULEÓN RODRÍGUEZ (eds.), Antonio de Cabezón. Obras de música para tecla, arpa y vihuela. (Madrid, Francisco Sánchez, 1578). Puebla, Benemérita Universidad Autónoma de Puebla (BUAP), 2008 [con Prólogo a cargo de Antonio Ezquerro Esteban]. [Facsímil del ejemplar de la Biblioteca "José María Lafragua" de la BUAP (con topográfico BL CB046998)].

LÓPEZ MARTÍNEZ, Nicolás, "Los Cabezón de Castrillo", Anuario Musical, 21 (Barcelona, 1966): 17-21.

MALDONADO FERNÁNDEZ, Manuel, "Don Luis Zapata de Chaves, III Señor del Estado de Çehel de las Alpujarras y de las Villas de Jubrecelada (Llerena) Ulela y Ulula", Revista de Estudios Extremeños, 58/3 (Badajoz, 2002): 991-1029.

MOLL ROQUETA, Jaime, "Músicos de la corte del cardinal Juan Tavera (1523-1545): Luis Venegas de Henestrosa", Anuario Musical, 6 (Barcelona, 1951): 155-178.

NELSON, Robert Uriel, The Technique of Variation: A Study of the Instrumental Variation from Antonio de Ca- bezón to Max Reger. Berkeley-Los Ángeles, University of California Press, 1948.

PALACIOS SANZ, José Ignacio, "La organería en Castilla y León en tiempos de Antonio de Cabezón", Revista de Musicología, 34/2 (Madrid, 2011): 285-316.

PARADA Y BARRETO, José, Diccionario técnico, histórico y biográfico de la música. Madrid, Bonifacio Eslava, 1868.

PEDRELL, Felipe (ed.), Hispaniae Schola Musica Sacra. [Antonius a Cabezon]. Leipzig, Breitkopf \& Härtel, vols. III y IV, 1895; vols. VII y VIII, 1896 [Barcelona, Juan Bautista Pujol \& Cía. eds.].

PEDRELL, Felipe, Diccionario biográfico y bibliográfico de músicos y escritores de música españoles, portugueses e hispano-americanos antiguos y modernos. Barcelona, Víctor Berdós, 1897.

PEDRELL, Felipe (ed.), Antología de Organistas Clásicos Españoles. (Siglos XVI-XVIII). Madrid, Ildefonso Alier, 1908.

PEDRERO ENCABO, Águeda, "Estrategias compositivas de Cabezón en su glosado de Ultimi miei sospiri de Verdelot", Revista de Musicología, 34/2 (Madrid, 2011): 317-332.

PÉREZ PASTOR, Cristóbal, "Escrituras de concierto para imprimir libros", en Revista de Archivos, Bibliotecas y Museos, $3^{a}$ época, 1 (Madrid, 1897): 363-371.

QUEROL GAVALDÁ, Miguel, "La canción popular en los organistas españoles del siglo XVI”, Anuario Musical, 21 (Barcelona, 1966): 61-86.

REIMANN, Margarete, "Die Überlieferung von Antonio de Cabezóns Klavierwerken und ihre Spiegelung in seinen Diferencias", Anuario Musical, 21 (Barcelona, 1966): 27-38.

ROA ALONSO, Francisco Javier, "Tecla, arpa y vihuela: aspectos de la cultura material en la época de Cabezón”, Revista de Musicología, 34/2 (Madrid, 2011): 109-132.

ROBLEDO ESTAIRÉ, Luis, “La música en la corte madrileña de los Austrias. Antecedentes: Las casas reales hasta 1556", Revista de Musicología, 10 (Madrid, 1987): 753-796.

ROCHA, Edite, "Obras e Flores de Música: Contribuiçoes para um estudo comparativo", Revista de Musicología, 34/2 (Madrid, 2011): 357-373.

ROIG-FRANCOLÍ, Miguel Ángel, Compositional theory and practice in mid-sixteenth-century Spanish instrumental music: the "Arte de tañer fantasía" by Tomás de Santa María and the music of Antonio de Cabezón. Tesis doctoral, Ann Arbor, Indiana University, 1990.

ROIG-FRANCOLÍ, Miguel Ángel, "En torno a la figura y la obra de Tomás de Sancta Maria: aclaraciones, evalua- 
ciones y relación con la música de Cabezón”, Revista de Musicología, 15 (Madrid, 1992): 55-85.

ROIG-FRANCOLÍ, Miguel Ángel, "Playing in consonances: a Spanish Renaissance technique of chordal improvisation", Early Music, 23 (Oxford, 1995): 437449.

ROTH, Dietmar, "Los instrumentos de tecla en la corte del primer Marqués de los Vélez en época de Antonio de Cabezón”, Revista de Musicología, 34/2 (Madrid, 2011): 375-392.

RUBIO CALZÓN, Samuel, "Las glosas de Antonio de Cabezón y de otros autores sobre el Pange lingua de Juan de Urreda", Anuario Musical, 21 (Barcelona, 1966): 45-59.

SAGASTA, Julián, "El órgano de Antonio de Cabezón en la catedral de Burgos", Anuario Musical, 21 (Barcelona, 1966): 23-26.

SALDONI, Baltasar, Diccionario biográfico-bibliográfico de efemérides de músicos españoles. 4 vols. Madrid, Antonio Pérez Dubrull, 1868.

SCHLAGER, Karlheinz, RISM. A/I/2. Einzeldrucke vor 1800. Band 2. Kassel-Basilea-Tours-Londres, Bärenreiter, 1972, p.1.

SORIANO-FUERTES, Mariano, Historia de la música española desde la llegada de los fenicios hasta el año de 1850. 4 vols. Madrid, Martín y Salazar, 1855-1859.
TERNI, Clemente, "Ricordo di Antonio de Cabezón", Chigiana, Rassegna Annuale di Studi Musicologici, 23 [Nueva Serie, No. 3] (Florencia, 1966): 25-41.

VEGA CERNUDA, Daniel, "La técnica variativa de las diferencias sobre ¿Quién te me enojó, Ysabel? de Antonio de Cabezón", Nassarre, 22 (Zaragoza, 2006): 653-675.

WARD, John M., "The editorial methods of Venegas de Henestrosa", Musica Disciplina, 6/1-3 (Roma, 1952a): 105-113.

WARD, John M., "The Use of Borrowed Material in 16th Century Instrumental Music", Journal of the American Musicological Society, 5 (Richmond, 1952b): 88-98.

YOUNG, William, "Keyboard Music to 1600", Musica Disciplina, 17 (Roma, 1963): 163-193.

ZALDÍVAR GRACIA, Álvaro, "La teoría musical en tiempos de Cabezón, su presencia en la música práctica del organista burgalés: efectos y afectos modales", Revista de Musicología, 34/2 (Madrid, 2011): 133-156.

ZAPATA, Luis, Miscelánea (Varia Historia). Tomo I: Facsímil. Badajoz, Institución "Pedro de Valencia"-CSIC, 1983.

ZAPATA, Luis, Miscelánea o varia Historia. Llerena (Badajoz), Editores Extremeños, 1999.

http://bibliotecadigitalhispanica.bne.es (http://bdh-rd.bne. es/viewer.vm?id=0000037786

Recibido: 20.06.2011

Aceptado: 20.06.2011 